HS | 2018

Hors-série Yambo Ouologuem

\title{
Livre culte, livre maudit : Histoire du Devoir de violence de Yambo Ouologuem
}

Jean-Pierre Orban

\section{OpenEdition}

\section{Journals}

Édition électronique

URL : https://journals.openedition.org/coma/1189

DOI : $10.4000 /$ coma. 1189

ISSN : 2275-1742

Éditeur

Institut des textes \& manuscrits modernes (ITEM)

\section{Référence électronique}

Jean-Pierre Orban, «Livre culte, livre maudit : Histoire du Devoir de violence de Yambo Ouologuem », Continents manuscrits [En ligne], HS | 2018, mis en ligne le 29 mai 2018, consulté le 12 janvier 2023 URL : http://journals.openedition.org/coma/1189; DOI : https://doi.org/10.4000/coma.1189

Ce document a été généré automatiquement le 12 janvier 2023.

\section{(C) $\odot \Theta \Theta$}

Creative Commons - Attribution - Pas d'Utilisation Commerciale - Pas de Modification 4.0 International - CC BY-NC-ND 4.0

https://creativecommons.org/licenses/by-nc-nd/4.0/ 


\title{
Livre culte, livre maudit : Histoire du Devoir de violence de Yambo Ouologuem
}

\author{
Jean-Pierre Orban
}

\section{NOTE DE L'AUTEUR}

(c) Jean-Pierre Orban pour le texte et son architecture

(c) Ayants droit de Yambo Ouologuem pour les documents de sa main

(c) Le Seuil ou ayants droit respectifs de leurs auteurs pour les autres documents.

L'auteur remercie Ava Ouologuem, Ambibé Ouologuem, les Éditions du Seuil - en particulier Olivier Bétourné, Hugues Jallon et, tout au long, Frédéric Mora -, Isabelle et Antoine Gallimard, l'Institut Mémoires de l'édition contemporaine - en particulier André Derval -, Simone Schwarz-Bart, Georges Kiejman, Pascal Flamand et Michel Plateau pour leur confiance, ainsi que Céline Gahungu, Claire Riffard, Michelle Garcin et Emmanuel Pierrat pour leur aide et soutien.

1 En septembre 1968, paraît aux Éditions du Seuil le roman d'un jeune Malien inconnu de vingt-huit ans : Yambo Ouologuem. Le 18 novembre suivant, Le Devoir de violence obtient le premier prix Renaudot attribué à un écrivain africain. Son succès est rapide et, traduit dans dix langues, l'ouvrage dépasse les frontières, des États-Unis au Japon. Mais le 5 mai 1972, le Times Literary Supplement (TLS) londonien accuse l'auteur de plagiat à l'encontre de l'écrivain britannique Graham Greene. Un scandale éclate. Il poursuivra Yambo Ouologuem jusqu'à sa mort en 2017.

Cinquante ans après la première édition du Devoir de violence et alors que le roman reparaît au Seuil dans la collection "Cadre Rouge» qui l'avait accueilli à l'origine, quarante-six ans, mois pour mois, après le début de l'« Affaire Ouologuem » dans le TLS, qu'en est-il du bien ou mal-fondé des rumeurs qui ont surgi, en sens divers, sur la genèse et le traitement éditorial de ce livre culte devenu livre maudit? 
3 S'appuyant sur le seul dossier solide à ce jour ${ }^{1}$, celui des archives du Seuil déposées à l'IMEC (Institut Mémoires de l'Édition contemporaine) et rendues publiques pour la première fois ${ }^{2}$, cette étude vise à relater, sur la seule base des documents disponibles, en réduisant au minimum les extrapolations risquées et les interprétations hâtives, l'histoire du Devoir de violence et, à travers elle, de son auteur, depuis ses premières approches des Éditions du Seuil en 1963 jusqu'à sa retraite définitive au Mali vers $1976^{3}$. Et son enfermement dans le silence public.

4 Des documents ainsi présentés, se dégage le récit d'un cas éditorial exemplaire où se mêlent et souvent s'entrechoquent ambitions littéraires et règles éditoriales, liberté d'écriture et contraintes éthiques, malentendus, susceptibilités et maladresses. Se dessine alors, de la gloire à la chute, le parcours d'un auteur qui rêvait d'écrire un cycle monumental sur « La Chair des civilisations ${ }^{4} »$.

\section{« Roman feuilleton [...] roman cochon. Non. »}

5 «Éditions du Seuil. Manuscrit 7646. Lecteur : «SYLVESTRE ». Auteur : Ygambo [sic] Ouologuem. Décision : R[efusé]»

6 La première trace d'un contact de Yambo Ouologuem avec les Éditions du Seuil date de septembre 1963. Une note de lecture ${ }^{5}$ en atteste. Elle figure dans les dossiers du fonds du Seuil relatifs à l'auteur et déposés, comme les autres dossiers d'auteur du Seuil (Paris), à l'Institut Mémoires de l'Édition Contemporaine, en Normandie (France).

7 Le manuscrit a été reçu le 27 septembre 1963. L'auteur est né le 22 août 1940 à Bandiagara, dans le pays dogon au centre du Soudan français, nom du Mali avant son indépendance en 1960. Fils d'un inspecteur de l'Éducation nationale, Yambo Ouologuem a terminé ses études secondaires au Mali avant de rejoindre Paris ${ }^{6}$ et d'y suivre, dès 1960, les classes littéraires préparatoires à l'École normale supérieure. En première année au sein du prestigieux lycée Henri IV ${ }^{7}$. Ensuite - selon le témoignage d'un compagnon d'hypokhâgne ${ }^{8}$ - au lycée du Parc à Lyon' ${ }^{9}$. La note de lecture tapuscrite du Seuil datée de septembre 1963 indique cependant que le manuscrit a été présenté «par » le « Lycée Henri IV, 23 rue Clovis $\left(5^{\mathrm{e}}\right)$ » et mentionne pour adresse «Préparation à l'École Normale Supérieure ».

8 Le titre du manuscrit est... « le devoir de violence » [sic sur la note de lecture]. Le résumé rédigé par le lecteur du Seuil a peu à voir, sinon que l'érotisme y tient une part importante, avec la future publication du Devoir de violence en 1968 :

Mme Hayem, industrielle, et sa servante, Mina, ont recueilli une jeune étudiante, Eva, trouvée souffrante et en détresse. On apprend aussitôt qu'Eva a été victime d'un viol de la part de son oncle médecin, venu chez elle vérifier l'état de sa virginité, des doutes courant sur la pureté des rapports qu'elle entretient avec Duchalier, l'étudiant qui partage son appartement. Telle est du moins la version des faits que Duchalier présente à Mme Hayem.

9 La critique du lecteur à l'égard du texte - dont on apprend qu'il ne concerne nullement l'Afrique - est sévère : "Aucun sens de la composition romanesque, aucune véracité psychologique, aucune véracité tout court [...] », écrit « Sylvestre » qui poursuit :

[...] c'est un perroquet, non un homme, qui a voulu écrire ce roman à la française, avec des personnages français, en mêlant tristement les conséquences intellectuelles (ou autres) d'un roman feuilleton, d'un roman policier, d'un roman cochon et d'un manuel de philosophie. Non. 

violence de 1968, une remarque évoque "idées, citations, formules " que "l'auteur semble s'être employé à pêcher au hasard de ses lectures et de ses études » et " qu'il nous ressert ici, recuites. »

11 La conclusion est écrite à la main par le lecteur : « [abréviation illisible] hélas. Je dis hélas parce que j'ai vu l'auteur, sympathique et qu'il m'a déclaré avoir mis cinq ans à "composer" cette chose». Ouologuem aurait donc, selon lui, entamé l'écriture de ce roman en 1958, à dix-huit ans.

\section{« II faudrait toutefois suivre l'auteur »} Seuil. Cette fois, un recueil de poèmes: "La salive noire". Le sous-titre en est " Histoires à chanter ». L'auteur donne cette fois pour adresse «FOM », 47 boulevard Jourdan à Paris $14^{\mathrm{e}}$, c'est-à-dire la Maison de la France d'Outre-Mer à la Cité internationale universitaire.

14 À l'inverse du manuscrit précédent, celui-ci aborde des thèmes "noirs ». Le rejet, communiqué oralement à l'auteur le 12 mars 1964, n'en est pas moins, lui aussi, brutal : la note de lecture ${ }^{10}$ parle de « toc » et de «truc ». «Ce petit étudiant ", écrit la lectrice, " a lu très vite et pêle mêle ${ }^{11}$ Césaire et Prévert et ses frères de l'Anthologie africaine et malgache.... et à partir de cela tantôt on enfile des perles et tantôt on casse et concasse ses phrases...»

Yambo Ouologuem ne se décourage pas pour autant. Prolifique et rapide, il envoie un nouveau roman le 4 novembre 1964.: "Humble soif». Ici aussi, il y a une présence « racialisée » et une dramaturgie qui lui est liée. Le protagoniste est un métis, marié à une jeune femme blonde, de père allemand nazi et de mère suédoise. Leur amour «se heurte à l'opposition farouche » du père de la jeune femme et au " racisme latent des européens ${ }^{12}$ ». La note de lecture qualifie l'écriture « d'un formalisme excessif », avec de «longues périodes éblouies, métaphores toujours lyriques [...qui] s'écoutent et semblent se satisfaire d'un bel académisme ${ }^{13}$ ». Elle conclut cependant qu'il «faudrait, toutefois, suivre l'auteur ». C'est le sens de la lettre de refus envoyée à l'auteur le 8 décembre 1964 par Christiane Reygnault qui a déjà signé la lettre de refus du premier manuscrit de 1963 et de « Salive noire » quelques mois plus tôt : « Il est bien apparu que ce texte constituait une étape positive dans votre travail ». Pour atténuer la déception de l'auteur, Christiane Reygnault termine en écrivant: «L'écriture est une entreprise de patience autant que de passion ${ }^{14} »$.

Yambo Ouologuem ne manque ni de l'une, ni de l'autre. Et il semble prendre davantage de temps avant de présenter un nouveau manuscrit. Le 20 avril 1967. Comme adresse de correspondance, Yambo Ouologuem - qui, en treize ans d'échanges ayant laissé des traces dans les dossiers du Seuil, aura multiplié les adresses - donne le 42 rue Descartes dans le cinquième arrondissement de Paris. Précédé de "Présence Africaine»: l'adresse est en effet celle du siège, à l'époque, de la célèbre revue et maison d'édition fondée par Alioune Diop et autour duquel gravitent les intellectuels africains et antillais et leurs sympathisants, d'Aimé Césaire ${ }^{15}$ à Jean-Paul Sartre.

Continents manuscrits, HS | 2018 
17 Ce n'est pas à Présence Africaine que paraîtra le manuscrit de 1967. Mais bien au Seuil. Car cette fois, le manuscrit ira jusqu'à la publication. Ce sera Le Devoir de violence.

\section{« Vous êtes condamné à écrire un chef d'œuvre »}

18 Le chemin vers la publication ne sera, cependant, pas exempt de rebondissements. Une note de lecture par un certain Weber - non datée mais rédigée entre le 20 avril et le 24 mai 1967, date de la réponse mentionnée à l'auteur - est négative ${ }^{16}$ :

La forme de ce roman participe de la compilation (recueil de documents) et de la narration orale (récitation ponctuée d'interjections...).

Ainsi différents styles s'enchevêtrent sur le fond d'une geste naïve :

Discours politiques, documents ethnographiques, dialogues diplomatiques, scènes amoureuses, considérations philosophiques, sorcellerie, pornographie, esquisse de la société française, analyses sociologiques, lettres... autant de textes spécifiques reliés dans un mouvement que l'auteur voudrait «un» et dont on pourrait dire qu'il est celui d'un certain désarroi devant la réalité africaine.

19 «Manque total d'originalité africaine», «contenu du roman [...d'une] étrange lourdeur ", textes philosophiques «d'une confusion extrême » ou «directement extraits d'un article de journal, d'une déclaration officielle etc.», textes historiques d'un « didactisme ennuyeux », " scène amoureuses, [...] descriptions pornographiques [...] proprement lamentables ». « En général l'auteur veut trop dire et dit mal. [...] L'on passe trop souvent d'un ample propos à la description complaisante d'un viol sadique ou de copulations fantastiques. »

20 Au-delà de la rudesse de sa critique, ce que cette note indique, c'est que le manuscrit original présenté par Ouologuem contient déjà le fil du récit qui sera publié l'année suivante :

Ce roman peut se décomposer en trois parties.

1) La légende des Saïfs retrace à partir du XVI siècle ${ }^{17}$ l'histoire mouvementée et cruelle de cette dynastie et du peuple qu'elle asservit.

2) La seconde partie est centrée sur la période de Colonisation. Les rapports entre un souverain fourbe et rusé et l'Administration coloniale, les détours obscurs et violents d'une politique d'assassinats et de trahisons constituent en gros le contenu du chapitre II.

3) Les deux derniers chapitres concernent le processus de décolonisation. Les enfants de Saïf sont désormais les personnages prédominants. Séjours en France, aménagement progressif d'une indépendance fallacieuse, phénomènes sociaux que recouvrent [sic] le thème de décolonisation sont les éléments fondamentaux $d u$ texte.

21 La division en quatre parties (appelées alors « chapitres " par l'auteur ou par le lecteur ou la lectrice) est déjà présente et trois de leurs titres définitifs s'y retrouvent :

Ce manuscrit développe au travers de quatre chapitres :

1) La légende des Saïs

2) La nuit des Géants

3) Les enfants du Général

4) Et cela s'appelle l'aurore ${ }^{18}$ 
Note de lecture (recto-verso) du manuscrit du Devoir de violence signée Weber, 20/4/1967

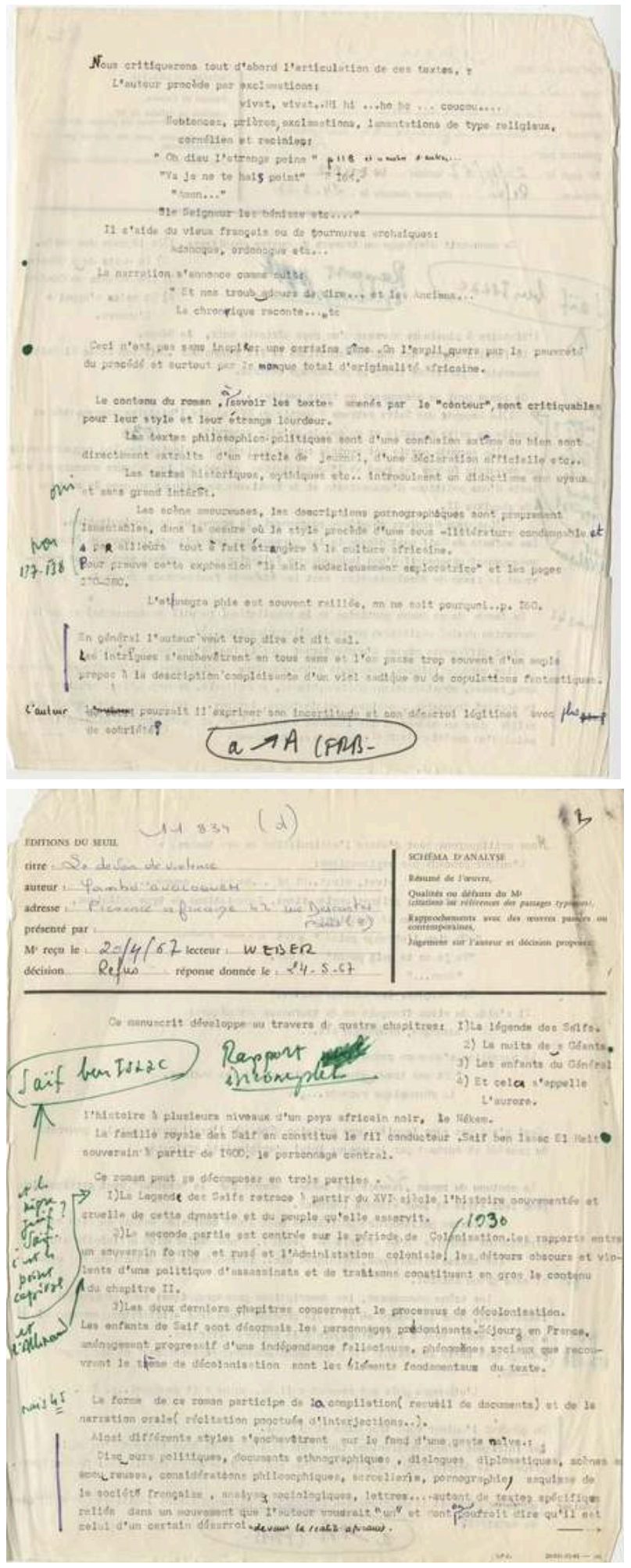

IMEC, SEL 3772.2

Tous droits réservés

Une autre note de lecture est donnée de façon plus informelle sous forme d'une lettre d'un certain $M\left(\right.$ ?) à « Régis " ${ }^{19}$. Ce prénom désigne sans doute François-Régis Bastide, écrivain ${ }^{20}$, éditeur au Seuil où il dirige la collection de fiction "Cadre Rouge ». C'est 
aussi à lui qu'est transmise la note de Weber. Et c'est lui qui va bientôt s'occuper du manuscrit du Devoir de violence. Non datée, mais surmontée du numéro attribué par les Éditions du Seuil au manuscrit du Devoir de violence, la lettre est virulente :

Cher Régis,

Il y a là dedans

1/ un vademecum de la négritude rédigé par un collectionneur boulimique et peu organisé

2/ la transposition - sous une autre forme - des émois, glandulaires et autres, d'un jeune homme de couleur et de vingt ans, épars déjà, semble-t-il, dans les précédents $\mathrm{ms}$ [manuscrits]. [...]

Je ne trouve pas d'unité dans ce tas de briques. Pas de ton dans ce ramassis de lieux communs.

Des phrases d'un kilomètre, je veux bien. Mais quand elles pèsent une tonne. [...]

Je veux bien faire des fleurs aux sous-développés. Mais attendons au moins que le gars soit agrégé ès-lettres (j'oubliais qu'il a renoncé à Normale. Tant pis).

«Suis-je trop sévère? ?, se demande le signataire de cette lettre.

La dureté des notes de lecture aboutira en tout cas au rejet du manuscrit. Le 24 mai 1967, un mois après la soumission du manuscrit par Yambo Ouologuem, FrançoisRégis Bastide lui écrit :

Monsieur,

Je suis au regret de vous faire savoir que nos lecteurs n'ont pas cru devoir retenir votre manuscrit intitulé Le devoir de violence. Certes, il y a dans votre propos une belle ambition. Vous êtes, si j'ose dire, condamné à écrire un chef-d'œuvre. Vous êtes trop attendu à ce merveilleux tournant de la civilisation africaine. Il semble que vous n'ayez pas tout à fait réussi parce que vous avez trop à dire. Il faudrait absolument être impitoyable à l'égard de votre talent, proscrire toutes les tournures archaïques françaises qui ne peuvent que nuire à votre démarche. Il faut trouver des équivalents africains. Les méditations philosophico-politiques, les textes historiques, mythiques, les aperçus ethnographiques donnent l'impression d'être juxtaposés. On ne sent pas un auteur qui domine sa matière. Il paraît dérisoire de vous demander plus de sobriété, l'exubérance devant faire partie de votre œuvre. Pourtant c'est à un peu plus d'ordre que nous nous permettons de vous inviter.

En vous priant d'excuser la rapidité et la sécheresse forcées de mes remarques, veuillez croire [...]

\section{« Cette recherche du "Temps perdu" africain »}

Les choses ne s'arrêteront cependant pas là. Ce que montrait déjà la note de lecture de Weber, c'est qu'il y a eu au moins discussion au sein du Seuil à propos du manuscrit de Ouologuem.

La note est en effet marquée de réactions manuscrites dans la marge et dans le texte même. On y lit ainsi, en tête, une mention presque rageuse : "Rapport incomplet». Avant " incomplet », un mot a été barré qui pourrait être «nul ». Dans la marge, à côté du résumé de la première "partie ", il est écrit : « et le nègre Juif ? Saif. C'est le point capital. » À côté du résumé de la deuxième " partie ", il est griffonné : « et l'Allemand ». $\mathrm{Au}$ verso, en réaction au paragraphe sur les "scènes amoureuses lamentables ", il est écrit « non 137-138 » en un renvoi à la pagination du manuscrit.

De quand datent ces réactions plus positives? Entre la soumission et son rejet, ou plus tard encore ? En tout cas, la lettre de refus signée F.-R. Bastide est, elle aussi, marquée 
d'annotations de la même main et dans la même couleur que les remarques en marge de la note de Weber. Ces annotations sont traversées de doutes ou de questionnements : «fumisterie ? / incohérence 184 / Henry ? l'évêque - la flûte / Kassoumi : pédé / trop personnages ». Et puis il y a cette question qui résonne étrangement quand on connaît le débat qui surgira plus tard sur les plagiats dans Le Devoir de violence et les guillemets qui - ainsi que Ouologuem l'affirmera - auraient été retirés du manuscrit: «Guillemets? ? Rien ici n'indique s'il s'agit de guillemets à enlever ou à intégrer. Selon les notes de lecture, le manuscrit semblait truffé de références. Certaines d'entre elles étaient-elles entre guillemets? Ou l'auteur des annotations se posait-il la question de l'utilité d'en placer? Rien ne permet ici de le déterminer.

De même, il est difficile à ce stade de l'investigation de savoir qui est l'auteur des annotations manuscrites (peut-être François-Régis Bastide lui-même?). Mais on connaît la personne qui, au vu des documents conservés, sauva le manuscrit. Il s'agit de Jean Cayrol.

Cayrol, auteur reconnu d'une œuvre importante ${ }^{21}$, rédige une note de lecture non datée où il évoque tout à la fois Voltaire, Queneau, Jarry et... Proust :

J'ai lu avec un très vif plaisir, malgré les rapports qui ont été faits sur lui, ce manuscrit et je suis un peu étonné des réactions sur ce livre qui me paraît être la première chronique en prose du monde africain.

J'ai été intéressé par le talent de cet auteur qui a su, en utilisant différentes écritures et tonalités, nous donner une sorte de fresque de l'Afrique Noire et d'un certain territoire, le Nékem ${ }^{22}$, depuis la fin du 19ème ${ }^{23}$ jusqu'à 1950 environ. Bien que j'aie pu lire depuis des années des manuscrits d'écrivains noirs, je n'ai jamais trouvé une telle liberté dans la manière de raconter en utilisant le mode caricatural ou le mode délirant, un tel panorama où tout se mêle : cruauté, érotisme, images fiévreuses etc. Les deux premiers tiers du manuscrit se lisent sans aucune difficulté. Il y a de tout mais en même temps une visualisation étonnante de ce monde noir rusé, instinctif et en même temps prêt à tous les excès. Le roman se gâte dès que le héros arrive en France et là, l'écriture excessive se perd dans ses excès, devient elle-même sa propre caricature car ses métaphores sont outrées et l'auteur se prend les mots dans la plume. C'est dans cette partie où il y a le plus de travail, de corrections et de rewriting. Texte très riche où il $\mathrm{y}$ a de tout, à boire et à manger, brassant l'insolence, l'impudeur, le dérèglement, mais en même temps racontant avec beaucoup d'aisance des choses insolites. Ça hésite quelquefois entre Voltaire et Queneau pour en arriver jusqu'à Jarry. Mais, à chaque page, il y a des trouvailles, même dans les échecs de style. Où l'auteur se trompe c'est dans la chronologie. Il est évident que la pénicilline n'est pas inventée [mots barrés et remplacés par: "n'a pas été " suivi d'un mot illisible] en 1900, par exemple. Mais si l'auteur pouvait arriver à reprendre son texte, à le nettoyer de ses scories de langage, à simplifier parfois son écriture, nous aurions le premier récit africain en prose qui ne soit pas aveuglé par ce qu'il écrit mais qui garde une certaine distance vis à vis de ce qui est raconté.

Si l'écrivain accepte de reprendre son texte, alors je suis favorable à l'édition du manuscrit, mais de toute manière tel qu'il est j'ai été agréablement surpris par cette recherche $d u$ « Temps perdu » africain. 
Note de lecture non datée du manuscrit du Devoir de violence par Jean Cayrol

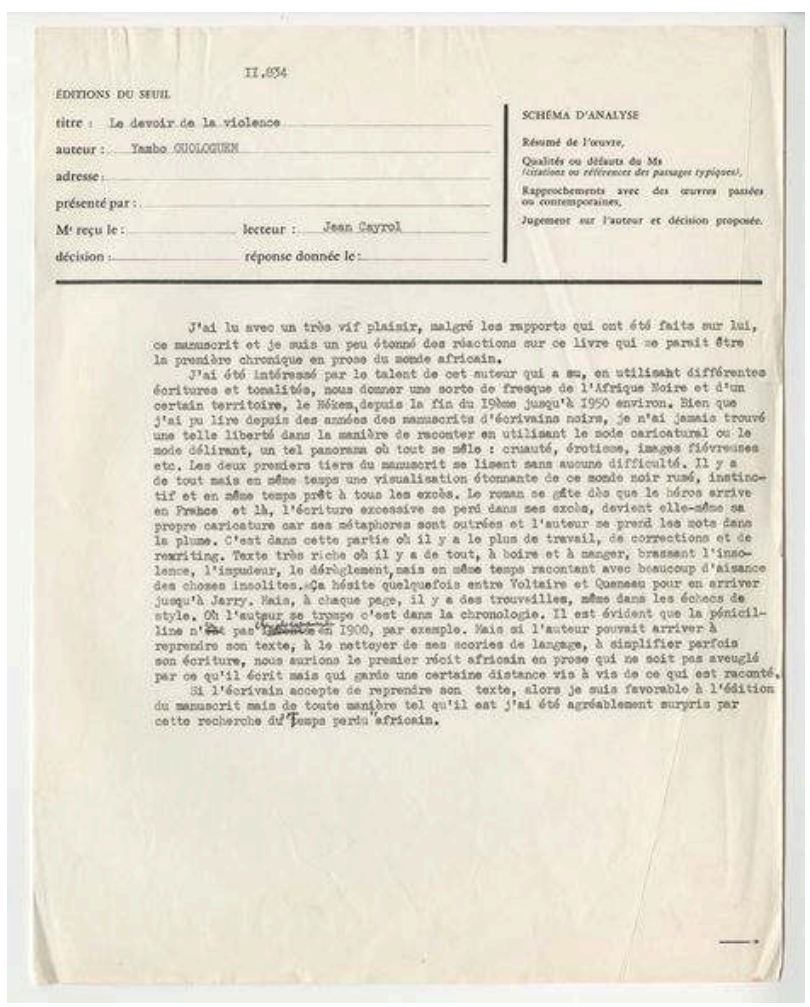

IMEC, SEL 3772.2

Tous droits réservés

Le manuscrit semble à nouveau circuler au Seuil. Une note de Christine Reygnault (CR) du 15 octobre 1967 est négative, mais ne se prononce ni pour une acceptation ni pour un refus. Mais un post-scriptum montre que le manuscrit a maintenant ses défenseurs :

On comprendra que je serais complètement désarmée d'avoir à prendre l'initiative d'un remodelage de ce texte. Mais il va de soi que si l'on peut m'indiquer clairement ce qu'on peut et ce qu'on ne peut pas «laisser passer » [...] je suis prête à faire le travail en question. Ceux qui aiment ce texte peuvent seuls en juger.

J'ai écrit tout cela assez tristement mais somme toute paisiblement car le triple intérêt de PF [Paul Flamand, directeur du Seuil], JC [Jean Cayrol] et FRB [François-Régis Bastide] est là pour soutenir ce manuscrit.

La note de Christiane Reygnault, de toute manière, arrive trop tard : le contrat d'édition entre Isabelle Bardet, fille du cofondateur - avec Paul Flamand (1909-1998) - des Éditions du Seuil, et Yambo Ouologuem pour Le Devoir de violence a été signé quatre jours plus tôt, le 11 octobre 1967. La remise du manuscrit retravaillé est fixée au $1^{\text {er }}$ janvier 1968 et le premier tirage prévu est de 4000 exemplaires. Ce ne sera pas non plus Christiane Reygnault qui s'attellera à préparer le manuscrit pour l'édition: ce sera, avec l'auteur, François-Régis Bastide ${ }^{24}$.

\section{«Vivre, c'est s'aveugler sur ses propres dimensions »}

Le travail de remodelage du manuscrit et les échanges entre Bastide et Ouologuem ont commencé d'ailleurs bien plus tôt. Une lettre du premier ${ }^{25}$ au second, envoyée à Présence Africaine et datée du 31 août 1967, en témoigne : 
Monsieur,

J'ai pu examiner à nouveau et faire examiner votre roman. Il y a toujours des pages superbes et il y a toujours plusieurs vices de construction. Du moins, c'est notre opinion qui est peut-être erronée. De toute façon, je crois le moment venu d'avoir une conversation avec vous et à cette fin, je vous serais reconnaissant de passer me voir au Seuil Lundi 4 Septembre à 15 heures. Si ce rendez-vous ne convenait pas, vous pourriez téléphoner à ma secrétaire qui vous en donnera un autre.

Dans l'espoir de faire votre connaissance [...]

François-Régis Bastide

Bastide et Ouologuem ne se sont pas encore rencontrés. Le contrat n'est pas encore signé. Il le sera bientôt, on vient de le lire, dans le cours d'un travail de mise au point du texte du roman qui s'étend pendant plusieurs mois, avec des allers-retours entre l'auteur et son éditeur. En pleine conscience - il faut le noter pour la suite - de ce qui s'échange là et connaissance du texte qui s'établit dans ces passages de l'un à l'autre.

Ainsi : 22 décembre 1967, lettre de Bastide à Ouologuem, maintenant au 60, Square du Nord 95 à Gonesse :

[...] ]'étudie très longuement la nouvelle version de votre roman et n'ai pu achever cette étude avant la fin de cette année, comme je l'espérais.

Je crois pouvoir dire, dès maintenant, que vos corrections semblent excellentes. Je reprendrai contact avec vous très prochainement pour l'établissement du dossier de presse. Je me permettrai d'appeler à Présence Africaine ${ }^{26}$.

3 janvier 1968, autre lettre de Bastide à Ouologuem :

Cher Ouologuem,

Je viens de relire entièrement, ligne à ligne, votre livre. J'ai encore des petits détails à vous montrer qui, tous, posent des questions. Nous ne sommes pas loin de l'achèvement. [...]

Il faudrait que nous puissions parler et du manuscrit et de la notice pendant deux petites heures. Voulez-vous Vendredi 5 à 15 heures? Entre temps, j'essaie de vous joindre à Présence africaine pour que vous passiez plutôt demain, Jeudi.

Bien amicalement à vous.

François-Régis Bastide ${ }^{27}$

Le dossier avance bien et, somme toute, si on tient compte des remarques formulées lors des premières lectures du manuscrit original, assez vite. Au point que le texte est mis en fabrication ${ }^{28}$ le 14 mars 1968. La première chemise en faisant mention porte le nom de François-Régis Bastide ${ }^{29}$. La publication est prévue en septembre de la même année.

Comme Bastide l'annonçait fin décembre à Ouologuem, le dossier de presse se prépare, avant même la mise en fabrication. Le texte du Devoir de violence, établi par l'auteur et son éditeur, est transmis le 22 mars au Service de Presse ${ }^{30}$. Autre date importante : le 29 mars, le même texte est communiqué à « P.F.» Ce sera donc la première fois que Paul Flamand aura en main le texte définitif, dernières corrections mises à part.

À propos de la campagne de presse qui s'entame là, Yambo Ouologuem a écrit peu avant - le 28 décembre 1967 - la première longue lettre ${ }^{31}$ que l'on possède de lui dans les archives de l'IMEC. Une lettre manuscrite. Une lettre d'écrivain. Un écrivain qui, soudain, se rend compte de ce qu'implique la publication de son roman et prend position à cet égard :

Mon bon monsieur,

Le propos de cette lettre n'est pas d'élever une succession de temples à des prétextes. À dire vrai, j'ai peur de n'être pas fait pour ce commerce qui semble l'inévitable revers de vos fonctions. Vous voudrez bien excuser ces lieux communs 
de commis-voyageur - mais est-il vraiment nécessaire de jouer « pour le dossier de presse » ce jeu, assez pénible pour l'auteur, de montreur d'ours savants dans la foire littéraire ? Le texte, efficacement soutenu par une Maison du renom de la vôtre, ne se suffit-il pas à lui seul ? Je blasphème sans doute : mais vivre, c'est s'aveugler sur ses propres dimensions - dans un sourire qui surplombe des paysages anéantis.

Je ne m'intéresse pas moi-même - et le premier venu tout autant que mon travail comptent davantage à mes yeux. Et puis... et puis... ma personne - vous le savez bien - n'intéresse personne: encore moins la singularité toute relative des accidents de ma vie de débutant. L'œuvre ! l'œuvre ! - et au diable l'homme...

Je répugne assez à me " présenter ». Je ne sais rien de ceux-là qui ont écrit - avec une habileté adroitement scénique ! - le beau roman de la Bible. Et pourtant quel chef-d'œuvre... J'aurais voulu l'avoir écrit au lieu de cette gaudriole négraillonne qu'est sans doute « Le devoir de violence».

Comprenez-moi, mon bon monsieur, il est nécessaire, pour que je continue à travailler pour la maison, que je ne donne pas dans le compromis en me livrant à la presse : je serais achevé avant le deuxième livre. Je vis affreusement seul - mais j'ai besoin, pour mon travail, de capitaliser dans la solitude une angoisse où je ne me pense pas en termes d'aurore. À ce titre, j'aimerai refuser toute publicité autour de ma personne : reportez-la exclusivement autour et sur l'œuvre - puisque vous m'avez fait l'honneur de me dire que croyiez à cette "épopée nègre " (l'expression est de vous).

J'ambitionne de créer un monument saisissant de nationalité contemporaine : je crois en vous pour ne pas m'égarer: l'entreprise est vaste - il la faut féconde. Soutenez-en le premier pas: «Le devoir de violence", et permettez-moi de travailler loin de toutes ces élucubrations de la presse: la galerie des Têtes de Nègres n'est elle pas assez encombrée?

L'écriture a forgé en moi le sens de la tendresse et de la dérision, et le hasard m'a conduit, m'a contraint à décrire - du moins dans le premier cycle de « La Chair des civilisation »- la déroute de l'aventure négro-coloniale, alors même que je pouvais la transgresser dans la douceur amère de la mauvaise foi. C'est une souffrance sans expression, et que la création trompe à l'heure du gouvernement du corps par le corps, - quand l'esprit est [?] et silence, et qu'alors vous devenez l'aveugle qui dispose du monde, et n'a pas de mains. Je m'efforce d'œuvrer vos précieuses recommandations : écrire, m'avez vous appris, c'est gommer.

Voilà pourquoi cette danse de saltimbanque m'indispose dans mes forces vives - qui veut récupérer ma virilité à coups de coupures de presse.

Je vous serre la main, mon bon monsieur, en vous priant de m'excuser d'avoir été si long et sans doute, si vain.

Y. Ouologuem

\section{R. Bastide, qui lui répond dans un courrier du 3 janvier $1968^{32}$ :}

[...] Quant à votre lettre, je comprends parfaitement votre désir de refuser toute publicité et tout commerce avec la presse. Il vaut mieux, en effet, croyez-moi, écrire que publier. Cela dit, nous vous publions. Je suppose que vous ne pouvez pas ne pas avoir envie de relire le texte qui figurera au verso de votre livre. De même, il est d'usage de donner des indications biographiques, même succinctes, sur l'auteur, son âge, son lieu de naissance, ses études etc. [...]

Ouologuem et Bastide ont établi un lien personnel et se voient, après cette lettre, en janvier 1968. Ce lien perdurera longtemps, à travers les frictions. Jean Cayrol aussi parle à Ouologuem. En avril, c'est au tour de Paul Flamand de chercher à rencontrer le jeune auteur. Le ton du mot, qui suit un rendez-vous manqué, augure de la tension qui règnera bientôt entre les deux. Or, c'est entre eux qu'auront lieu le plus d'échanges épistolaires. 


\begin{abstract}
Cher Monsieur,
Pourquoi n'êtes-vous pas venu me voir? Si même vous n'aviez aucune question précise à me poser, j'aurais été heureux, moi, de faire votre connaissance et de vous parler de votre roman que j'ai lu attentivement et avec beaucoup de satisfaction.

Jean Cayrol m'a dit quelques mots de la conversation qu'il avait eue avec vous : il y a des décisions que vous seul pouvez prendre. Mais tout ce que je puis vous dire, c'est que vous êtes un écrivain.

Alors, à bientôt, tout de même.

Cordialement vôtre.

Paul Flamand ${ }^{33}$
\end{abstract}

Les premiers acteurs de ce qui sera un succès avant de devenir un drame sont en place. Le livre peut bientôt paraître.

\title{
«C'est le sort des Nègres d'avoir été baptisés dans le supplice... »
}

Des projets de couverture sont établis. Dont l'un - de Yambo Ouologuem lui-même ? sur feuillet léger : à la main, le cadre rouge - celui de la collection dans laquelle le roman va être intégré - est dessiné à la main. Sont tapés à la machine : le nom de l'auteur, le titre du roman, le genre, l'éditeur et ce sur-titre que l'auteur destine au cycle «monumental» qu'il ambitionne d'écrire et dont Le Devoir de violence serait le premier volume : « La chair des civilisations ».

\section{Projet de couverture avec sur-titre " La chair des civilisations »}

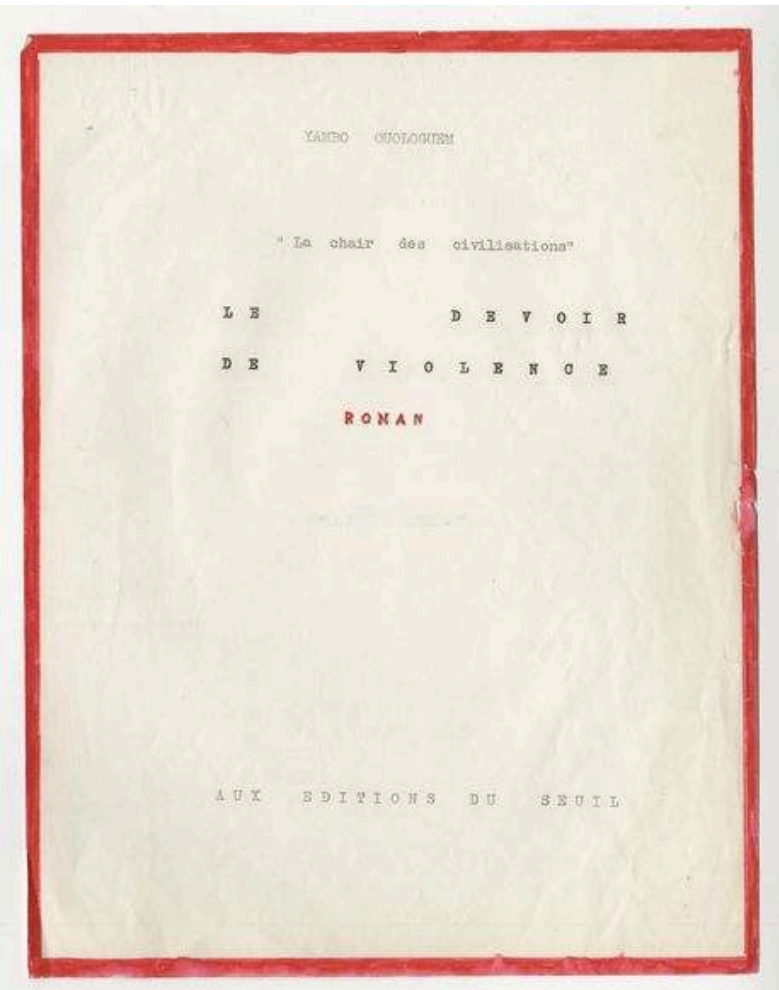

IMEC, SEL 4645

Tous droits réservés 

«colonialisme des Notables africains » et indique - fait significatif pour la controverse qui va suivre - une référence explicite (biblique). Ce projet de $4^{\mathrm{e}}$ est-il aussi de Yambo Ouologuem? Le style, ainsi qu'une correction manuscrite peuvent le laisser penser. D'autres corrections, traits barrant des passages et annotations sont d'une autre main. En voici le début, sans les suppressions ni modifications :

Rugissement de l'homme dans la cage de ses infirmités. C'est le sort des Nègres d'avoir été baptisés dans le supplice: essentiellement par le colonialisme des Notables africains, puis la Conquête Arabe. L'Eternel, selon la légende, n'a-t-Il pas, dans sa bénédiction implacable, fait de la négraille le serviteur des serviteurs, et du Blanc, son maître ? (Genèse, verset 27).

Ensanglantée plus de cent millions de fois par les Empereurs Saïf - négro-juifs et berbéro-peulhs [mots barrés illisibles] la promenade des Nègres glisse de cette fresque à la chronique (1202-1900), puis au romanesque à clés où l'auteur nous enfonce dans l'extase et le drame souvent dérisoire des Fils de la Nuit, au long des siècles fétichistes, musulmans et chrétiens. [...]

Une autre version ${ }^{35}$ développe davantage la question ethnique ${ }^{36}$ et insiste sur le « colonialisme », cette fois, de la dynastie des Saïfs qui règne sur l'empire Nakem, décor principal du Devoir de violence.

[...] Cham ou Japhet ? Nègres, Peulhs, Leuco-Ethiopiens ? Juifs d'Orient émigrés de Cyrénaïque, puis du Touat, et descendant de la Reine de Saba? - les avis des ethnologues sont partagés ; mais sanglants colonialistes, les Saïfs [...] le sont avant même l'Homme Blanc, qui, tout à son insu, a joué le jeu des Notables africains.

Beaucoup sera supprimé de ces introductions. Le texte final de la $4^{e}$ de couverture, plus court, plus sobre, plus neutre, commencera finalement par « C'est le sort des Nègres d'avoir été baptisés dans le supplice : par le colonialisme des notables africains, puis par la conquête arabe. La promenade des Nègres va de la fresque (1202-1900) à la chronique puis au romanesque contemporain et au drame souvent dérisoire des Fils de la Nuit. $[\ldots] »$ 
Tirés à part de la couverture ( $\mathrm{C} 1$ et $\mathrm{C} 4)$ de l'édition originale

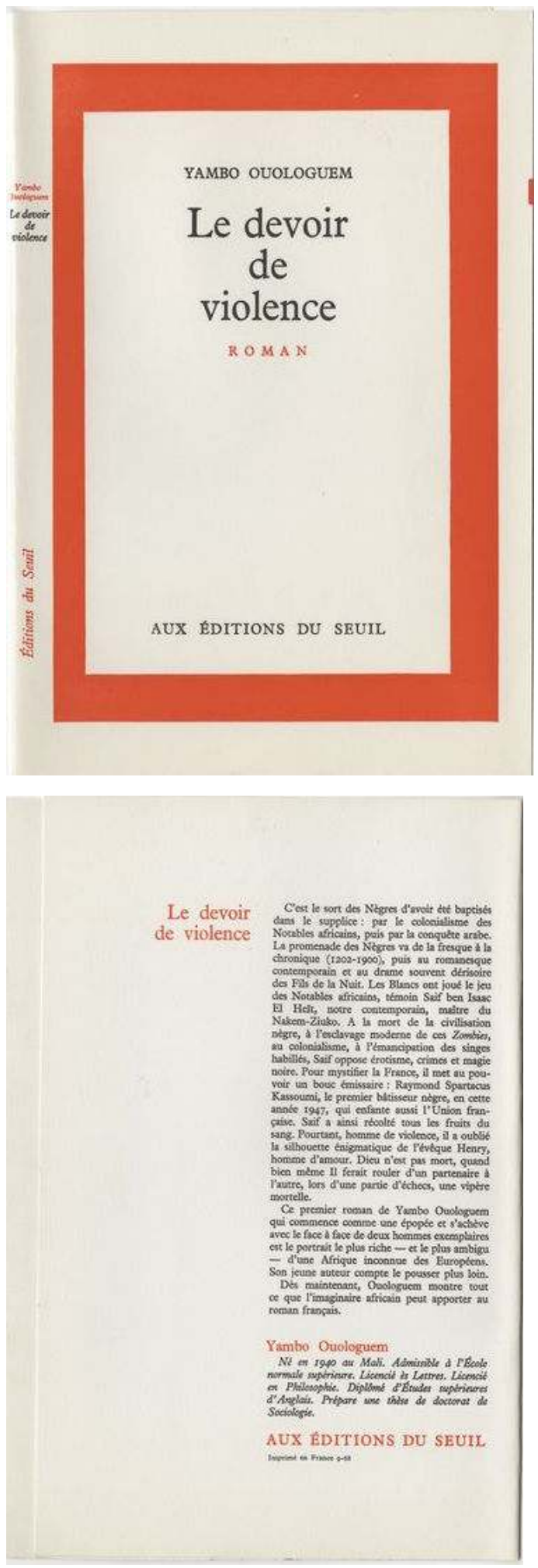

IMEC, SEL 4645

Tous droits réservés

La notice biographique de l'auteur est aussi fixée : "Yambo Ouologuem, né en 1940 au Mali. Admissible à l'École Normale Supérieure. Licencié ès Lettres. Licencié en 
Philosophie. Diplômé d'Études Supérieures d'Anglais. Prépare une thèse de Doctorat en Sociologie ${ }^{37}$. »

L'ouvrage est imprimé en juillet 1968, divers documents comptables et techniques, dont une facture de l'imprimerie Aubin, l'attestent. Un bandeau l'est aussi qui entoure le bas de la couverture. Il porte la mention : «C'est le sort des Nègres d'être baptisés dans le supplice... » Le prix est fixé à $15 \mathrm{Fr}$. À l'intérieur, 413500 signes d'un texte qui va faire parler de lui.

Bandeau de couverture de l'édition originale

$$
\begin{gathered}
\text { C'est le sort des Nègres } \\
\text { d'avoir été baptisés dans } \\
\text { le supplice } \\
\text { S E U I L }
\end{gathered}
$$

\section{« Le Prix Renaudot est attribué au Devoir de violence... »}

La réception sera mitigée et les avis partagés en France ${ }^{38}$. Le Monde, sous la plume de Mathieu Galey, titre, le 12 octobre 1968 : « Un grand roman africain » et écrit : «Voici peut-être le premier roman africain digne de ce nom. Et un roman tout court comme on n'a pas souvent le bonheur d'en découvrir dans le fatras d'une rentrée. » Deux semaines plus tôt, Le Figaro Littéraire ${ }^{39}$, en la personne du critique Robert Kanters et sous le titre "Mes ancêtres, les nègres... », n'a pas été aussi élogieux :

Tout n'est pas bon dans ce roman, parfois M. Ouologuem semble vouloir nous prouver qu'il peut écrire aussi mal et dans un jargon aussi prétentieux que n'importe quel petit Blanc intellectuel. Ce qui vient de son souffle profond, de sa race et de son cœur, est toujours excellent ${ }^{40}$.

En réalité, le succès viendra le 18 novembre 1968, lorsque la presse annonce : «Le Prix Renaudot est attribué au Devoir de violence ». Il l'a été à sept voix contre trois pour $L a$ Barque de Georges Buis. Cette année-là, le Goncourt va à Bernard Clavel pour Les Fruits de l'hiver, le Médicis à Elie Wiesel pour Le Mendiant de Jérusalem, tandis que le choix du Fémina se porte à l'unanimité sur L'œuvre au Noir de Marguerite Yourcenar et que le prix de l'Académie française couronne Albert Cohen et sa Belle du Seigneur.

Le jour même du prix, une commande de retirage du Devoir de violence est lancée : le roman est réimprimé à 15000 exemplaires et dix jours plus tard à 21000 exemplaires $^{41}$. Les interviews et rencontres avec la presse se succèdent. Les organes littéraires confirment ou infléchissent leur jugement à l'égard du roman et de son auteur. Alain Bosquet dans Le Monde: "Voilà un être d'élite, et sans doute, après Léopold Sédar Senghor, l'un des rares intellectuels d'envergure internationale que l'Afrique noire ait 
donnés au monde. À vingt-huit ans, cela tient du prodige ${ }^{42}$. » Dans Le Figaro littéraire, Jean Chalon titre un entretien: "Yambo Ouologuem a uni le français le plus pur et l'Afrique la plus noire dans Le Devoir de violence ${ }^{43}$ ».

Les tirages se multiplient. Le 13 janvier 1969, Paul Flamand reçoit chez Drouant ${ }^{44}$ pour fêter le succès du livre. Dans son invitation, il écrit que le tirage vient d'être porté à 101000 exemplaires, que les ventes ont dépassé 80000 et qu'à ce rythme, ces chiffres seront «certainement porté[s] plus loin ${ }^{45} »$. Cette performance n'est pas qu'absolue, elle est aussi relative : un article du Monde de juillet $1969^{46}$ nous apprend que les ventes du Devoir de violence ont dépassé de 40000 exemplaires celles du prix Renaudot $1967^{47}$.

51 L'écho de la réussite atteint l'étranger. Plus de dix contrats de cession de droits en langues étrangères seront signés cours des semaines et mois suivants : aux États-Unis, Pays-Bas, Japon, Danemark, Brésil, en Grande-Bretagne, Allemagne, Italie, Argentine, Suède et Norvège.

Tout devrait donc aller pour le mieux pour Yambo Ouologuem, comme entre lui et Le Seuil. Le ciel va cependant s'assombrir.

\section{« Je voudrais fixer le nombre de romans que je publierai à 15 »}

53 Le 18 mai 1968, avant même l'impression du roman, Yambo Ouologuem exprime par écrit à Paul Flamand toute son ambition littéraire et décrit son avenir au Seuil ${ }^{48}$. Les bases sont ainsi posées d'un début de malentendu entre auteur et éditeur et de frustrations entre les rêves du premier et la réalité à laquelle le second est ou se contraint. Dans une longue lettre (voir l'intégralité en annexe 1) où il expose ses vues sur le roman et l'épopée et où il indique les avoir confrontées à sa lecture d'André Schwarz-Bart et d'Édouard Glissant, et évoque les liens de Léopold Sédar Senghor avec Le Seuil et son homosexualité présumée, l'auteur parle du contrat qu'il aurait souhaité :

Mais il y a autre chose, de plus important, dont je voulais vous entretenir lors de notre première entrevue. Je n'ai pu le faire, alors que c'est la raison précise pour laquelle j'avais sollicité un rendez-vous. Voici donc.

Il s'agit de notre contrat, auquel j'aurais souhaité des clauses particulières.

Tout d'abord, je veux dire qu'il ne s'agit pas pour moi d'écrire « des » romans : il me faut un système, à l'échelle de la vision que j'estime être celle des Noirs en général. N'anticipons pas et ne parlons pas de «négritude».

[...] en écrivant des "fragments ", c'est-à-dire des romans sans le système d'une espèce de "comédie humaine", je risque tout simplement d'être le concierge attardé d'une forme de littérature négro-africaine, fort inégale dans ses tentatives, et, de toute façon, vouée à être une espèce de continuation directe du grand roman social réaliste $\mathrm{du} 18^{\mathrm{e}}$ siècle - lié à la situation post révolutionnaire (prérévolutionnaire ?) de l'Afrique.

Or, je le crois, les énormes transformations politico-sociales ont éveillé le sens de l'histoire, non pas seulement en Afrique, mais dans le « Tiers-Monde » tout entier. Je sais bien que, de par ma littérature (et par les larges concessions qu'elle fait à l'action, à l'épopée qui occasionne comme une subversion radicale des valeurs, conditionnant ainsi une contestation critique, voire une adhésion motivée), le monde ne s'en trouvera pas modifié, alors que le monde n'était plus le même après le voyage d'Ulysse. C'est pour cela que je conçois mes personnages sous une ampleur épique - malgré toutes les césures de style ou de présentation - faisant en sorte que les personnages s'accomplissent, se dépassent et transcendent une réalité qui semblait les définir complètement. Du même coup, la réalité ou l'irréalité du 
monde qui les entoure apparaît, je crois, plus clairement après leurs actions épiques. Le reste est question de métier propre à donner un substrat romanesque à l'expérience créatrice. De là aussi, indirectement il est vrai, le rôle prépondérant de l'ironie, arme de la satire d'autant plus que je répugne à l'invective et à la dénonciation enragée. Et l'attaque ironique, prudente, feutrée, est comme un hommage au lecteur, jugé assez intelligent pour saisir les sous-entendus. Il est dans ces conditions évident que je ne crois pas avoir la niaiserie de penser qu'un livre a une quelconque "couleur raciale », en raison de laquelle un éditeur investirait les capitaux d'une édition.

Bref, ce que je voudrais que vous m'accordiez, c'est un contrat avec des clauses particulières: fixer le nombre de titres de romans que je publierai à la suite du premier, non pas à 5, mais à 15 ; ensuite, avoir le droit non pas à 2 mais à 3 refus de manuscrit pour reprendre ma « liberté ».

Il ne s'agit pas, je vous l'ai expliqué, je crois, de s'enfermer dans la gaudriole de la "négritude» et de ses éventuelles incidences épiques. Il s'agit de ne pas se condamner, dès le départ, à amener les briques isolées d'un édifice épars.

Et c'est là un premier travail fondamental que de s'entendre bien sur cette optique littéraire. J'avais déjà mis en sous titre, dès le "devoir de violence", «La chair des civilisations ». Ce titre "La chair des civilisations » est la désignation générale de l'ensemble des 15 volumes que je veux écrire pour vous. J'envisage encore deux titres centrés sur l'Afrique; ensuite, ce sera de façon incidente. Il y faut les États Unis, l'Amérique latine, et le Monde Occidental et Asiatique.

C'est parce que j'avais la conviction ferme qu'il n'en pouvait être autrement que je m'interrogeais, me demandant si je savais écrire. Je ne parle pas de ce coup de pouce habile, que l'on nomme la «chique» en peinture et qui est affaire d'ingéniosité alors même que la vie en est absente. Et comme, par ailleurs, il y a plus de médailles que d'écrivains, je n'ai pu m'empêcher, au terme d'une abominable période d'angoisse, d'aller déranger Mr Cayrol. [...]

Vous voudrez bien excuser la longueur de cette lettre. Il est vrai que nos ennuis ennuient les autres. Mais c'est parce que je ne vous vois pas comme un marchand que je me refuse à vous voir comme un marchand, que j'ai pris la liberté de vous écrire. [...] 


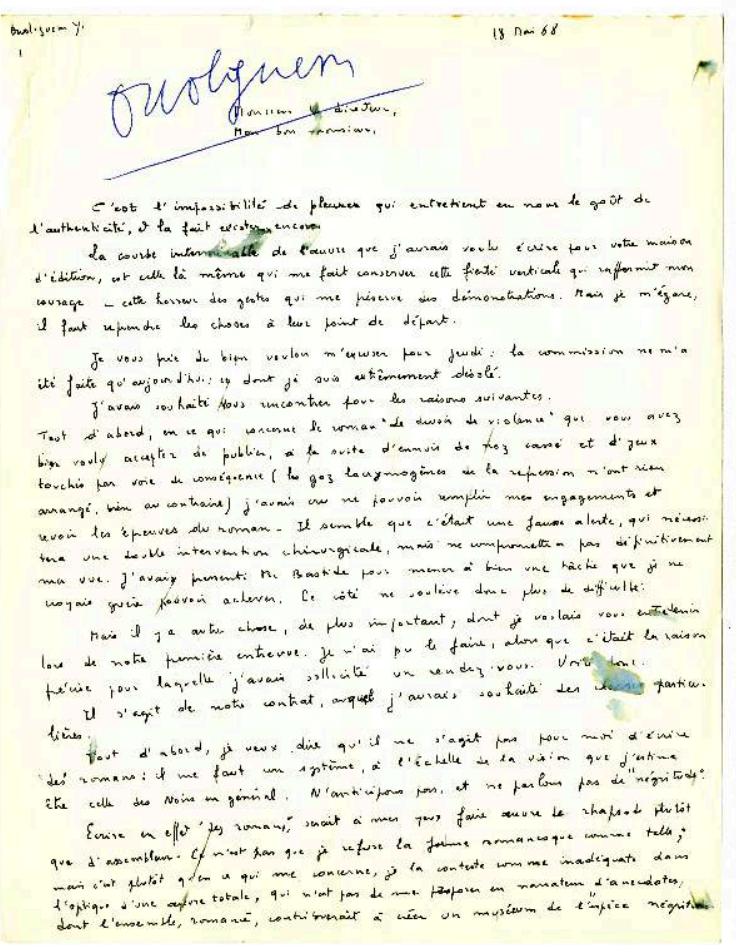

IMEC, SEL 3772.2

Tous droits réservés

On ne possède pas la réponse de Paul Flamand. Il n'y en eut peut-être jamais: Ouologuem l'affirmera plus tard. Le contrat, de toute façon, est signé depuis sept mois et ne changera pas. Et Le Seuil ne publiera, en définitive, qu'un seul ouvrage de Yambo Ouologuem.

La question des autres textes inédits est évoquée pour la première fois, publiquement, dans Le Monde, dans l'entretien avec Philippe Decraene, qui accompagne la critique du Devoir de violence : «Quatre années de travail pour rédiger ce Devoir de violence n'ont pas découragé Yambo Ouologuem. Il vient d'achever une Lettre ouverte à la France nègre, adressée au général de Gaulle, "Mon cher grand-père et libérateur", pour laquelle il cherche un éditeur ${ }^{49}$." Provocateur, Ouologuem y proclame qu'il s'agit d'un «billet ouvert à toutes les victimes de l'antiracisme ». À nouveau, le jeune auteur prend la lecture de l'Histoire à contre-courant et son public à rebrousse-poil.

Le pamphlet composé d'une collection de textes brefs et intitulé Lettre à la France nègre trouvera un éditeur, mais un " petit »: Edmond Nalis. Dans une lettre envoyée au Monde et publiée partiellement dans le quotidien le 14 décembre $1968^{50}$, Nalis s'en prend à l'écrivain Philippe Hériat (1898-1971) qui, dans une interview ${ }^{51}$, avait asséné que les mauvais livres s'éliminent d'eux-mêmes - à savoir ceux qui sont publiés chez des éditeurs inconnus - et annonce que Lettre à la France nègre va paraître ce même mois de décembre. 


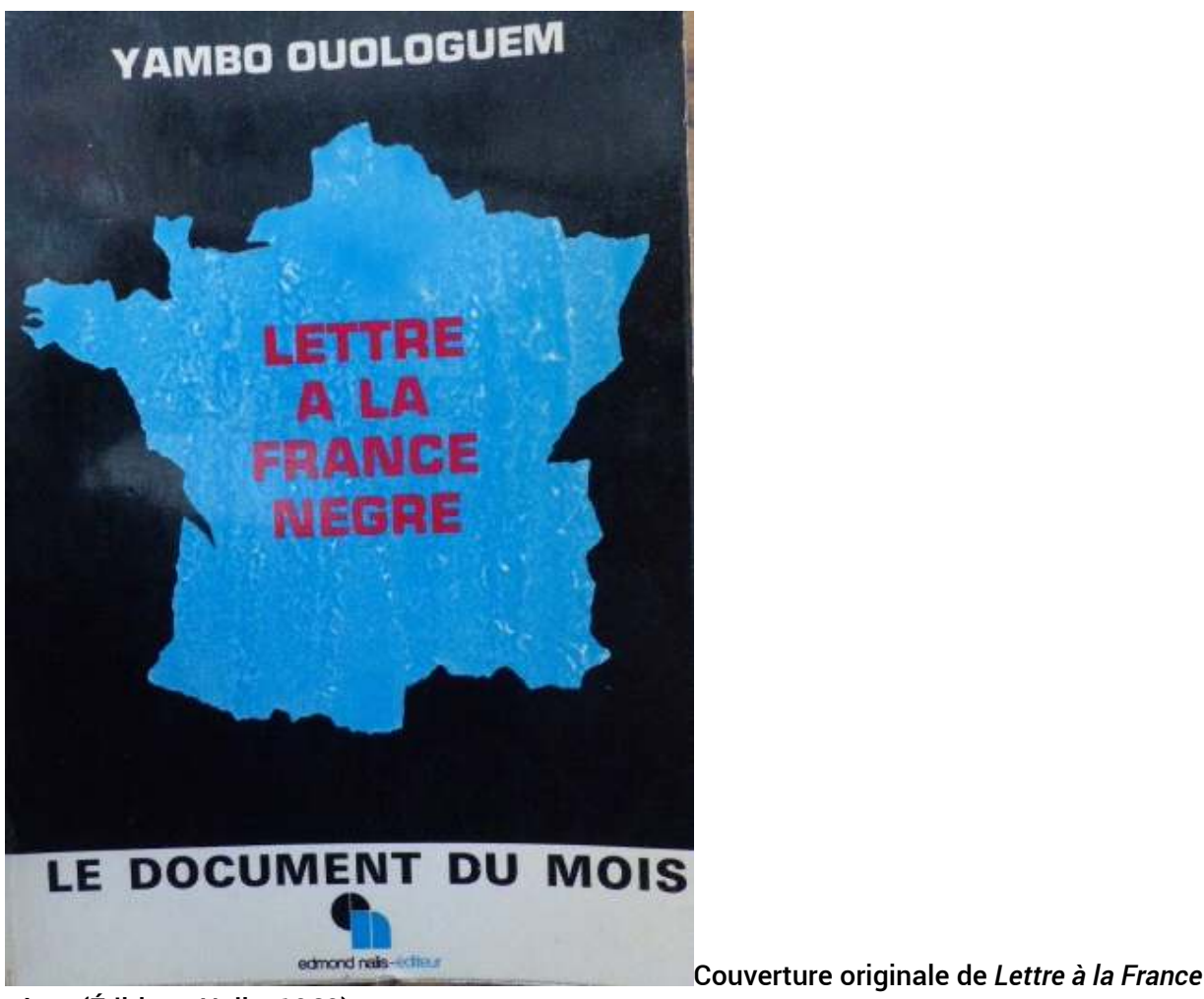

nègre (Éditions Nalis, 1969)

Dans un entrefilet du 27 janvier $1969^{52}$ intitulé "Le devoir d'insolence ", Le Figaro littéraire en fait part : «Le jeune Malien accable presque chaque jour son éditeur de requêtes : exigences, récriminations [...] Il fait suer le burnous. »

Le lendemain même, Ouologuem réagit dans une lettre ${ }^{53}$ acerbe et ironique adressée, non pas au Figaro Littéraire, mais à Paul Flamand :

Monsieur le Directeur,

Je vous prie de bien me croire désolé de constater qu'il nous semble à l'un et à l'autre, difficile de parler le même langage ; puisque, tout aussi bien - loin d'évoluer dans une coopérante compréhension- nos rapports, macérant en mille escarmouches navrantes - dégénèrent en un malentendu qui n'était guère de première nécessité.

En effet, «être insolent» n'a jamais été mon propos: et encore moins une composante de mon éducation, voire de mon tempérament, lesquels répugnent à l'indiscrétion, tout autant qu'à la vulgarité.

Comprenez-moi. Il ne s'agit ni d'« aliénation ", ni de pseudo-drame du déchirement. Mais bien, plutôt, d'une évidence. Je ne suis pas dans ma patrie, Monsieur le Directeur, et n'écris pas ma langue. Quoi d'étonnant que je n'ai jamais cru au Devoir de Violence - et moins encore à un quelconque prix littéraire ?...

Je vous l'ai dit, et vous le savez: il est plus de médailles que d'écrivains. J'ai donc cherché à trouver chez mon éditeur - c'est à dire votre maison - ce hâvre de sérénité où l'intransigeance vis à vis de soi-même fasse désespérer d'une certaine pureté, engendrant ainsi - et comme surgie des zones d'ombres d'une objectivité qui s'interroge - cette sève vive, laquelle fait aimer devoir mieux faire encore : c'est à dire écrire.

Vous vous en souvenez, Monsieur le Directeur, je vous l'avais écrit : sur la dédicace $\mathrm{du}$ « DEVOIR DE VIOLENCE ». De là sans doute, le caractère éminemment primordial du climat humain. Ce qui, convenez-en, m'a toujours fait défaut aux Éditions du SEUIL.

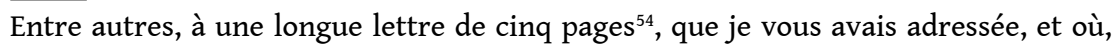


bien avant le Renaudot, je vous exposais mon propos (d'ordre purement littéraire, d'ailleurs), jamais réponse n'a été faite. Malgré mon nez fracturé par les matraques du service d'ordre, en mai dernier, pendant que je passais l'agrégation, j'étais venu à vous, m'informer des suites de la dite lettre : ici encore, un mur...

Enfin, depuis plus de quatre mois, j'ai remis à Monsieur BASTIDE, une dizaine de pages - les premières de mon second roman - afin d'être guidé dans mes quêtes : j'en étais à ma huitième ébauche. Là également, la littérature a été saluée par la conjuration d'une indifférence polie, et le silence le plus total. Comment, dans ces conditions, aurais-je osé vous laisser la «LETTRE À LA FRANCE NEGRE » au delà des trois jours où Monsieur F.R. BASTIDE - qui avait tout le loisir de l'emporter, ou, tout au moins, de la mettre en lecture, à défaut de la lire lui-même - l'a laissée sur son bureau?

Par ailleurs, LE MONDE, dans son article du 12 Novembre 68, signalait, sous la plume de Monsieur Philippe de CRAENE «Yambo OUOLOGUEM vient d'achever un pamphlet intitulé - LETTRE À LA FRANCE NEGRE - pour lequel il chercher un éditeur ". Il a fallu que je reçoive des propositions d'autres éditeurs, que j'hésite à les accepter, (puisque j'avais préjugé votre silence pour me penser écrivaillon), que je vous dise que le pamphlet était prêt, pour que vous me le demandiez. Les réclamations instantes des autres ont fait que j'ai cédé.

Et tout ceci, sans doute, n'eut pas tiré à conséquence, sans ce prix Renaudot.

Mieux, afin, sans doute, de me remettre à ma place d'auteur ouvrier « en me faisant la leçon ", vous avez tenu, Monsieur de Directeur, à me signaler votre puissance, par la force de votre frappe : la presse - et l'article assez infamant que vous savez, lequel, titré " le devoir d'insolence ", est tout à la dérision de ma personne, et d'un livre que, pourtant, vous avez édité.

Permettez, Monsieur le Directeur, que je veuille, en dépit de tant de contrariétés qui me donneraient lieu de me sentir circonvenu de toutes parts - oser conserver de vous une image autre que celle d'un éditeur-président-directeur général pour qui dialoguer avec un auteur, c'est d'abord et avant tout l'initier au rite d'un conformisme obséquieux - surtout dès lors que l'auteur à le tort, comme moi, de ne compter que vingt huit ans : et que jeunesse, contrairement à noblesse, désoblige.

«Devoir d'Insolence ", dites vous dans l'article commandé au Figaro Littéraire $\mathrm{n}^{\circ}$ 1186. «Le jeune Malien accable presque chaque jour son éditeur de requêtes: exigences, récriminations... Il fait suer le burnous » dites-vous.

Ne voulant pas vous importuner davantage, j'ai l'honneur de vous prier de bien vouloir trouver ci-joint, le chèque $\mathrm{N}^{\circ} 1510955$ tiré sur mon compte du C.R.C.A.M. d'un montant de $20.000 \mathrm{Fr}$. (VINGT MILLE FRANCS).

Vos libraires ne vous ayant pas réglé, selon vos propres termes, cette somme représente la différence entre les 150.000 Frs (CENT CINQUANTE MILLE) que vous comptiez me verser - conformément d'ailleurs à l'esprit de votre lettre du 13 janvier, et les $170.000 \mathrm{Fr}$. (CENT SOIXANTE DIX MILLE) que vous m'avez effectivement versés, à titre d'acompte sur les droits d'auteur du «DEVOIR DE VIOLENCE ».

Avec toute l'expression de ma sincérité, veuillez agréer, Monsieur le Directeur, l'expression de mes sentiments respectueux.

Yambo OUOLOGUEM

« Je dois dire que ma plus vive surprise est que vous paraissiez croire qu'il s'agit d'une interview donnée par quelqu'un du Seuil », lui répond rapidement Paul Flamand ${ }^{55}$. [...] Je vous renvoie votre chèque de $20000 \mathrm{Fr}$. [...] Bon? Voulez-vous que nous tirions un trait sur tous ces "incidents de parcours" [...] Ce qui compte maintenant, c'est votre œuvre littéraire, c'est votre prochain roman. » Et Flamand joint la copie du mot qu'il a adressé à l'auteur de l'entrefilet :

$\mathrm{Au}$ retour d'un voyage de dix jours, je prends connaissance de l'entrefilet «Le devoir d'insolence ».

Je ne puis empêcher quiconque de reproduire les propos qu'il a entendus au cours 
d'un déjeuner auquel il était convié.

Mais je ne puis admettre qu'il soit prêté à la « rue $\mathrm{Jacob}^{56}$ » des réflexions qui n'ont jamais été tenues. s'agit des Pèlerins de Capharnaüm, un récit mythico-religieux dense, parfois touffu, dont le début dactylographié sur 79 feuillets est conservé dans les dossiers du Seuil à l'IMEC $^{63}$. Ce tapuscrit, à ce jour encore inédit et sans doute inachevé, fera l'objet d'échanges, notamment épistolaires, avec un autre éditeur du Seuil, Paul-André Lesort, ainsi qu'avec Paul Flamand. Au terme de ces échanges, où l'auteur conteste les arguments des éditeurs et renâcle à réécrire son texte dans les termes demandés, Ouologuem ira le proposer à d'autres maisons. Cela fera l'objet d'un contentieux.

Couverture du Secret des orchidées (réédition Poche Select, 1979)

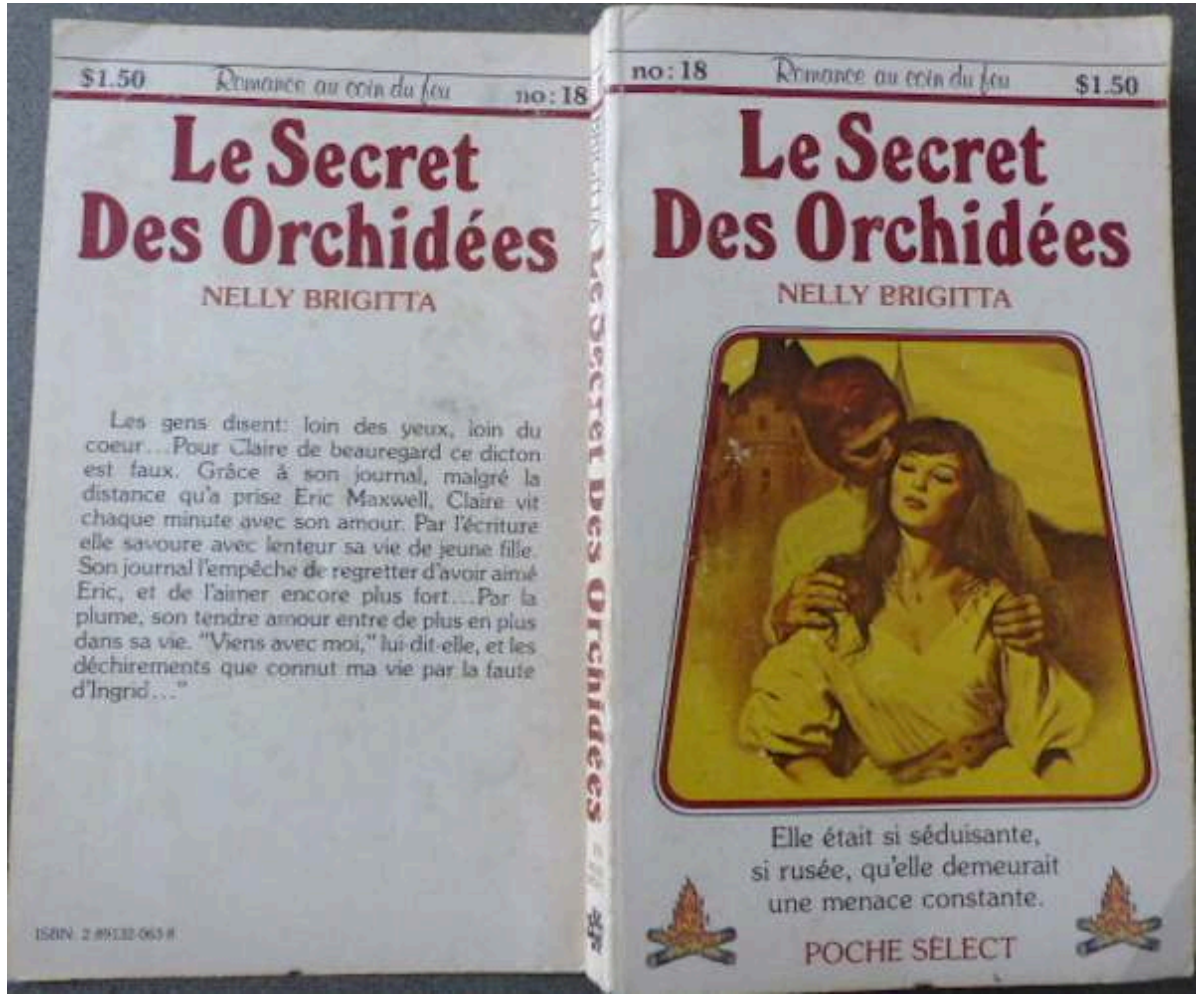




\section{«Parce que je n'ai pas d'ami » : comptes et mécomptes}

63 Il n'y a pas que la publication des inédits qui pose problème entre le Seuil et le jeune homme à la fois altier et procédurier qui découvre les lois de la république des Lettres française, les bouscule et parfois s'en affranchit avec aussi peu de réserve qu'il a fustigé les notables africains. Dès le 8 janvier 1969, à l'apogée de son succès et après avoir exigé de vérifier les tirages de son roman sur la base des factures d'imprimerie, Ouologuem réclame de toucher ses droits avant l'échéance prévue. Le 13, Paul Flamand lui écrit :

Cher Ami,

Comme suite à notre conversation du 8, au cours de laquelle vous m'avez exprimé le désir de toucher immédiatement les droits sur 100000 exemplaires de votre roman, je vous prie de trouver ci-joint un chèque de $174611,34 \mathrm{~F}$.

J'y joins un relevé provisoire, pour mémoire. Il s'entend bien que le chiffre de vente n'a pas encore atteint les 100000 exemplaires et que le plus grand nombre de ceux qui sont vendus ne sont point payés puisque, comme vous le savez, les libraires règlent à quatre-vingt-dix jours et nous-mêmes ne pouvons établir de compte définitif d'exercice que trois mois après le 31 décembre. Mais enfin, puisque cela vous arrange, c'est avec plaisir que je réponds à votre vœu nous réservant pour la suite l'établissement d'état comptable plus exact que celui-ci ${ }^{64}$.

64 Une autre lettre de Flamand à Ouologuem, datée du même jour, mentionne que la "vente actuelle est en fait de 87000 exemplaires ${ }^{65}$ ». Flamand y ajoute les 13000 exemplaires non vendus et il envoie à son auteur un chèque de 170000 francs.

Août 1969, mai 1970, novembre 1970, janvier 1971 : les échanges à propos des comptes se succèdent. Les réponses détaillées (état des stocks, récapitulation des tirages, modalités de calculs des droits) de Paul Flamand ne suffisent pas. Pas plus que la réévaluation des pourcentages des droits d'auteur suite à l'instauration de la TVA en janvier 1969 et le succès du roman. Yambo Ouologuem s'accroche et ne cède pas, mêlant parfois - et ceci explique peut-être cela - aux exigences matérielles, des attentes qui dépassent ces dernières et des reproches où la susceptibilité dénature parfois la stricte vérité :

Cher Monsieur Bastide,

Mon bon monsieur,

Permettez-moi, encore une fois, de vous remercier d'avoir bien voulu m'honorer de votre présence et de celle de Mme Bastide, lors de notre dernière rencontre, d'ordre, si j'ose dire, extra-professionnel. Bon.

Je viens de recevoir une lettre de Mr Paul Flamand, qui fait état de l'augmentation de pourcentage de mes droits d'auteur hissés jusqu'à $15 \%$, réflexion faite.

Voyez-vous, si je me suis permis avec vous, de faire allusion à ce qui était ou n'était pas une "anomalie»- à savoir mon taux maximum de $12 \%$, tout ainsi que le versement des droits survenu, effectivement, le 13 janvier 69 - ce n'était nullement pour obtenir la réévaluation de mon premier contrat avec «le Seuil», par le biais d'une rencontre avec vous.

Le but de cette rencontre - compte tenu de divers déboires miens, d'ordre privé était tout simplement, d'assurer à travers ce que vous représentez littérairement, une espèce de lien [...], sans ombre portée, et qui me fasse mieux encore aller de l'avant : en vous présentant mon second roman. Parce que je n'ai pas d'ami.

$\mathrm{Vu}$ la différence d'âge, il serait bien évidemment saugrenu de chercher en vous un ami, [dans le] sens véritable du mot. Le mot est fréquent d'emploi, certes, et avec toute relation; mais il est [gal]vaudé par là-même. C'était donc une admirative 
amitié, plutôt, que j'avais cru pouvoir [entre]tenir.

Par ailleurs, convenez-en, je n'ai plus rien à perdre. Ceci pour relever l'arbitraire de [mon] état de compte de droits d'auteur, et l'arbitraire de la manière dont je viens seulement $[\grave{a}]$ présent d'être tenu au courant : sans l'avoir réclamé. Pas plus que je n'ai réclamé le justificatif des divers tirages du « Devoir de violence $»^{66}$. [...]

J'espère que vous voudrez ne point voir là des « récriminations ». Mais seulement un constat. [...] $]^{67}$.

En mai 1970, une note interne au Seuil avertit Flamand que Ouologuem entend désormais confier le dossier comptable à son avocat et à la justice. Ce qui adviendra finalement près de deux ans plus tard. Le 18 février 1972, les Éditions du Seuil sont assignées à comparaitre le 25 au Tribunal de Grande Instance de Paris pour non-remise des comptes à Yambo Ouologuem. Une expertise indépendante sera ordonnée. Entremêlée à d'autres qui surgiront, l'affaire se poursuivra jusqu'en 1976.

\section{Magie noire, Fayard et Doubleday : de Paris à New York}

67 Malgré les tiraillements sur les comptes et les inédits, les rapports entre Yambo Ouologuem et son éditeur resteront chaleureux tout au long de l'année 1969. «Cher Yambo, Quelle joie de recevoir votre carte de Dordogne!», écrit Bastide en juin. " Votre lettre m'a touché », fait savoir Ouologuem à Flamand à la même période. « Avec tout mon attachement ", conclut Ouologuem dans une carte à Jean Cayrol envoyée d'Alger. 1970 ne se passe pas trop mal, malgré une alerte sur un ouvrage « en langue étrangère » (vraisemblablement en anglais) qu'aurait écrit Ouologuem et dont il n'aurait pas parlé à Paul Flamand ${ }^{6}$.

Deux conflits de ce type tournant autour du droit de préférence envenimeront les relations.

«Cher Yambo Ouologuem, [...] je viens de recevoir un coup de téléphone de Denoël qui me dit que vous lui avez proposé un essai intitulé : Magie noire. J'aimerais là aussi que vous acceptiez de me dire quelque chose de ce projet $^{69}$. $»$ La veille de cette lettre du 29 janvier 1971, Paul Flamand a reçu un mot de ses services demandant qu'il rappelle les Éditions Denoël à propos d'un manuscrit d'essai proposé par l'auteur malien. Le 2 février, Denoël parle d'un essai illustré sur la magie noire « que l'auteur se propose de réaliser pour $[e u x]^{70}$ \%. La maison de la rue Saint-André des Arts veut s'assurer que l'ouvrage n'entre pas dans le cadre du contrat entre Ouologuem et Le Seuil et demande l'accord de la maison de la rue Jacob. On ignore si un accord est jamais intervenu. Toujours est-il que l'essai n'a jamais paru.

70 Le deuxième épisode du même type est de plus grande ampleur et, si on en accentue les traits, relèverait presque du genre picaresque.

71 Alors qu'en janvier 1971, l'adresse de correspondance de Yambo Ouologuem était encore celle des Éditions du Dauphin, à Paris, une autre apparaît en février : au 24 de la plus célèbre avenue de New York, la Fifth Avenue, au Fifth Avenue Hotel, près de Washington Square. C'est que l'auteur s'est envolé vers les États-Unis pour la promotion de la version américaine du Devoir de violence. Bound to Violence ${ }^{71}$ parait à ce moment. Ouologuem s'installe dans la métropole américaine pour plusieurs mois :

FIFTH AVENUE HOTEL

Twenty four, Fifth Avenue, 
New-York, N.Y., 10011 USA

New-York, ce 26 février 1971,

A Monsieur Paul Flamand

Monsieur le Directeur,

Mon bon monsieur,

[...] Ici, ma venue n'a pas ete inutile, du moins pour ce qui est du succes de presse.

J'ai estime devoir apporter avec moi des documents anciens, pour situer hors de tout contexte de polemique facile (le Devoir de violence est un de ces livres dont il est difficile de prevoir l'accueil par les Noirs) la presentation de mon premier roman. Le resultat n'a pas ete mauvais : des dirigeants noirs americains y ont ete favorablement sensibles au travail. Mieux, ils ont patronne la critique au New York Times (deux pages avec critique et interview) entre autres... Je n'ai pas regrette les mille dollards qu'il m'a fallu lacher à la douane pour passer mes gravures d'epoque. [...]

Bien respectueusement à vous et avec mes excuses : j'utilise une machine à clavier americain, c'est-a-dire sans accents.

YAMBO OUOLOGUEM ${ }^{72}$

« Je ne savais pas où vous écrire jusqu'à ce que me parvienne votre lettre du 26 février qui n'est arrivée qu'il y a deux jours », lui répond Paul Flamand le 15 mars $^{73}$. Et il lui annonce qu'il arrive lui-même à New York le 21 pour une dizaine de jours en compagnie de Jacqueline Lesschaeve (en charge des cessions de droits) et de Denis Roche (écrivain et éditeur au Seuil, 1937-2015) : « nous espérons bien vous rencontrer là. [...] Je suis heureux de vous revoir. J'ai eu des nouvelles par Madame Wolff [éditrice de Bound to Violence] et nous avons été contents de voir les premières réactions, bonnes, de la Presse Américaine ».

Celles-ci sont, en majorité, positives :

Yambo Ouologuem's voice is one we must hear because he tells us what we haven't heard and need to know. He tells us about a historical black culture that parallels and is at least as widespread as the white. He shows us an unblocked black sexuality that reveals our own erotic revolution as primitive. Mythic and epic, horrifying and beautiful... the authentic voice of Black Africa.

Webster Schott, Life.

74 Flamand et Ouologuem se verront sans doute à New York. Mais c'est à Paris, alors que Ouologuem est toujours aux États-Unis ${ }^{74}$, que Flamand apprend que son auteur a signé un contrat pour cinq livres, avec Doubleday, un éditeur américain qui n'est pas celui de Bound to Violence et avec lequel Le Seuil n'est pas en relation commerciale ${ }^{75}$. Le contrat porte sur quatre essais et un roman. La signature a été assortie d'une "somme énorme ${ }^{76}$ ", dont on saura plus tard qu'elle s'élève à 30000 dollars ${ }^{77}$, et une promesse d'édition de poche " pour des sommes encore plus importantes ${ }^{78}$ ».

Le milieu éditorial s'agite, depuis l'agent américain du Seuil, Georges Borchardt, jusqu'à l'éditrice de Bound to Violence, qui en est choquée :

Rien, je suis sure [sic, ainsi que pour le reste de l'extrait], peut nous surprendre en regard de ce drôle de génie qui semble sujet à la contrainte de mordre les mains qui l'ont nourri. Mais Bill Jovanovich ${ }^{79}$ et moi aimerions savoir comment les choses se présentent du point de vue légale. Nous allons insister sur notre option, vu le fait que c'est par nos efforts que la réputation de Ouologuem s'est faite aux Etats-Unis. Bien entendu, il ne m'a rien dit de ses arrangements, que j'ai appris par Borchardt et Secker.

Un jour que j'espère prochain, on causera encore de l'expérience Ouologuem certaines choses se sont passées qui ne se prêtent guère à la communication écrite ${ }^{80}$ ! 
On en apprend plus dans la suite des correspondances. Les essais pour lesquels Ouologuem a signé un contrat avec Doubleday comprennent une histoire de l'Afrique contemporaine en plusieurs volumes ${ }^{81}$. Pour ce qui est du roman, à savoir Les Pèlerins de Capharnaüm $^{82}$, il en a parlé à son éditrice américaine, Helen Wolff qui dit avoir témoigné un vif intérêt, mais avoir estimé que le roman, s'il était édité par Le Seuil, lui reviendrait et que ce n'était pas à elle de signer un contrat d'édition pour ce roman :

[...] Très franchement, ce Monsieur vous a raconté des histoires qui ne sont nullement vraies. Je n'ai pas été «souffrante» un seul jour, il m'a constamment visité dans mon bureau, des heures entières, et dire qu'il s'est senti libéré de son droit d'option par un manque d'intérêt de ma part est du pur mensonge. Il n'a jamais hésité de me visiter ni de me téléphoner, je lui ai toujours témoigné de l'intérêt - vous connaissez ce Monsieur suffisamment pour savoir que son imagination est plus forte que sa raison.

La chose est très simple : Yambo Ouologuem s'est figuré que nous aurions dû vendre 60000 exemplaires de son roman ; or, nous en avons vendu à ce jour environ 14000 (le chiffre est incertain à cause de la possibilité de renvois). Pour le premier livre d'un inconnu, et une traduction, et en vue du fait que, par son écriture, ce n'est pas un livre du genre bestseller, c'est à mon avis pas mal. Ce que fera son prochain livre dépend de la qualité de ce livre, et évidemment, ayant fait la réputation de Yambo Ouologuem à grand effort de tout le trade department, et en vue de notre contrat avec vous pour son prochain roman, moralement et légalement nous avons le droit de voir ce roman et de faire notre offre après lecture, ne pensez-vous pas?

Ouologuem était à New York, moi j'étais chaque jour dans mon bureau, il n'avait qu'à me demander si oui ou non je me désintéresserai à son livre. Rien en ce que j'ai dit ou fait a pu lui donner cette impression ${ }^{83}$.

77 Les choses s'aggraveront avec la nouvelle que, lors d'un voyage à Londres fin juillet de cette année 1971, Ouologuem a cherché à signer un contrat pour un même roman à venir avec Secker \& Warburg, l'éditeur de la version britannique de Bound to Violence ${ }^{84}$, le soumettant «à grande pression ${ }^{85}$ ».

Et, non content d'explorer le marché anglo-saxon, pas plus qu'ébranlé par les cris d'orfraie de ses éditeurs, Ouologuem, de retour en Europe en septembre, va à nouveau frapper aux portes des maisons françaises, dont les Éditions Fayard, pour placer Les Pèlerins de Capharnaüm, découragé sans doute par le peu d'enthousiasme du Seuil.

En définitive, la situation se calmera sur le front anglo-saxon, où aucun des nouveaux projets n'aboutira. Le Britannique Secker \& Warburg rejettera l'offre de Ouologuem et l'éditeur américain Doubleday fera amende honorable auprès du Seuil, qui gardera son «droit de suite » sur les romans de Ouologuem:

Après en avoir pris connaissance, notre Publisher, Mr. Samuel Vaughan, me demande de vous dire qu'il regrette infiniment qu'un fâcheux malentendu se soit produit, pouvant nuire aux rapports de Doubleday avec les Editions du Seuil, rapports qui ont toujours été très amicaux et très importants pour nous ${ }^{86}$.

En France, en revanche, Fayard ne lâche pas le morceau et traite avec la rue Jacob par avocats interposés : pour le premier Maître Brossolet, pour la deuxième Maître Georges Kiejman, ténor du barreau ${ }^{87}$, qui a accompagné et accompagnera Le Seuil de ses conseils juridiques tout au long de son histoire depuis les années 1960.

81 Nous sommes au printemps 1972. Pendant trois ans, les accrochages se sont succédé. Tout est en place pour que la tension culmine. L' «affaire Ouologuem » va bientôt éclater. Par un biais que personne n'avait prévu... 


\section{"Something new out of Africa? "}

5 mai 1972. Le très respecté Times Literary Supplement publie un article incendiaire sur le plagiat que Yambo Ouologuem a commis dans Le Devoir de violence par rapport à un roman de l'écrivain britannique Graham Greene (1904-1991), It's a Battlefield ${ }^{88}$. Sous le titre de "Something new out of Africa? », «Du nouveau venu d'Afrique? » aussi littéraire par ses références au roman de Karen Blixen (Out of Africa ${ }^{89}$, 1937) qu'ironique par l'italique du mot «new» et le point d'interrogation final, le magazine reproduit, en regard sur deux colonnes, des extraits en français ${ }^{90} \mathrm{du}$ Devoir de violence de Ouologuem et ceux, en anglais, du roman de Greene dont ceux-là seraient inspirés.

Pages de l'article du Times Literary Supplement du 5 mai 1972 présentant en regard les pages " plagiées » de It's a Battlefield de G. Greene et les pages incriminées du Devoir de violence

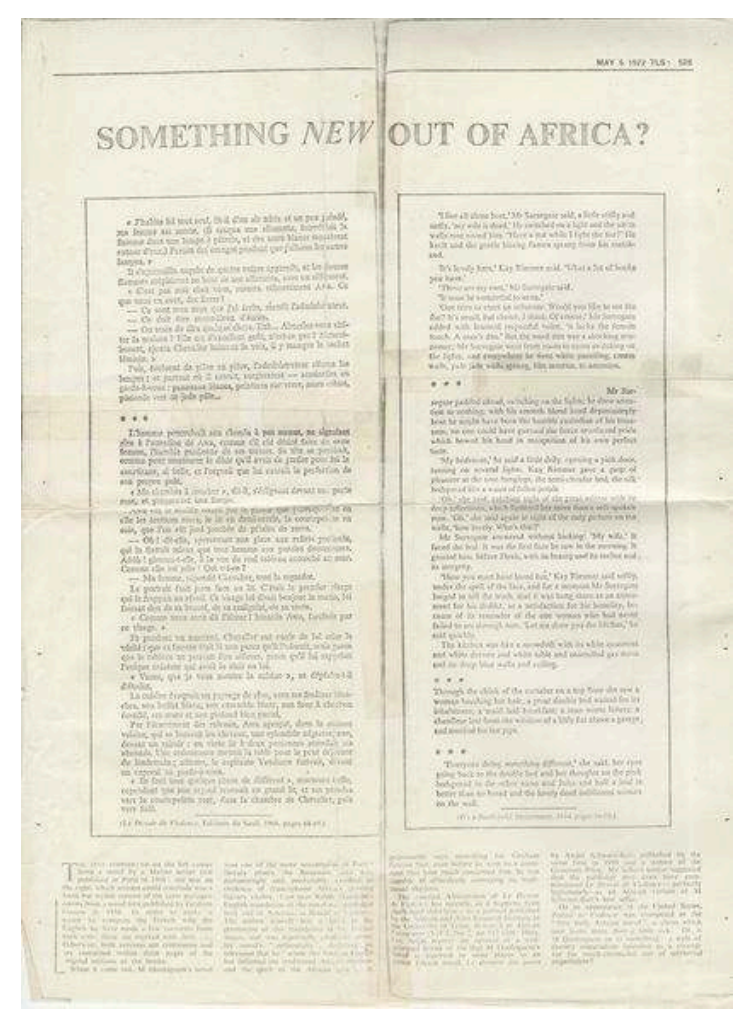

IMEC, SEL 2923.8

Comment, quatre ans et demi après la parution du Devoir de violence et un an après celle de sa version anglaise, la découverte d'un plagiat a-t-elle abouti dans les bureaux du Times Literary Supplement?

"Un jeune universitaire noir, de langue anglaise, [va] faire paraître dans une revue africaine une longue étude intitulée "Bound to Violence, a case of plagiarism" [Le Devoir, un cas de plagiat $]^{91}$ ", écrit Paul Flamand dans sa première lettre à Yambo Ouologuem à ce sujet. Il semble cependant que la révélation publique d'un élément de plagiat ${ }^{92}$ ait suivi des voies plus inattendues encore.

Dans Quand l'Afrique réplique, La collection "African Writers" et l'essor de la littérature africaine ${ }^{93}$, James Currey, qui dirige la collection de poche où a paru la version brochée (paperback) de Bound to Violence au sein du même groupe éditorial, Heinemann où publie 
Graham Greene, parle d'un «étudiant australien qui menait des recherches en Zambie » :

Un matin, Alan Hill [directeur de Heinemann Educational Books] me demanda de le rejoindre au plus vite dans son bureau de Mayfair. Il était à son gigantesque bureau, le téléphone collé à l'oreille. La tension nerveuse était palpable à la façon qu'il avait de passer le téléphone d'une main à l'autre. Il couvrit le combiné de sa main et murmura : "C'est ce vieux Graham Greene ! " Comme Alan Hill l'a indiqué au Times d'une manière très imagée (5 mai 1972) :

«Greene m'a passé un coup de fil. Le ton était sec, sa voix faisait penser à du vieux papier friable. On aurait pu le déchirer. J'ai immédiatement feuilleté le livre et je suis tombé sur le passage en question. Il était inouï de constater comme cela transparaissait malgré la traduction. »

Alan Hill me demanda de comparer certaines pages du livre de Yambo Ouologuem avec le livre de Graham Greene, It's a Battlefield, publié par William Heinemann en 1934. C'est un étudiant australien qui menait des recherches en Zambie qui avait informé Graham Greene que certains passages de la traduction française de son roman qui se passe dans une pension avaient été transposés par Yambo Ouologuem dans un cadre tout aussi désolant en Afrique et avec des personnages différents ${ }^{94}$.

Averti à son tour, Tom Rosenthal, directeur de Martin Secker and Warburg où est éditée la version reliée (hardback) de Bound to Violence écrit à Paul Flamand une lettre polie dans laquelle il n'accuse pas l'éditeur français, mais davantage l'auteur malien à qui il a eu affaire, dit-il, pendant six mois lors des tractations pour le nouveau roman. Cependant, de façon ferme, Flamand lui demande des explications qu'il puisse transmettre à Graham Greene.

«Tenez! Voilà un œuf de Pâques... ", tapote Flamand sur un feuillet à l'adresse de son conseil Georges Kiejman, en joignant la lettre de l'agent littéraire de Graham Greene en France qui lui demande un rendez-vous. Les échanges juridiques, éditoriaux et commerciaux pour contenir le drame commencent.

En Grande-Bretagne, Graham Greene se montre conciliant: il «accept[e] immédiatement l'offre d'Alan Hill qui lui propose d'intégrer un avertissement dans le livre ${ }^{95} »$. C'est cependant lui qui demande à son éditeur d'informer le Times Literary Supplement et met donc, indirectement, le feu aux poudres ${ }^{96}$.

En France, Paul Flamand écrit immédiatement aux éditeurs étrangers avec lesquels il a conclu ou est en tractations de «suspendre toutes négociations ou reproductions du livre tant que [Yambo Ouologuem] n'aur[a] pas envoyé un nouveau texte pour remplacer les pages délictueuses ${ }^{97}{ }^{\prime}$.

90 Les éditeurs ne cèdent en général ni à la panique ni aux récriminations. L'éditeur allemand répond, ainsi, qu'il arrive au bout du tirage et qu'il n'en envisage pas d'autre. Et Heinemann se contente de bloquer un réassort vers le Nigeria, en notant toutefois que 3000 exemplaires circulent déjà au Kenya.

91 La réaction de l'éditeur américain, Harcourt Brace Jovanovich, est, elle, différente.

92 Le jour même où le Times Literary Supplement publie la preuve, à ses yeux, du plagiat à l'encontre de Graham Greene, le Times quotidien dont il est originellement issu se fait l'écho de la nouvelle en Une : «Echoes of Graham Greene halt prizewinning book» et en suite, page 2: "Stir in European publishing houses». Quelques heures plus tard, le New York Times fait de même de l'autre côté de l'océan: "Novel is Likened to Greene's Book. African "Bound to Violence" Held Similar to "Battlefield" ". "L'affaire flambe ", annonce

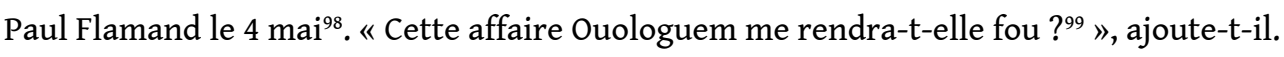


Très tôt, Harcourt Brace Jovanovich envisage, sur le conseil de son avocat, de pilonner les stocks. À la demande de l'agent américain de Graham Greene, il retire en tout cas de la vente 3400 exemplaires du roman et interrompt les négociations avec l'éditeur prévu pour l'édition de poche. The Times londonien et le New York Times parlent tous deux de coûts liés au retrait de l'édition de Bound to Violence de l'ordre de 10000 dollars. La réalité sera inférieure, autour de 6000 dollars. Mais ces 5 598,62 dollars - pour être précis - Harcourt Brace Jovanovich les réclamera en dédommagement au Seuil. La transaction s'établira finalement à 4786,12 dollars. Somme que la maison d'édition parisienne réclamera ensuite à Yambo Ouologuem, dont elle débitera le compte d'auteur au fur et à mesure des rentrées ${ }^{100}$.

L'affaire, cependant, ne se limite pas au monde anglo-saxon et au plagiat à l'encontre de Graham Greene. Elle rebondit immédiatement en France.

\section{«Yambo Ouologuem n'emprunte qu'aux riches »}

5 C'est que, dans l'article du Times Literary Supplement, il est fait mention d'un article publié six mois plus tôt par un chercheur américain, Eric Sellin, dans une revue sur les littératures africaines de l'université du Texas ${ }^{101}$. Dans cet article, Eric Sellin évoque le témoignage d'un certain Mohamed-Salah Dembri - dont tout ce qu'on apprend est qu'il est l'ami de Sellin - selon lequel Le Devoir de violence ne serait rien d'autre qu'une imitation du Dernier des Justes. Il parle là du roman d'André Schwarz-Bart sur le drame de l'antisémitisme en Europe, en particulier en Pologne, depuis le XIII ${ }^{\mathrm{e}}$ siècle jusqu'à l'extermination des Juifs dans les camps nazis. Comme Le Devoir de violence, Le Dernier des Justes a été publié au Seuil. En 1959. Il remporte cette même année le prix Goncourt et connaîtra un des plus grands succès de l'histoire du prix.

Imaginez ma consternation et ma perplexité quand j'ai comparé les incipit du «premier vrai roman africain » (que j'avais moi-même recensé avec enthousiasme dans French review),

écrit Sellin. Et de citer ces incipit :

[Ouologuem :] Nos yeux boivent l'éclat du soleil, et, vaincus, s'étonnent de pleurer. Maschallah! oua bismillah !... Un récit de l'aventure sanglante de la négraille - honte aux hommes de rien ! - tiendrait aisément dans la première moitié de ce siècle ; mais la véritable histoire des Nègres commence beaucoup, beaucoup plus tôt, avec les Saïfs, de l'an 1202 de notre ère, dans l'Empire africain de Nakem, au Sud du Fezzan, bien après les conquêtes d'Okba ben Nafi et Fitri.

[Schwarz-Bart:] Nos yeux reçoivent la lumière d'étoiles mortes. Une biographie de mon ami Ernie tiendrait aisément dans le deuxième quart du $\mathrm{XX}^{\mathrm{e}}$ siècle ; mais la véritable histoire d'Ernie Lévy commence très tôt, vers l'an mille de notre ère, dans la vieille cité anglicane de York. Plus précisément : le 11 mars 1185.

Sellin poursuit ensuite par les autres similitudes entre les deux œuvres : le titre de leurs premières parties («La Légende des Saïfs », "La Légende des Justes »), la structure, d'autres paragraphes, et ce jusqu'à la finale des récits : « Dans l'air, l'eau et le feu, aussi, la terre des hommes fit n'y avoir qu'un jeu... » (Ouologuem), «Mais il n'y avait nul souffle dans l'air, aucun nuage dans le ciel... il n'y avait qu'une présence » (SchwarzBart).

Plus insidieusement, Sellin rapporte les propos de Dembri à qui, selon ce dernier, Le Seuil aurait dit avoir commandé à Ouologuem un Dernier des Justes africain. 
L'essentiel de ceci, le Times Literary Supplement le résume en quelques lignes. Il n'en faut pas plus pour qu'en France, Le Figaro littéraire s'empare du scandale et, reprenant les informations du TLS, titre, huit jours plus tard, sous la plume de Guy Le Clec'h: "Ouologuem n'emprunte qu'aux riches ${ }^{102}$ ». La longue chute de Yambo Ouologuem, une chute aux enfers, commence là.

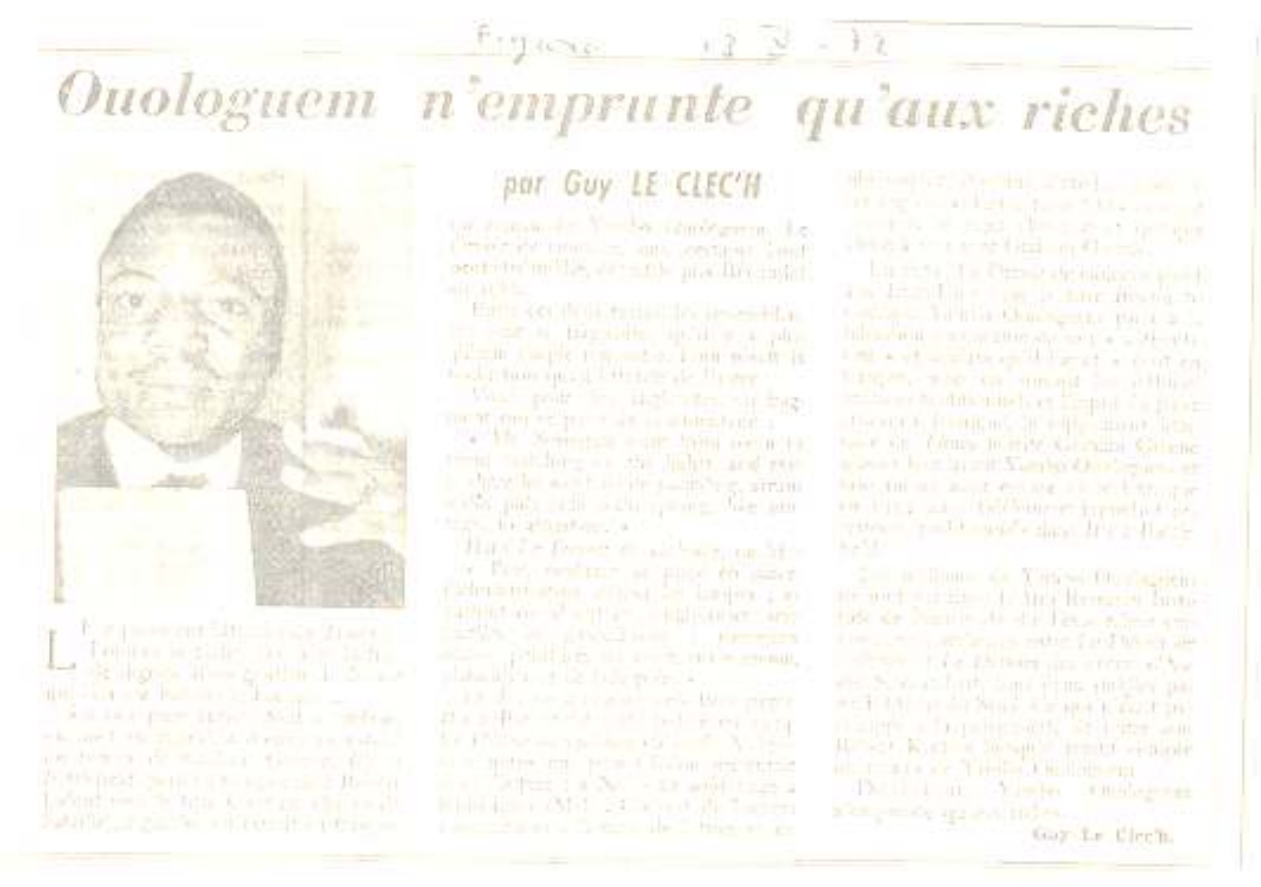

\section{Deux hommes au front : Paul Flamand et Yambo Ouologuem}

Face aux attaques, deux hommes font front: le directeur éditorial du Seuil et son auteur.

101 À l'article de Guy Le Clec'h dans Le Figaro Littéraire, Yambo Ouologuem réagit en demandant un droit de réponse. Il y parle pour la première fois de "techniques " littéraires, reconnaît une autre "référence " à Rudyard Kipling (1865-1936) et, pour la première fois aussi, de ce qui sera un de ses arguments principaux de sa défense, repris par la suite par les détracteurs du Seuil : des guillemets de citation auraient figuré dans son manuscrit, ce qui sous-entend que son éditeur les aurait enlevés. Son droit de réponse est publié dans l'édition du Figaro Littéraire du 10 juin 1972 :

[...] Ainsi, le passage de Mr Graham Greene incriminé de plagiat, mais en fait cité en guillemets (tout comme quelques lignes de Schwarz Bart) dans mon manuscrit déposé chez mon avocat, précédait une scène folle où un Blanc, déguisé sous les traits de l'administrateur Chevalier, faisait s'accoupler une Noire et un chien. Je suis Noir. Il est évident que si les faits évoqués par moi avaient été le fruit de mon imagination, mes frères de race ne m'auraient guère pardonné d'avoir sali les Noirs ${ }^{103}$. 
Récusant toute faute de sa part, il s'en prend à son éditeur qui, lui, « plaide coupable en [s]on nom sans même [l]'interroger et sans la moindre réclamation de Mr Graham Greene, $[. .$.$] retire [s]$ on livre de la vente dans le monde entier. »

Ouologuem ira plus loin : il assignera Le Figaro Littéraire en justice pour diffamation. Il sera cependant débouté.

Pour sa part, Le Figaro Littéraire ne ménagera pas l'auteur malien. Sous le droit de réponse de Ouologuem, il publiera deux courts textes. L'un, intitulé «Le devoir d'exactitude » est une lettre de l'agent littéraire de Graham Greene en France évoquant sa demande formulée auprès du Seuil d'interdire «toutes reproductions » du roman tant que l'auteur n'aurait pas réécrit les pages incriminées. L'autre, titré « Le devoir de vérité », est signé B.P., initiales où l'on devine Bernard Pivot, alors journaliste au Figaro Littéraire. En trois points, B.P. répond aux affirmations de Ouologuem, notamment sur la question des guillemets :

Yambo Ouologuem se défend en invoquant des guillemets qui figureraient dans son manuscrit. L'ennui, c'est qu'ils sont absents du livre auquel, faut-il rappeler cette évidence, les critiques et le public ont seulement accès.

Dans un quatrième point, il conclut :

Quand Yambo Ouologuem n'emprunte qu'à lui-même, sa pensée est confuse et sa prose emberlificotée. Il ne viendrait pas à l'idée de Graham Greene de le plagier. Ni à quiconque.

Flamand, de son côté, utilise plusieurs arguments selon ses interlocuteurs et selon ce qui est reproché au livre, à l'auteur et à l'éditeur.

À Helen Wolff, l'éditrice américaine, il parle de la jeunesse de l'auteur, des remaniements apportés au manuscrit et, comme auprès de Tom Rosenthal, l'éditeur britannique, il minimise les plagiats, réduits à des « lambeaux de phrase » :

Il me paraît indéniable que l'on ait retrouvé dans le Devoir de violence des passages où apparaissent des traces d'autres œuvres, mais il me paraît également exagéré de parler de "plagiats».

En effet, si l'on examine les passages incriminés, on peut constater qu'il ne s'agit pas de citations mais de lambeaux de phrases qui sont truffés de changements apportés par l'Auteur. Comment cela a-t-il pu se produire ? Nous sommes là devant le premier roman d'un jeune Auteur. Ce roman dont nous avons eu le manuscrit pour la première fois entre les mains (au début nous l'avions refusé) a été maintes et maintes fois remanié par l'Auteur. L'hypothèse la plus plausible est que celui-ci, ayant relevé dans ses notes des passages venus d'autres œuvres, les a retranscrites d'une version à l'autre de son roman sans une attention suffisante et en s'appropriant - et en modifiant - des textes qui au départ ne lui appartenaient pas. C'est une hypothèse, mais c'est celle qui me paraît la plus plausible car (nonobstant toutes les autres considérations personnelles) [... ] pourquoi mettrait-on en doute l'honnêteté littéraire de Ouologuem ${ }^{104}$ ?

À l'agent américain du Seuil, plus proche de lui, il ajoute un argument de cohérence :

Ouologuem argue que c'est nous (Bastide) qui, en mettant son manuscrit au net pour l'impression, lui avons dit de faire sauter les guillemets des citations, mais cet argument est absurde parce qu'on n'a jamais vu un romancier « citer » des scènes ou des situations entières d'un autre Auteur - et du reste s'il s'agissait vraiment de citations, pourquoi Ouologuem les aurait-il tronquées d'ajouts et de changements de sa part pour mieux faire croire à un texte original (ce qui constitue un aveu...) ? Je crois que mon hypothèse est plus valable si même, de vous à moi, je ne suis pas sûr qu'elle couvre toute la question ${ }^{105}$.

Continents manuscrits, HS | 2018 
J'aimerais que vous portiez à la connaissance de vos lecteurs

$1^{\circ}$ je n'ai jamais rencontré Monsieur Dembri et je ne sais pas de qui il s'agit.

$2^{\circ}$ Monsieur Ouologuem n'a pas écrit son roman le Devoir de violence à notre instigation, mais il nous a apporté le manuscrit comme le fait n'importe quel Auteur pour un premier roman à un premier Editeur.

110 Il y ajoute un troisième argument qu'il répétera à l'envi par la suite et qui sera cité dans tous les articles et études sur l'affaire des plagiats dans le roman de Yambo Ouologuem :

$3^{\circ}$ Quand nous avons constaté que dans le Devoir de Violence, on pouvait trouver des échos du Dernier des Justes, nous en avons avisé Monsieur Schwarz-Bart qui nous a répondu par une lettre dont j'ai à cœur de citer ces quelques lignes :

"L'utilisation faite du Dernier des Justes ne me gêne en aucune manière... J'ai toujours vu mes livres comme des pommiers, content qu'on mange de mes pommes, et content qu'on en prenne une, à l'occasion, pour la planter dans un autre sol. A plus forte raison suis-je profondément touché, bouleversé même, qu'un écrivain noir ait pu prendre appui sur le Dernier des Justes pour faire un livre tel que le Devoir de Violence. Ainsi donc Monsieur Ouologuem n'est pas mon débiteur, mais moi le sien ".

Cette lettre de Monsieur Schwarz-Bart est datée du 16 août $1968^{106}$.

À l'attention d'Eric Sellin qui est cité dans le TLS et a écrit la première charge sur les plagiats dans Le Devoir de violence, Flamand reprend les mêmes arguments. Mais, au cours d'une correspondance qui s'instaure entre eux et où Sellin pose des questions incisives ${ }^{107}$, Paul Flamand, peut-être touché au vif, va plus loin :

Monsieur,

Je vous prie de m'excuser si je vous écris à la main : je suis en vacances et n'ai pas de machine à écrire; je n'ai pas non plus tous les documents datés qui me permettraient de vous répondre encore plus précisément. Mais croyez qu'avec tous les désagréments qu'elle me cause cette affaire est bien dans ma tête et que ce que ce que je vais vous dire, je vous le donne comme sûr.

$1^{\circ} \mathrm{Je}$ sais la différence qu'il faut faire entre "publisher » et " editor ». Il se trouve que je suis le Président des Editions du Seuil et que c'est moi qui signe tous les contrats. J'ai donc connu le manuscrit Ouologuem dès son acceptation. Je puis vous affirmer de la façon la plus absolue que cette œuvre n'a pas été commandée par nous, qu'elle nous est arrivée dans la composition générale qu'elle a actuellement et que le travail sur manuscrit effectué avec l'auteur était essentiellement stylistique. $2^{\circ}$ Ce travail a été fait par l'auteur avec « l'editor » chargé de le suivre. Il s'appelle François-Régis Bastide. Bien entendu les similitudes d'architecture [du livre ?] avec Le dernier des Justes ne lui a pas échappé : mais pourquoi s'en serait-il offusqué? N'a-t-on jamais vu un jeune auteur imiter une œuvre précédente qu'il admire? De plus, Schwarz-Bart n'a-t-il pas toujours rapproché le cas des Juifs et celui des Noirs ? [...] Qu'un jeune écrivain noir s'y soit référé par émulation ou hantise [?] n'impliquait pas plagiat. Et cela semblait tellement évident que le «prière d'insérer » ne l'a pas caché un instant.

$3^{\circ}$ Ce dont F.R. Bastide (qui évidemment avait lu Schwarz-Bart mais de loin) ne s'était pas avisé, c'est qu'il y avait là des démarquages de passages entiers. Ce fait a été découvert, quand le volume est sorti des presses, par «l'editor» de SchwarzBart au Seuil, qui s'appelle Paul-André Lesort. Celui-ci l'a immédiatement signalé et en a écrit sur le champ à André Schwarz-Bart qui a fait la noble réponse que j'ai citée. [...]

Ce n'est qu'après cette publication que Ouologuem a publié chez Nalis (?) sa Lettre à la France nègre \& qu'il nous l'a envoyée... Mais comment aurions-nous pu nous douter, sur manuscrit, des «emprunts » faits par l'auteur, quasi textuellement, à d'autres œuvres ? M. Mannheim lui-même, ce traducteur excellent et érudit, a 
traduit l'œuvre en anglais sans s'en aviser...

Dans toute cette affaire, si désagréable (c'est le moins que je puis dire !) ce qui me paraît le plus insupportable, c'est le soupçon jeté sur notre maison (prise en bloc ou en partie) que nous ayons commandé une œuvre qui soit une réplique "nègre » de l'œuvre « juive » de Schwarz-Bart. Je vous donne ma parole qu'il n'en est rien. Et je viens de vous expliquer, de manière la plus simple et la plus franche, comment les choses se sont passées: Ouologuem n'a rien ajouté, sur notre incitation, à son manuscrit, pas plus la «Légende des Saïfs » que le reste. Et, en retour, j'attends de ce Monsieur... (Demi ? Je ne me souviens plus de son nom) qu'il déclare quel est le collaborateur des Editions du Seuil qui lui aurait tenu ce propos.

Monsieur, vous savez comme moi, combien les écrivains africains ont été et demeurent hantés par l'Europe, combien il leur est difficile de trouver leur complète identité. Des poètes noirs ont imité $\mathrm{S}^{\mathrm{t}} \mathrm{John}$ Perse, ou les surréalistes, ou François Coppée. Et ce que nous avons fait, au Seuil, depuis des décennies c'est de donner hospitalité à ces nouveaux talents qui, à travers ces imitations, tâchaient de trouver leur voix - leur voie originale. Cela n'allait pas sans risque, nous le voyons aujourd'hui ; ce n'est pas une raison pour regretter les services que nous avons pu rendre en des cas plus heureux.

Je vous prie de croire, Monsieur, à mes meilleurs sentiments.

Paul Flamand [signature manuscrite + en lettres capitales] ${ }^{108}$

La lettre manuscrite de Paul Flamand - qu'à son retour à Paris, il demandera à Eric Sellin de ne pas publier telle quelle - est une de celles au ton le plus sincère dans les dossiers. Eric Sellin y sera sensible, qui répondra en se rangeant aux arguments de Flamand :

J'assume la responsabilité de rédiger une rectification sur le rôle des Editions du Seuil et vous prie de ne pas en vouloir à M. Dembri qui est un critique brillant et sérieux et dont j'ai peut-être faussé les mots et qui n'avait aucune intention luimême de nuire la maison Seuil. [...] Un mot pour me permettre de publier vos deux lettres dans RAL [Research of African Literatures) et nous essaierons de faire un rappel à l'ordre et d'éliminer la spéculation désormais! [...] J'apprécie et votre ton raisonnable et votre franchise ${ }^{109}$.

\section{Schwarz-Bart, Maupassant et Mac Donald : le spectre des démarquages}

Entre Londres et Paris, par un détour au Texas, le centre du débat est passé de Graham Greene à André Schwarz-Bart. Mais, comme Paul Flamand le reconnaît lui-même, les « démarcages »- pour utiliser le même terme et la même orthographe que le directeur du Seuil - à l'égard du Dernier des Justes n'ont pas surgi soudainement du néant à la parution de l'article du TLS. Plus encore, Le Seuil est averti tôt des "emprunts» effectués par Yambo Ouologuem aux œuvres de la littérature mondiale.

Outre des invectives de lecteurs relatives au contenu osé du Devoir de violence ( À couronner des imbéciles, auteurs d'une littérature immonde [...] ÆEuvres de plus en plus infectes, d'un style de ramass[?] de poubelles, d'une moralité au dessous du niveau le plus bas $\left.{ }^{110} »\right)$, Le Seuil reçoit très tôt, dès l'attribution du prix Renaudot, des alertes quant aux "démarcages». Le 29 novembre 1968, un étudiant en Droit et Sciences Politiques, de 19 ans, écrit au Seuil ${ }^{111}$ pour signaler que "Oualoguem »- comme il l'écrit - a "plagié " la nouvelle "Le Port » de Guy de Maupassant. Et il liste trois emprunts. "Je suis fondé à parler de plagiat pur et simple, tant la similitude est 
frappante ". "Votre juvénile rigueur vous a entraîné un peu trop loin ", lui répond François-Régis Bastide :

À première vue, on ne peut qu'être frappé par ces ressemblances entre Maupassant et Ouologuem. Toutefois, si vous connaissiez notre auteur, vous sauriez qu'il est, comme un grand nombre de jeunes universitaires africains, doué d'une mémoire d'éléphant. Il peut réciter les poésies qu'il apprenait quand il avait dix ans, des passages entiers de Bergson, des passages entiers de Flaubert. L'enseignement français en Afrique a beaucoup utilisé la mémoire des Africains pour leur fourrer dans le crâne des cadences de phrases, du matériel verbal car on savait très bien que, rentrés chez eux, ils n'entendraient plus parler que leur dialecte. C'est pourquoi je n'ai pas été étonné du tout par ces similitudes, même frappantes. Il est probable tout simplement que Ouologuem a dû apprendre par cœur une «dictée » de Maupassant. Il ne l'oubliera jamais.

Ce qui est drôle c'est qu'il n'a pas pour Maupassant une prédilection particulière et que dans sa bibliothèque je n'ai trouvé aucun livre de cet écrivain.

Cela dit, je comprends parfaitement votre émoi. Vous êtes jeune, vous connaissez l'Afrique, vous avez le respect que l'on doit pour la chose imprimée. Tout cela est parfait.

Si j'en avais le temps, je pourrais citer un bon nombre d'exemples de pastiches involontaires dans la littérature française. Cela irait de Racine à Proust en passant par Stendhal. Je vous rappellerais aussi la phrase de Cocteau, son conseil donné à Radiguet: "Efforce-toi de faire des pastiches volontaires pour être sûr de n'en pas faire d'involontaires».

Votre juvénile rigueur vous a entraîné un peu loin. Même s'il y avait eu dans le livre de Ouologuem un bien plus grand nombre de réminiscences involontaires, cela n'aurait rien ôté à la valeur de son livre. Vous ne pouvez pas dire qu'une partie du Devoir de violence est une pâle imitation d'une nouvelle bien antérieure ${ }^{112}$. Yambo Ouologuem lui-même dans la réponse quasi identique qu'il fait, quelques mois plus tard, à un autre lecteur qui signale la reprise d'une douzaine de lignes d'une autre nouvelle de Maupassant, « Le Gueux » ${ }^{113}$ :

Vous n'êtes pas le premier à avoir remarqué, dans Le devoir de violence, cette douzaine de lignes qui appartiennent à Maupassant.

Quand j'en ai fait la remarque à Ouologuem, c'était sur le ton un peu courroucé que vous pouvez imaginer. Je ne le connaissais pas encore bien, et je ne connaissais pas $\mathrm{du}$ tout l'Afrique francophone. Entre temps, j'ai parfaitement compris son explication. Les Africains qui ont appris très jeunes le français [etc.]. Ouologuem n'a pas « copié ». [...] $]^{114}$

116 La réponse de Bastide et, à travers lui, de Ouologuem vaut ce qu'elle vaut pour ce qui est de Maupassant. Mais l'amplitude de la culture du jeune auteur malien - manifeste dans sa correspondance - et sa boulimie de lecture - tout aussi évidente - le mènent à picorer ailleurs que dans le fonds français classique. Ainsi, le 5 février 1970, Claude Gallimard (1914-1991) - qui n'a pas encore repris la présidence des Éditions Gallimard mais travaille encore sous la direction de son père, Gaston - envoie un mot teinté d'ironie à son confrère Paul Flamand, accompagné des passages litigieux :

Cher Ami,

Des lecteurs nous ont exprimé leur étonnement devant d'étranges similitudes de texte entre le roman de Yambo OUOLOGUEM : «LE DEVOIR DE VIOLENCE » paru à vos éditions en 1968, et la traduction française de John D. MacDonald, «LES ENERGUMENES », publiée en 1962 dans la "Série Noire » et réédité fin 1969 dans «La Poche Noire».

Vous pourrez voir, en comparant les phrases soulignées dans les quelques pages mises en regard, que je vous adresse sous ce pli, qu'il ne peut s'agir là de pure 
coïncidence ni de simple réminiscence, mais d'un recopiant pur et simple qui revêt le caractère d'une véritable contrefaçon.

Il est certes assez flatteur pour le style de la « Série Noire » d'avoir été jugé digne du Prix Renaudot. Et je ne doute pas un instant de votre bonne foi dans cette curieuse histoire. Mais je ne peux faire autrement, vis-à-vis de Marcel DUHAMEL et de son traducteur, que de vous demander de veiller à ce que M. OUOLOGUEM modifie son texte en cas de réimpression.

Je vous prie de croire, Cher Ami, à mes sentiments les meilleurs.

Claude Gallimard ${ }^{115}$

Lettre de Claude Gallimard à Paul Flamand, 5 février 1970

\section{Editions Gallimard}
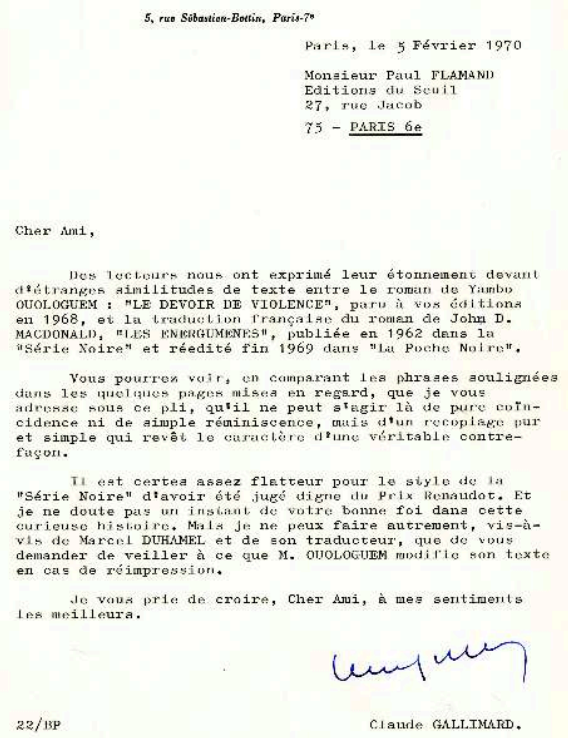

\section{IMEC, SEL 2923.9}

Tous droits réservés

117 L'appropriation - et sous réserve d'une analyse approfondie extérieure à celle-ci - la réappropriation (littéraire, historique, voire culturelle) principale, dans ce qui apparaît plus d'une fois comme un montage vertigineux de textes repris d'autres auteurs ou d'œuvres anonymes, telles la Bible ou le Coran, touche cependant Le Dernier des Justes d'André Schwarz-Bart (1928-2006). Elle concerne, on l'a vu, des phrases et des passages entiers du roman, mais aussi, en partie, la structure du livre et, plus encore, son enjeu : écrire, pour Ouologuem, le drame d'une société africaine en raison des errements et de la cruauté d'une partie d'entre elle, de la même manière que Schwarz-Bart avait déroulé le récit comme inéluctable de la tragédie juive sous l'effet de plus en plus destructeur de l'antisémitisme européen, tous deux dénonçant l'un la puissance niaise, l'autre la barbarie - comme à fronts renversés - de l'Occident.

À lire les coupures et les documents de l'époque, on est étonné que si peu, dans la presse - hormis Robert Kanters, comme incidemment, dans Le Figaro Littéraire - ou le jury du prix Renaudot, aient constaté, en tout cas signalé les similitudes entre les deux 
œuvres. L'étonnement est encore plus grand pour ce qui est des Éditions-mêmes qui avaient publié, avec un succès retentissant, le roman de Schwarz-Bart et s'apprêtaient à le faire pour son épigone, Yambo Ouologuem. Aucune note de lecture ne mentionne les échos. Jean Cayrol évoque Jarry, Queneau et Voltaire pour la tonalité, mais ne relève pas Schwarz-Bart. Repêché par Cayrol après le refus initial, le roman de Ouologuem est assumé par la suite par Paul Flamand en tant que publisher comme il l'écrit lui-même. Toutefois, dans sa lettre du 3 juillet 1972 à Eric Sellin, Flamand écrit que l'editor de Schwarz-Bart, Paul-André Lesort ${ }^{116}$, s'est avisé des démarquages à la sortie des presses du Devoir de violence ${ }^{117}$.

Quand l'editor du Devoir de violence se rend-il, lui, compte du jeu de miroir entre la fresque de Schwarz-Bart et celle de Ouologuem ? Tôt, va-t-il l'admettre. Mais il n'y voit pas une difficulté majeure et ne juge pas nécessaire d'en avertir, sinon vaguement, André Schwarz-Bart dont il est également l'éditeur pour un roman paru en $1967^{118}$. Le manuscrit entre en fabrication le 14 mars 1968. En juillet, le livre est imprimé. À sa sortie des presses, François-Régis Bastide envoie à Schwarz-Bart un exemplaire du Devoir de violence accompagné d'une lettre - que l'on ne possède plus - où il signale les deux emprunts aperçus par Paul-André Lesort.

André Schwarz-Bart reçoit le livre le 7 août, le lit et, de Lausanne où il habite alors, réagit le 16 dans une lettre dont on cite toujours - à commencer par Paul Flamand comme on l'a vu - un extrait de la première partie, mais jamais la deuxième partie, inédite :

Lausanne le 16.8.68

Mon cher Bastide,

Aux premières pages du livre, j'ai cru qu'il s'agissait d'une parodie du Dernier des Justes, je me suis trouvé violemment heurté, choqué même, par une cruauté si soutenue qu'elle m'a paru de système. Et c'était normal, car un tel cri n'avait pas encore jailli d'Afrique, à ma connaissance. C'est donc surtout en deuxième lecture que j'ai pu prendre la mesure de ce livre, qui est une chose considérable. Il ne s'agit pas seulement de beaux endroits, comme tu le dis. L'œuvre est toute entière traversée d'un même frisson. Il est vrai que ce frisson se relâche, parfois, lorsque la transe onirique fait place à l'observation courante. Ainsi, dans certains passages d'Europe, plus particulièrement. Mais tel quel, avec ses défauts de jeunesse, ce livre marquera, sans doute, une date dans la littérature africaine. Quant à la langue, lorsque l'auteur se sent chez lui, et rêve à son aise, cette langue devient royale. Je ne sais si l'Afrique de Ouologuem est l'Afrique, ce qui regarde les spécialistes ; mais, à coup sûr, nous nous trouvons devant une rêverie merveilleusement africaine sur l'Afrique : ce qui nous regarde tous, gens d'Afrique et d'ailleurs.

Quant à l'utilisation faite du Dernier des Justes, elle ne me gêne en aucune manière. Comme je l'ai dit à Monique Nathan, le jour de la réception du livre et de ta lettre, 7 août dernier, j'ai toujours vu mes livres comme des pommiers, content qu'on mange de mes pommes, et content qu'on en prenne une, à l'occasion, pour la planter dans un autre sol. À plus forte raison, suis-je profondément touché, bouleversé, même, qu'un écrivain noir ait pu prendre appui sur le Dernier des Justes pour faire un livre tel que Le devoir de violence. Ainsi donc, monsieur Ouologuem n'est pas mon débiteur, mais moi, le sien. Tout ce que je regrette, c'est qu'il n'ait pas jugé utile de m'adresser jamais le moindre mot.

Mais je ne connais pas Ouologuem, il n'est pas mon ami. Et tout serait parfait si son livre avait paru n'importe où, sauf au Seuil.

Ce qui me gêne, vois-tu, ce qui m'offense, c'est ton mutisme tout au long de l'élaboration de ce travail. Écrivain toi-même, tu sais que ton devoir était de m'avertir dès que tu eus connaissance de ce projet. D'autant, et tu le sais aussi, que ma femme et moi travaillons à un projet voisin depuis huit ans ${ }^{119}$. Il se trouve, mais 
tu l'ignorais, que le livre de Ouologuem ne gêne en rien le nôtre. Il se trouve également, mais tu l'ignorais aussi, que, Simone et moi, depuis toujours, avons pour conviction que jamais livre n'en a gêné un autre. Ceci posé, ton attitude se présente, sinon comme un abus de confiance, du moins comme un "cachotterie" incompréhensible, et que je trouve ridicule, et qui me blesse. Je ne puis voir dans ce silence, et dans cette mise devant le fait accompli, qu'un geste inamical à mon endroit ; et désinvolte, pour le moins, vis-à-vis de mon travail. Et maintenant, à qui pourrai-je accorder confiance et amitié, dans cette maison que je considérais mienne, le Seuil, alors qu'il ne s'est pas trouvé une seule personne parmi vous pour avoir la loyauté de me prévenir?

Votre comportement est d'autant plus étrange, que, prévenu, j'aurait pu éviter à l'auteur certaines reprises, trop apparentes, du Dernier des Justes. Ces reprises n'ont aucune importance en elles-mêmes, mais elles risquent d'accrocher certains critiques étroits, ou malintentionnés. Tout courageux et plein de talent qu'il soit, l'auteur est jeune, il est noir, il peut s'en soucier démesurément, s'en affliger peutêtre, comme je le fis, en d'autres temps, lors de la cabale montée contre le Dernier des Justes.

Je te le répète, je n'y comprends rien, à ce silence, à ce silence stupide, blessant, que vous avez maintenu jusqu'au bout, au risque de balayer toute confiance et toute amitié : ce qui est chose faite.

À toi,

André Schwarz-Bart ${ }^{120}$

121 À cette charge qui lui est personnellement adressée, François-Régis Bastide, piqué au vif, répond presque aussitôt. Il le fait dans une missive ${ }^{121}$ où on lit le récit des faits selon lui. Il y dit aussi qu'il a demandé à Ouologuem d'écrire à Schwarz-Bart, ce qui ne semble jamais avoir été fait :

Paris, le 22 août 1968

Mon cher Schwarz-Bart,

Ta lettre m'a plongé dans la stupéfaction la plus totale. Monique Nathan m'avait dit que tu lui avais téléphoné et que le ton de l'entretien avait été, somme toute, fort sympathique à Ouologuem, et, en aucune manière, aussi violent contre ton éditeur.

J'ai fait travailler, seul, Ouologuem. J'ai tout de suite vu, comme je crois te l'avoir écrit, une certaine parenté, avouée, avec la structure et avec quelques-unes des intonations du Dernier des Justes. Sans qu'on puisse comparer vraiment les deux livres, le tien m'apparaissant, naturellement, très supérieur. Cette parenté ne m'a pas gêné du tout, car à aucun moment je ne l'ai trouvée littérale. Je me souviens même en avoir fait compliment à Ouologuem. Quand il m'a apporté son manuscrit revu sur mes indications, j'avoue que je n'ai pas songé à voir s'il y avait des passages précisément empruntés à ton livre. Paul-André Lesort l'a lu, imprimé : il a remarqué les deux détails de structure, dans deux phrases, ou dans deux paragraphes, que je t'ai signalés dans ma première lettre. Comme moi, il n'a pas pensé une seconde qu'il y avait là quoi que ce fût qui puisse te fâcher.

Néanmoins, j'ai demandé à Ouologuem de t'envoyer son livre et de t'écrire une lettre particulière dans laquelle il te dirait ce qu'il m'a toujours dit, à savoir l'admiration, et même plus, qu'il éprouve pour ton livre. Je vois qu'il ne l'a pas fait, et je me propose de lui en faire la remarque. Il est vrai qu'il a bien des soucis, de tous ordres, actuellement. Là-dessus, tu m'envoies une bordée d'épithètes bien sonnantes. Me voici donc cachotier, inamical, désinvolte, blessant.

Je te demande de te mettre à ma place, pour quelques minutes. Qu'aurais-tu fait ? Il est vrai, et c'est ma seule faute précise, que je n'ai pas remarqué les deux structures précises de ces deux phrases que je t'ai signalées. Je n'ai pas relu Le Dernier des Justes depuis sa parution, et je le regrette. Néanmoins, penses-tu que j'aurais dû t'envoyer le manuscrit de Ouologuem, en te disant : "Voilà, nous avons un jeune citoyen du Mali qui vient d'écrire cela, que nous trouvons beau, que nous allons publier. C'est indirectement de la famille du Dernier des Justes. Qu'en penses-tu ?» 
Que pouvais-je faire d'autre? Ne m'aurais-tu pas répondu ce que tu me réponds aujourd'hui, à savoir que tu ne juges pas Ouologuem ton débiteur ? Très franchement, j'ai beau tourner et retourner ta lettre en tous sens, je n'arrive pas à me trouver chargé du péché d'avoir balayé ta confiance et ton amitié.

Mon rêve serait, bien sûr, que tu sois sur les rives de la Seine, comme Ouologuem et comme moi. Mon rêve serait de nous réunir tous les trois, et de nous dire dans la confiance et dans l'amitié ce que nous avons à nous dire.

Pour l'instant je demeure, mon cher Schwarz-Bart, si tu veux bien, ton confiant et amical.

François-Régis Bastide

À n'en pas douter, un des nœuds du processus éditorial à l'intérieur du Seuil, se trouve là. Dans l'attitude de François-Régis Bastide où il est impossible de distinguer entre la faible prise de conscience des risques de plagiats, l'assomption de ces risques dans une tradition littéraire où les plagiats reconnus et même revendiqués sont loin d'être rares (de Racine, comme Bastide le dit ailleurs, à Lautréamont qui les défend ${ }^{122}$ ) et la légèreté à l'égard du principal auteur copié.

Le mal, en tout cas, est fait du côté d'André Schwarz-Bart qui, blessé par les réactions de la communauté juive à la parution du Dernier des Justes, se sent trahi ${ }^{123}$ par son éditeur - et dépossédé par un autre auteur - au moment où il essaie de contourner la thématique juive par le biais d'une tragédie symétrique à ses yeux, celle de l'esclavage des peuples noirs.

La collaboration d'André Schwarz-Bart, tout comme de son épouse Simone, avec Le Seuil se poursuivra cependant, même au-delà de la mort d'André, avec la parution des œuvres posthumes.

Mieux, malgré sa blessure, André Schwarz-Bart confirmera qu'il ne souhaite porter aucun tort à Yambo Ouologuem lors d'un épisode avec la presse suisse, dont on se dit que s'il avait abouti, l'histoire du Devoir de violence aurait été différente: l' "affaire Ouologuem » n'aurait sans doute pas attendu 1972 pour éclater, ni la Grande-Bretagne et les États-Unis où le roman n'aurait peut-être pas été traduit.

Le 6 décembre 1968, dans une lettre ${ }^{124}$ à François-Régis Bastide, Franck Jotterand, rédacteur en chef de La Gazette Littéraire, supplément de La Gazette de Lausanne, relaie les réactions de lecteurs et d'un des rédacteurs de la Gazette ayant remarqué une « inspiration" du Devoir de violence dans Le Dernier des Justes d'André Schwarz-Bart. Il mentionne aussi le cycle que ce dernier a entrepris avec Un plat de porc aux bananes vertes: une "grande et mystérieuse geste des Noirs». Et il pose trois questions à Bastide :

Pourquoi avez-vous publié ce livre?

Comment expliquez-vous ses ressemblances avec le Dernier des Justes?

Pensez-vous que la littérature actuelle pourrait devenir en quelque sorte collective ou anonyme comme au Moyen Âge en reprenant des formes ou des thèmes connus pour les adapter à des situations diverses ? ${ }^{125}$

127 Mais treize jours plus tard, Franck Jotterand écrit une nouvelle lettre où il se rétracte, à la demande même d'André Schwarz-Bart :

Cher Monsieur,

A la suite de la lettre que je lui avais adressée aux Editions du Seuil, M. André Schwarz-Bart m'a demandé de ne pas publier l'enquête que j'avais entreprise au sujet des ressemblances entre «Le devoir de violence » et « Le dernier des justes ». J'estime trop cet auteur et ses livres pour ne pas tenir compte de ses désirs. Il craint en effet qu'un débat ne suscite des réactions anti-africaines et ne nuise à la carrière 
d'un écrivain qu'il estime beaucoup. Pour la première fois, m'écrit-il, on voit naître une littérature africaine francophone, débarrassée des complexes blancs. Il ne faut rien faire pour la décourager. Ces raisons me paraissent pertinentes. [...] ${ }^{126}$

\section{«Clins d'œil, références, guillemets, narrations, analyses »} une moindre mesure sur ce plan, François-Régis Bastide - présentent un front commun forcé, qu'en est-il entre eux ? Quels arguments s'opposent-ils les uns les autres dans la question cruciale des plagiats, qui puissent éclairer un tant soit peu comment (et pourquoi) un écrivain a écrit un texte truffé de références et d'emprunts, et comment ce texte a poursuivi son parcours éditorial jusqu'à la publication sans que ne soit mise au jour ou sur le tapis l'ampleur de ce que Ouologuem va bientôt appeler un « système »? Et sans que - lorsque cela a été noté par l'editor -, ne soit mise en question la légitimité littéraire et morale (au sens autant juridique qu'éthique) des reprises et de leur aménagement dans Le Devoir de violence.

disparus ${ }^{127}$, en tout cas absents, nous ne pouvons nous en tenir qu'à la correspondance disponible.

Pour sa part, dès l'été 1968, François-Régis Bastide affiche, comme on l'a vu, sa position dans sa lettre à André Schwarz-Bart : «Cette parenté [entre le roman de Ouologuem et Le Dernier des Justes] ne m'a pas gêné du tout, car à aucun moment je ne l'ai trouvée littérale. ${ }^{128}$ » Et il parle de « deux phrases [...] dans deux paragraphes » dont il n'a " pas pensé une seconde qu'il y avait là quoi que ce fût qui puisse fâcher [André Schwarz-Bart] ${ }^{129}$ ».

131 À Schwarz-Bart, F.-R. Bastide ne parle que de Schwarz-Bart. En revanche, la question de plagiat éventuel dépasse les emprunts à l'œuvre de ce dernier et déborde le cercle des lecteurs anonymes ayant aperçu des similitudes entre Maupassant et Ouologuem, lorsque Claude Gallimard signale au Seuil le démarquage relatif à un titre de la "Série noire ».

Averti par Paul Flamand en mars 1970, Yambo Ouologuem répond - dans une lettre ${ }^{130}$ dont il envoie copie à Claude Gallimard ${ }^{131}$ - en décrivant pour la première fois par écrit et par le menu l' "architecture " de son roman, faite de "clins d'œil, références, guillemets, narrations, analyses » en mesure de construire une « légende » (à savoir, on le devine, un texte qui se détache de son auteur pour être offert à l'appropriation collective) et d'offrir au lecteur « une infinité de possibilités de lecture ${ }^{132}$ »:

Monsieur le Directeur,

Cher monsieur,

Suite à la lettre de Monsieur Claude Gallimard que vous avez eu l'obligeance de me faire parvenir, j'ai l'honneur de le devoir d'apporter les précisions suivantes:

La prétention majeure de Monsieur Claude Gallimard concernant l'usage de lignes dont la propriété littéraire revient à John Mac Donald (LES ENERGUMENES, Gallimard, 1962) je vois difficilement en quoi elle s'octroierait, d'emblée, et sans explications de ma part, le droit moral de crier à une contre-façon qui n'en n'est pas une.

Encore que mon propos présent ne soit pas ne soit pas de présenter LE DEVOIR DE VIOLENCE, permettez-moi, toutefois, d'affirmer que l'examen de le dépouillement 
de mes archives, rendent impossible qu'on parle de contrefaçon.

En effet, John Mac Donald est cité, comme Ki Zerbo, comme Leo Frobénius (sous le nom de Schrobénius) comme Okba ben Nafi el Fitri, comme le Tarik, divers griots, chroniqueurs noirs, s'exprimant en langues vernaculaires regroupant les principaux groupes linguistiques africaines (cf les italiques du roman) comme divers historiens arabes, portugais, espagnols, coptes, éthiopiens, ou, plus généralement, dans une perspective d'universalité du conflit violence et non violence, la Bible et le Coran, la correspondance de missionnaires blancs, Tacite, Suétone, Schwarz Bart (puisque l'Éthiopie, par Haïlé Sélassié juif de par la reine de Saba, ouvre la dimension de la conscience malheureuse antérieure à la négritude, et, dès lors, affranchie de la dialectique usée Noirs-Blancs), et enfin, deux maîtres du réalisme désabusé : Flaubert et Maupassant. Mon propos, ce faisant, était davantage l'histoire légendaire, puisque c'est par la seule légende qu'il est possible de créer un discours à l'intérieur de mythe vaste des civilisations en devenir. L'architecture initiale de mon roman était autre, en clins d'œil, références, guillemets, narrations, analyses.

Mais tout n'est pas d'expliquer ce que j'ai fait ou voulu faire : c'est pourquoi j'ai cherché à fournir des documents, à l'appui de mes dires. Aussi, permettez-moi, à cet effet, de joindre, outre trois feuillets de références historiques (lesquelles sont destinées à bien montrer que dans mon travail, j'ai toujours scrupuleusement noté à qui je devais mes sources) la photocopie d'un texte mien, publié dans la LETTRE A LA FRANCE NEGRE.

Les pages photocopiées relèvent d'un projet mené (tout comme la rédaction d'une série de manuels scolaires destinés à l'Afrique) de front avec la rédaction définitive du DEVOIR DE VIOLENCE. Comme vous pouvez le constater à la page 167 dudit document, le nom de John Mac Donald figure comme il figure sur le manuscrit original du DEVOIR DE VIOLENCE, première version refusée par le Seuil. Or, je conçois qu'on puisse mettre en doute cette affirmation, et avancer que j'aurais pu rajouter après coup ce nom à mon manuscrit original. C'est pourquoi je me réfère, pour attester ma bonne foi, à ce passage publié dans LA LETTRE A LA FRANCE NEGRE, passage qui n'est qu'un remaniement très condensé d'un projet soumis au Seuil presque en même temps que mon roman. Ce projet devait constituer une espèce d'anthologie du crime sous l'angle d'une infinité de possibilités de lectures. Un rapide coup d'œil sur l'ensemble du document vous remémorera ce projet, rejeté d'ailleurs par le Seuil après diverses discussions et entrevues; ce projet contenait des extraits dactylographiés de John Mac Donald, avec références dans le style de la page $175 \mathrm{du}$ document.

Par ailleurs, divers déboires dans ma vie privée [...] ont fait que j'ai retrouvé un matin, à mon réveil d'un travail de nuit de plusieurs heures, tous mes écrits (manuels, roman, projet d'anthologie du crime, thèse, devoirs de Normale Supérieure, etc...) entassés pêle-mêle dans une seule chemise de classeur, et jetés à la cave de l'appartement, quand ils ne jalonnaient pas les couloirs sombres ou qu'ils n'avaient pas été détruit par le vide ordures ...

Dès lors, l'ensemble de ce travail étant initialement dactylographié, classé répertorié, ou au besoin imprimé (comme c'est le cas de certains documents historiques qu'il était plus simple de faire imprimer en Afrique, la dactylo noire ignorant les heures supplémentaires) mais non pas toujours définitivement paginé, il est résulté de leur éparpillement un grand désordre, lequel, fatalement, a été préjudiciable à la possibilité de faire par la suite et selon mes habitudes universitaires des références exactes à l'ensemble de mon travail. C'est ainsi qu'ayant déménagé [...], mais n'ayant pas d'abord retrouvé, dans ma hâte et mon besoin d'avoir la paix, le texte manuscrit de mon roman, de mes manuels, de mes projets en cours, et qu'après une lettre de Monsieur François Régis Bastide (lequel me demandait d'ordonner davantage sans le châtrer le DEVOIR DE VIOLENCE, en supprimant les guillemets, les Italiques - Alain Bosquet, m'expliqua-t-il, avec son TIGRE EN PAPIER ${ }^{133}$, annoncé pour la même date de sortie faisant usage de la même 
technique, les innombrables références historiques, vernaculaires, moyenâgeuses jurant avec d'autres passages de sobriété plus racinienne) il a été impossible de voir clair dans tout le fatras de quelques trois mille pages ( 6 manuels scolaires, avec livres du maître, et plus d'un millier de pages de documents relatifs au DEVOIR DE VIOLENCE.)

La pudeur de faire mention publique de ma vie privée, d'ailleurs sans intérêt public, voilà qui, sans doute, devait contribuer à créer des malentendus. Ceux-ci, je tiens à le répéter, preuve à l'appui, ne relèvent nullement de malheureux concours de circonstances.

Le malheur nous rend simples et humbles, mais non salauds ; c'est pourquoi [si ?] écrire dans le malheur (écrit-on jamais heureux ?) c'est toujours désespérer de la pureté, au terme d'une densité d'être, mon honnêteté importune m'a poussé à les évoquer, ces circonstances, lors de mon déjeuner après l'attribution du prix, avec les membres du jury Renaudot.

Aussi devais-je dès lors choisir le silence, sachant que le temps parlerait et m'autoriserait enfin à mieux faire comprendre l'acte manqué d'un déjeuner dont le Seuil m'avait honoré.

Bien à vous,

[signature manuscrite: Y. Ouologuem]

Lettre de Yambo Ouologuem à Paul Flamand, 15 mars 1970

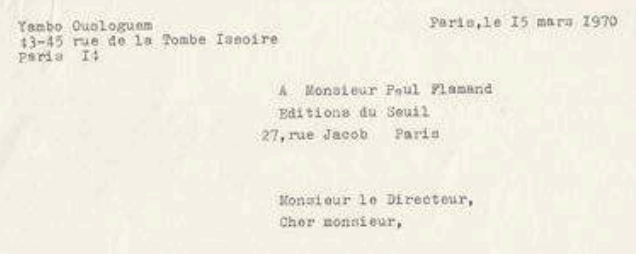

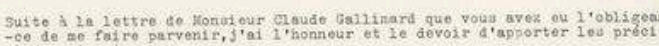

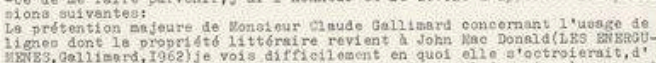

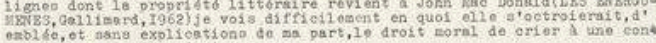

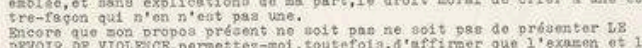

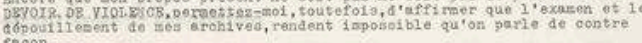

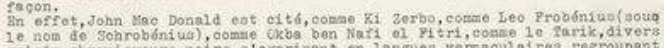

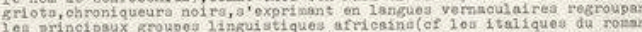

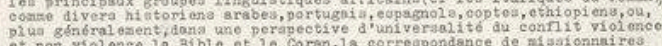

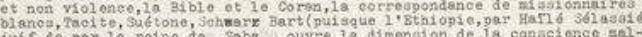

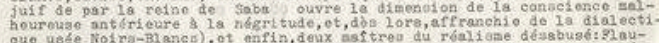

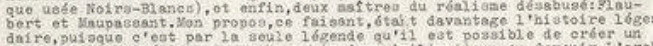

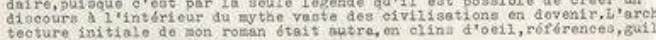

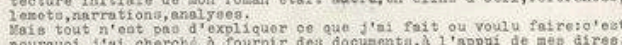

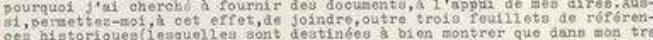

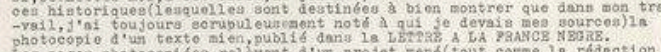

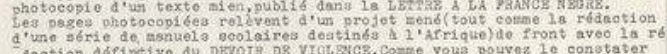

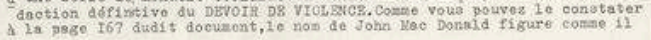




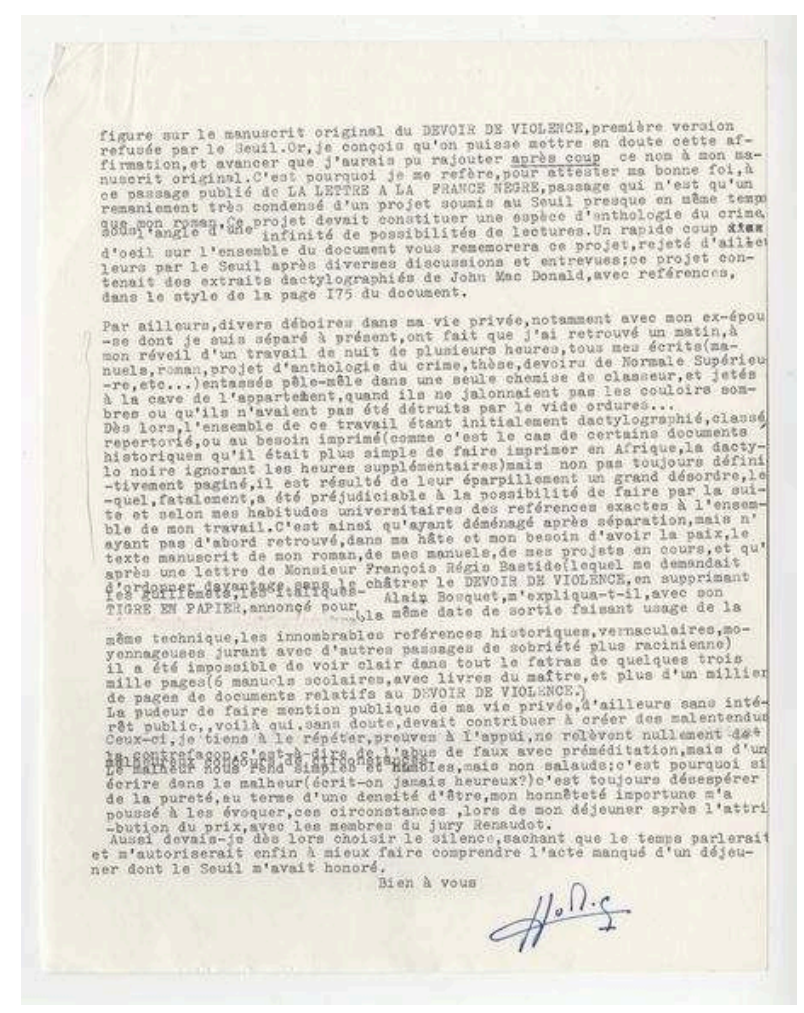

IMEC, SEL 2923.9

Tous droits réservés

Les trois feuillets historiques dont Ouologuem parle dans cette lettre concernent, suivant des chroniques portugaises des $\mathrm{XVI}^{\mathrm{e}}$ et $\mathrm{XVII}^{\mathrm{e}}$ siècles, les conversions massives réalisées au royaume du Kongo. Sous réserve d'analyse plus développée, ces sources historiques ont été utilisées pour la mise en scène de la visite au Nakem de l'évêque Thomas de Saignac et des baptêmes de foule dans la troisième partie du Devoir de violence, «La Nuit des géants ». Elles peuvent aussi avoir irrigué les luttes de succession dans la dynastie des Saifs. Dans les deux cas, le lien n'est pas direct, la source étant seulement inspiratrice et ne nécessitait pas de référence explicite.

Quant à la référence à Lettre à la France nègre, elle concerne, au sein de ce dernier ouvrage et plus précisément dans le chapitre « Lettre aux pisse-copie nègres d'écrivains célèbres ", la mention de John Mac Donald ${ }^{134}$ au rang des auteurs sur lesquels un "pisse-copie» doit, selon Ouologuem, se fonder pour devenir "nègre d'écrivains célèbres ${ }^{135}$ » ou "plumassier de la paperasse ${ }^{136}$ ». Sur la page, l'auteur a entouré au crayon rouge le nom de l'écrivain américain, indiquant par là ses sources, sans que cela démontre, pour autant, on doit le noter, que la référence ait été explicite dans le manuscrit du Devoir de violence. 
Page numérisée de Lettre à la France nègre où Y. Ouologuem a entouré au crayon rouge le nom de John MacDonald

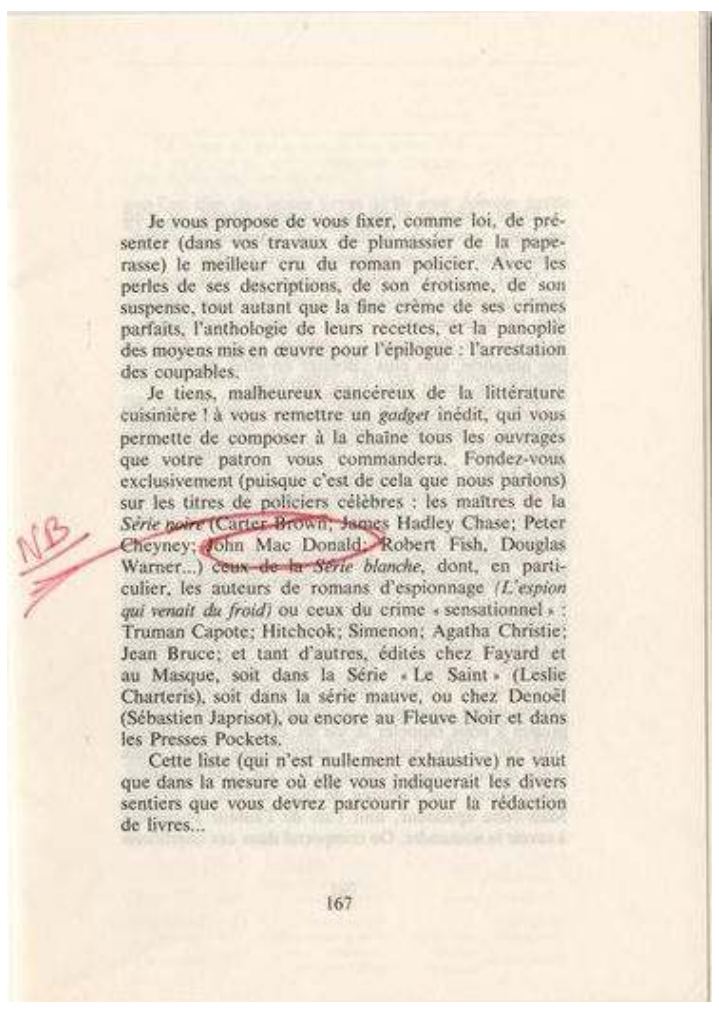

IMEC, SEL 2923.9

Tous droits réservés

On ne possède pas la réponse éventuelle de Paul Flamand à cette lettre de Ouologuem. Mais on en détient une autre, datant de 1972, au moment du déclenchement de l'affaire :

Votre singulière attitude me laisserait croire que vous avez sciemment provoqué des difficultés avec des éditeurs étrangers afin que ces derniers n'apportent point la collaboration nécessaire à la marche de l'expertise ${ }^{137}$ en cours, ou puissent exciper de pertes artificiellement créées, dont vous seriez d'ailleurs seuls responsables ${ }^{138}$.

Le même jour, 18 juillet 1972, l'Agence France Presse (AFP) publie un communiqué qui déclare que

Yambo Ouologuem accuse son éditeur Le Seuil d'avoir déclenché une campagne de presse afin de le salir pour ne pas payer les droits qui lui étaient dus. Yambo Ouologuem a affirmé que l'éditeur avait «de toute évidence " supprimé des guillemets en éditant son livre ${ }^{139}$.

Désormais, c'est sur les comptes que Ouologuem s'en prend au Seuil. Par ailleurs, depuis le début de l'année, il cherche à se libérer de son contrat pour poursuivre ses contacts avec les autres éditeurs, tel Fayard : «En conséquence [des agissements du Seuil et des refus opposés à plusieurs de ses manuscrits] l'application du contrat du 11 octobre 1967 ne peut être invoqué par vous et [...] nous avons tous deux repris notre liberté. ${ }^{140} »$

Plus largement, Ouologuem commence à prendre ses distances avec la France. Physiquement. Géographiquement. Il séjourne de plus en plus souvent au Mali. La dépêche de l'AFP commence par les mots «Yambo Ouologuem séjourne actuellement 
au Mali où il s'est rendu au chevet de son père malade." Le 10 novembre 1972, l'écrivain écrit aux Éditions du Seuil - il dépersonnalise et institutionnalise de plus en plus ses échanges - via le consul du Mali à Paris : «À toutes fins utiles, vous voudrez bien désormais m'écrire à l'adresse de l'Ambassade de la République du Mali, dont je suis le citoyen. ${ }^{141}$ "

Peu à peu, Ouologuem devient introuvable. En tout cas pour les Français. «[Yambo Ouologuem] a complètement disparu de la circulation. Son propre avocat le recherche sans savoir où il se trouve ${ }^{142} "$, note Paul Flamand dans une lettre à l'éditeur américain du Devoir de violence. Les autorités maliennes, de leur côté, refusent de servir d'intermédiaires: "Le Consul refuse de recevoir sa correspondance et nous l'a retournée ", ajoute Flamand dans la même lettre. Les accusations de complot et d'empoisonnement qu'aurait subis Ouologuem naîtront plus tard dans son entourage et dans les milieux maliens, à partir des circonstances imprécises de son départ de France ${ }^{143}$. Arrestation à la suite d'un esclandre sur la voie publique, internement, renvoi de France : entre les témoignages et l'établissement strict des faits, il est difficile de faire la part tant que ne seront pas rendus publics les documents probants.

En novembre 1973, Yambo Ouologuem semble en tout cas faire signe de vie et réapparaître en France. Dans une note à Paul Flamand, François-Régis Bastide rend compte d'un «long coup de fil » qu'il a eu avec une fonctionnaire du ministère des Affaires culturelles : «Ouologuem, dit-elle, voulait absolument voir le Ministre. Il est resté très longtemps dans la salle d'attente, puis au cabinet. Sa thèse est que nous l'avons escroqué. Il demande justice à la République ${ }^{144}$.»

Dans les dossiers du Seuil à l'IMEC, ce sera, pour un temps, la dernière trace d'échanges avec Ouologuem. Le 31 janvier 1975, cependant, Yambo Ouologuem réactive ses contacts avec le monde éditorial français. Depuis Sévaré, au Mali, il écrit à Paul Flamand :

Référence : Affaire

Les Pèlerins de Capharnaüm

Monsieur le Directeur,

J'ai l'honneur de vous prier de bien vouloir trouver ci-joint copie de la lettre que j'adresse ce jour à la Librairie Fayard, en vue d'une rencontre à trois entre Monsieur Alex Grall, vous-même et moi, afin de mettre un heureux terme à la situation que vous savez, et qui n'eut pu être autrement résolue plus tôt pour les raisons que vous trouverez dans ma lettre à la librairie Fayard.

Que Dieu vous garde, Yambo Ouologuem ${ }^{145}$

Ouologuem cherche à dénouer le conflit né trois ans plus tôt quand il a présenté aux Éditions Fayard le manuscrit des Pèlerins de Capharnaüm, alors qu'il était sous contrat avec Le Seuil pour les romans.

La lettre à Alex Grall - directeur de Fayard - mise en copie de la missive à Flamand donne pour «adresse personnelle: Yambo Ouologuem s/c Monsieur Boucari Ouologuem - inspecteur d'Enseignement - Sévaré (Mopti) République du Mali » et annonce la venue prochaine de l'écrivain :

Par la présente, j'ai l'honneur de vous confirmer à vous même comme au Seuil que je serai en personne à Paris dans trois mois au plus tard afin de mettre, pour l'honneur de l'édition française comme pour l'honneur de la France et le mien propre, un heureux terme à la situation que vous savez - et qui, indubitablement, réjouira autant la réputation des Editions du Seuil que celle de la Librairie Fayard. 
Le voyage sera retardé de près d'un an. Le 4 mars 1976, un carton manuscrit ${ }^{146}$ signé Yambo Ouologuem lors d'un passage à l'improviste (selon toutes les apparences) aux Éditions du Seuil, fait savoir qu'il est à Paris et qu'il repassera la même journée « afin de venir aux nouvelles et trouver un heureux terme à ladite situation - pour l'agrément de Dieu $^{147}$ et de tous ». "Je vous demande ce que vous comptez faire pour me permettre de reprendre mes activités, grâce à vous, dans le domaine des œuvres d'imagination ", écrit-il le 20 mars $^{148}$.

Mot de Yambo Ouologuem de passage au Seuil le 4 mars 1976, une des dernières traces d'échange entre l'auteur et l'éditeur

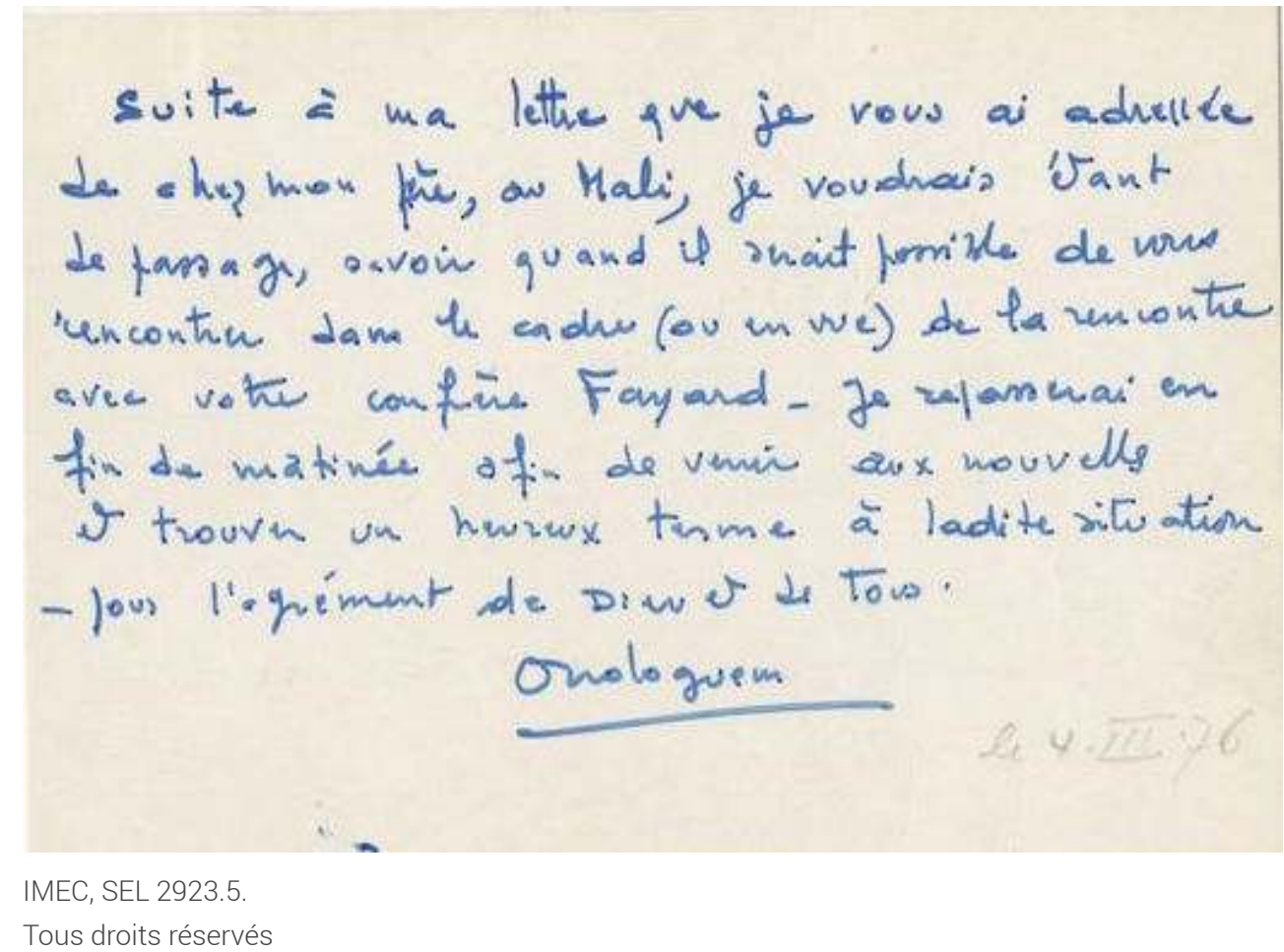

Une réunion avec Fayard se prépare et les termes d'un accord éventuel se discutent à l'intérieur des Éditions du Seuil, ainsi qu'avec leur Conseil, $\mathrm{M}^{\mathrm{e}}$ Georges Kiejman. Le Seuil prend contact avec Fayard. Une réunion tripartite (Seuil, Fayard, Ouologuem) a lieu le 29 avril 1976 à 16 heures $^{149}$. Le 3 mai, Paul Flamand écrit à Kiejman :

Comme transaction, j'ai proposé, pour enterrer la hache de guerre que, d'une part, Ouologuem retire la plainte qu'il a déposée contre nous et qui suit son cours, et d'autre part, que le Seuil renonce à son droit de suite. Il a semblé, à la suite d'une discussion extravagante que Ouologuem était d'accord et qu'il préviendrait ses Avocats qui se mettraient en contact avec vous pour les termes d'un tel protocole. Mais le fera-t-il ${ }^{150}$ ?

Le 13 mai, Georges Kiejman écrit à Paul Flamand :

Aff. LE SEUIL C/ OUOLOGUEM

Cher ami,

Je prends note des derniers développements de l'affaire Ouologuem mais comme vous, je ne puis qu'attendre ${ }^{151}$.

Les dossiers du Seuil ne possèdent pas de trace de contact avec Ouologuem au-delà de ce mot. Le Devoir de violence continuera à être imprimé et vendu, « selon un rythme tout à fait honorable ${ }^{152}$ ». En mars 1970, une note de Paul Flamand à la fabrication a pourtant 
fait savoir, suite à la plainte des Éditions Gallimard (« et d'autres [faits] du même ordre »), "qu'en cas de réédition le texte devra être complètement revu ${ }^{153}$ ». Le 26 octobre 1982, cette note resurgit soudain à la fabrication :

$\mathrm{Au}$ moment de réimprimer ce titre, je trouve dans le dossier la note ci-jointe

(plagiat Série noire) signée Paul Flamand. Que doit-on faire ? ${ }^{154}$

Le roman ne sera pas réimprimé. Le 28 novembre 1982, Le Seuil ferme le dossier de fabrication ${ }^{155}$. Il le rouvre trente-six ans plus tard pour la réédition du Devoir de violence dans sa collection d'origine, «Cadre Rouge $»^{156}$. Entre-temps, Yambo Ouologuem est mort le 14 octobre 2017.

\section{ANNEXES}

\section{ANNEXE 1}

Lettre du 18 mai 1968 de Yambo Ouologuem à Paul Flamand (IMEC, SEL 3772.2)

Monsieur le directeur, Mon bon monsieur, C'est l'impossibilité de pleurer qui entretient en nous le goût de l'authenticité, et la fait exister encore.

La courbe interminable de l'œuvre que j'aurais voulu écrire pour votre maison d'édition, est celle là même qui me fait conserver cette fierté verticale qui raffermit mon courage - cette horreur des gestes qui me préserve des démonstrations. Mais je m'égare, il faut reprendre les choses à leur point de départ.

Je vous prie de bien vouloir m'excuser pour jeudi ; la commission ne m'a été faite qu'aujourd'hui : ce dont je suis extrêmement désolé.

J'avais souhaité vous rencontrer pour les raisons suivantes.

Tout d'abord, en ce qui concerne le roman « Le devoir de violence » que vous avez bien voulu accepter de publier, à la suite d'ennuis de nez cassé et d'yeux touchés par voie de conséquence (les gaz lacrymogènes de la répression n'ont rien arrangé, bien au contraire) j'avais cru ne pouvoir remplir mes engagements et revoir les épreuves du roman. Il semble que c'était une fausse alerte, qui nécessitera une double intervention chirurgicale, mais ne compromettra pas définitivement ma vue. J'avais pressenti $\mathrm{Mr}$ Bastide pour mener à bien une tâche que je ne croyais guère pouvoir achever. Ce côté ne soulève donc plus de difficulté.

Mais il y a autre chose, de plus important, dont je voulais vous entretenir lors de notre première entrevue. Je n'ai pu le faire, alors que c'est la raison précise pour laquelle j'avais sollicité un rendez-vous. Voici donc.

Il s'agit de notre contrat, auquel j'aurais souhaité des clauses particulières. Tout d'abord, je veux dire qu'il ne s'agit pas pour moi d'écrire « des » romans : il me faut un système, à l'échelle de la vision que j'estime être celle des Noirs en général. N'anticipons pas et ne parlons pas de « négritude ». 
Ecrire en effet des « romans » serait à mes yeux faire œuvre de rhapsode plutôt que d'assembleur. Ce n'est pas que je refuse la forme romanesque comme telle ; mais c'est plutôt qu'en ce qui me concerne, je la conteste comme inadéquate dans l'optique d'une œuvre totale, qui n'est pas de me proposer en narrateur d'anecdotes, dont l'ensemble, romancé, constituerait à créer un muséum de "l'espèce négritudo-épique ».

La couleur historique, je ne la conçois que comme un moyen de surprendre l'attention du lecteur, en lui donnant une preuve en plus de la vérité d'un conte. Il y a en effet, il faut en convenir, une sorte de prestige attaché à cette résurrection de l'épopée, avec ses grands noms, ses mœurs, ses lois, ses évènements ; et l'on a peine à ne pas croire à l'existence réelle des personnages fictifs, lorsqu'on les voit se mouvoir dans la sphère de ces figures historiques que l'on sait par cœur. Mais là s'arrête ce que l'histoire doit prêter au roman ; cela se réduit à un canevas, à un fond de tableau sur lequel il reste à dessiner et à colorer l'histoire individuelle la plus propre à inspirer l'émotion, avec cependant ceci : le génie des détails vrais, puisqu'il semble qu'on ne relise une œuvre que pour ses détails.

Ici, permettez une parenthèse. J'ignorais les rapports personnels (tout autant que les accidents pénibles que avez connus au décès de votre fils) de vous et de Senghor.

Autrement, soyez assuré que si je le savais, je n'aurais pas porté mon manuscrit au Seuil. Il est en effet des valeurs qu'il faut respecter - et, quelque blasés que nous puissions être, nous avons chacun une zone d'ombre qui nous vaut d'y venir puiser des forces vives, en dépit de la dérision totale de l'ordre du monde.

Si donc j'ai incidemment parlé de certains aspects de sa vie, ce n'est guère pour cultiver l'inédit diffamatoire. Après tout c'est une question de conduite individuelle, qui n'a pas grand-chose de blâmable en soi, [mot illisible] l'absolu.

Eugène Sue (ce n'est pas une référence, je le sais) a commis l'erreur d'exposer l'histoire de la lutte de Louis XIV et Cavalier, qui est trop connue, et de ce fait n'intéresse pas le lecteur. Quand Walter Scott a voulu nous faire vivre avec Marie Antoinette et nous intéresser à son évasion, il ne l'a pas emprisonnée à Fotheringay, d'où elle n'est sortie que morte, mais à Loc[h]leven. Ainsi, on voit la primauté du roman sur l'histoire. De même, Senghor a été reconnu homosexuel davantage à son retour du Sénégal que lors de son séjour d'études en France. Vous me dites que pareille chose aurait fait du bruit. Mais elle a fait du bruit, puisque le conseil de notables maliens l'a su de par la bouche des notables sénégalais, que le « scandale » a été dévié par un soi-disant népotisme dont on accusa sa politique, pour sauver l'homme. Conséquence directe enfin: lors des avant dernières élections présidentielles, et quand on a opposé Mamadou Dia à Senghor, on a opposé la probité et l'intransigeance africaine à l'homosexualité et l'aliénation de l'évolué. Bilan 108 morts lors d'émeutes, avec force grenades lacrymogènes lâchées l'hélicoptères: Senghor lui même ne recevait plus ses repas que sous bonne garde. Enfin, lors de la scission du Mali et du Sénégal, cette question de mœurs est revenue sur le tapis. Mieux : les nationalistes ont accusé $\mathrm{M}^{\mathrm{me}}$ Senghor de ne vivre avec Léopold que parce qu'il était président : d'où railleries interminables sur la moralité des Blanches, que tout Nègre se respectant devrait fuir. Des contes indigènes, des ballades même illustrent ceci. Senghor a été obligé (ou s'est cru obligé) de devoir même en parler à la radio !...

Revenons à mon propos, et au but de cette lettre.

L'Afrique se meurt, elle est morte déjà.

Ecrire une suite discontinue de romans serait le plus grand péril pour moi. Je sais que vous avez l'habitude des livres que vous faites naitre, et qui survivent un mois ou un 
trimestre. De quoi avoir envie de casser sa plume... Mais vivre, c'est s'aveugler sur soimême, en un sourire qui surplombe des paysages anéantis.

Ici encore, permettez-moi un exemple. Il est grandiose, certes, mais pas inutile.

Schwarz Bart, après le « Dernier des justes ", en effet, n'a-t-il pas commis

l'impardonnable erreur de cultiver un misérabilisme facile en fabriquant « Un plat de porc aux bananes vertes »? Il est certain qu'une véritable intransigeance à l'égard de soi lui eût évité de se désavouer si grossièrement. On me dira que je ne suis pas Schwartz Bart : je ne cherche qu'à être moi. On me dira que je ne suis pas Juif : mais être Nègre, c'est précisément avoir la chance d'être le plus sale des Juifs. Ici, je saisis pourquoi l'auteur du « Dernier des Justes » a dévié vers « les Nègres ». N'était ce pas d'ailleurs, en 1964, je crois, le titre qu'il proposait de donner à un roman qu'il n'a sorti que bien plus tard?

Le mouvement de cette démarche est assez significatif. Tournez les yeux vers Glissant. « La Lézarde » approche le problème de l'épique, dans lequel le personnage principal sert uniquement de centre extérieur autour duquel les évènements gravitent. Mais Glissant a cultivé sa propre cuisine, appauvrissant son écriture - je veux dire la sève vive qui frappe les grandes créations - dans la spécialité formelle et historico-sociale du «Quatrième Siècle ».

Je sais bien que ce ne sont pas là des choses, peut-être, qu'il faille dire tout haut. Mais j'y suis bien contraint ; faute de quoi, en écrivant des « fragments ", c'est à dire des romans sans le système d'une espèce de « Comédie Humaine ", je risque tout simplement d'être le concierge attardé d'une forme de littérature négro-africaine, fort inégale dans ses tentatives, et, de toute façon, vouée à être une espèce de continuation directe du grand roman social réaliste du $18^{\mathrm{e}}$ siècle - lié à la situation post révolutionnaire (pré-révolutionnaire ?) de l'Afrique.

Or, je le crois, les énormes transformations politico-sociales ont éveillé le sens de l'Histoire, non pas seulement en Afrique, mais dans le « Tiers-Monde » tout entier. Je sais bien que, de par ma littérature (et par les larges concessions qu'elle fait à l'action, à l'épopée qui occasionne comme une subversion radicale des valeurs, conditionnant ainsi une contestation critique, voire une adhésion motivée), le monde ne s'en trouvera pas modifié, alors que le monde n'était plus le même après le voyage d'Ulysse. C'est pour cela que je conçois mes personnages sous une ampleur épique malgré toutes les césures de style ou de présentation - faisant en sorte que ces personnages s'accomplissent, se dépassent et transcendent une réalité qui semblait les définir complètement. Du même coup, la réalité ou l'irréalité du monde qui les entoure apparait, je crois, plus clairement après leurs actions épiques. Le reste est question de métier propre à donner un substrat romanesque à l'expérience créatrice. De là aussi, indirectement il est vrai, le rôle prépondérant de l'ironie, arme de la satire d'autant plus que je répugne à l'invective et à la dénonciation enragée. Et l'attaque ironique, prudente, feutrée, est comme un hommage au lecteur, jugé assez intelligent pour saisir les sous-entendus. Il est dans ces conditions évident que je ne crois pas avoir la niaiserie de penser qu'un livre a une quelconque « couleur raciale », en raison de laquelle un éditeur investirait les capitaux d'une édition.

Bref, ce que je voudrais que vous m'accordiez; c'est un contrat avec des clauses particulières : fixer le nombre de titres de romans que je publierai à la suite du premier, non pas à 5, mais à 15 ; ensuite, avoir le droit non pas à 2 mais à 3 refus de manuscrit pour reprendre ma « liberté ».

Il ne s'agit pas, je vous l'ai expliqué, je crois, de s'enfermer dans la gaudriole de la 
" négritude » et de ses éventuelles incidences épiques. Il s'agit de ne pas se condamner, dès le départ, à amener les briques isolées d'un édifice épars.

Et c'est là un premier travail fondamental que de s'entendre bien sur cette optique littéraire. J'avais déjà mis en sous titre, dès « le devoir de violence ", « La chair des civilisations ». Ce titre " La chair des civilisations » est la désignation générale de l'ensemble des 15 volumes que je veux écrire pour vous. J'envisage encore deux titres centrés sur l'Afrique ; ensuite, ce sera de façon incidente. Il y faut les États Unis, l'Amérique latine, et le Monde Occidental et Asiatique.

C'est parce que j'avais la conviction ferme qu'il n'en pouvait être autrement que je m'interrogeais, me demandant si je savais écrire. Je ne parle pas de ce coup de pouce habile, que l'on nomme la « chique » en peinture et qui est affaire d'ingéniosité alors même que la vie en est absente. Et comme, par ailleurs, il y a plus de médailles que d'écrivains, je n'ai pu m'empêcher, au terme d'une abominable période d'angoisse, d'aller déranger Mr Cayrol.

Je n'y ai aucun mérite, puisque c'est après avoir déchiré mon second roman « Les célibataires de la vérité » que je l'ai happé à brûle pourpoint.

Vous voudrez bien excuser la longueur de cette lettre. Il est vrai que nos ennuis ennuient les autres. Mais c'est parce que je ne vous vois pas comme un marchand, que je me refuse à vous voir comme un marchand, que j'ai pris la liberté de vous écrire. Vous voudrez bien demander, par écrit*, au cas où ma demande vous agréerait, à Monsieur F.R Bastide d'être intransigeant dans ses suggestions, et impitoyable chaque fois qu'il le jugera nécessaire.

Au risque d'être, peut-être, ridiculement démodé dans mes exigences littéraires, veuillez agréer, monsieur, l'assurance de ma sincérité la plus simplement dévouée. Ouologuem Yambo

* je veux dire que ce soit précisé sur mon contrat

\section{ANNEXE 2}

Article d'Eric Sellin dans Research in African Literatures, Automne 1971, Vol. 2, n II, p. $117-120$

\section{OUOLOGUEM'S BLUEPRINT FOR LE DEVOIR DE VIOLENCE}

Yambo Ouologuem, the Malian novelist, recently barnstormed in America in connection with the publication of the English translation of his work, Bound to Violence. Numerous articles in the leading newspapers celebrated the author whose vigorous novel had captured the imagination of French and American critics and had already received the coveted Prix Renaudot in 1968 when published in French by Editions du Seuil under the title Le Devoir de violence. Its American billing as "the first truly African novel" appeared unassailable. Ouologuem not only showed a New York Times interviewer his many "authentic" sources (photographs, ancient documents, and the like) but appeared on the Today Show to state, among other things, that he "wrote this book in French but followed the traditional African rhythms and the spirit of the African past". That the work is not fundamentally autoch thonous in its rhythms and in its genesis will come as a surprise to most readers. It did to me.

In the summer of 1970, when I asked my friend Mohamed-Salah Dembri his opinion of this brilliant novel, he was less than enthusiastic and said flatly that Le Devoir de violence was no more than an imitation of André Schwarz-Bart's Le Dernier des Justes, published in 1959 by the same house and awarded the Prix Goncourt only to have its authenticity subsequently 
questioned. Dembri said that the publisher had even told him that Seuil had commissioned Ouologuem to write an African Dernier des Justes. It had been years since I had read SchwarzBart and it was not until recently that I had time to give the books a close parallel reading. Imagine my dismay and bewilderment when I compared the opening of the "first truly African novel" (which I, myself, had glowingly reviewed in the French Review):

Nos yeux boivent l'éclat du soleil, et, vaincus, s'étonnent de pleurer. Maschallah! oua bismillah!... Un récit de l'aventure sanglante de la négraille - honte aux hommes de rien ! - tiendrait aisément dans la première moitié de ce siècle, mais la véritable histoire des Nègres commence beaucoup, beaucoup plus tôt, avec les Saïfs, de l'an 1202 de notre ère, dans l'Empire africain de Nakem, au Sud du Fezzan, bien après les conquêtes d'Okba ben Nafi el Fitri.

with the first paragraph of Schwarz-Bart's history of the Jews:

Nos yeux reçoivent la lumière d'étoiles mortes. Une biographie de mon ami Ernie tiendrait aisément dans le deuxième quart $\mathrm{du} \mathrm{XX}^{\mathrm{e}}$ siècle ; mais la véritable histoire d'Ernie Lévy commence très tôt, vers l'an mille de notre ère, dans la vieille cité anglicane de York. Plus précisément : le 11 mars 1185.

The first section of Schwarz-Bart's work in entitled "La Légende des Justes", that of Ouologuem's novel, "La Légende des Saïs". The rough lay-outs, certain paragraphs, and even the titles parallel one another remarkably-although less closely than the similarity in opening paragraphs would portend-right down to the works' closures where Ouologuem resumes his high fidelity, even resorting occasionally to assonance where shunning repetition:

Schwarz-Bart: Parfois, il est vrai, le cœur veut crever de chagrin. Mais souvent aussi, le soir de préférence, je ne puis m'empêcher de penser qu'Ernie Lévy, mort six millions de fois, est encore vivant, quelque part, je ne sais où... Hier, comme je tremblais de désespoir au milieu de la rue, cloué au sol, une goutte de pitié tomba d'en haut sur mon visage ; mais il n'y avait nul souffle dans l'air, aucun nuage dans le ciel... il n'y avait qu'une présence.

Ouologuem : Souvent il est vrai, l'âme veut rêver l'écho sans passé du bonheur. Mais, jeté dans le monde, l'on ne peut s'empêcher de songer que Saïf, pleuré trois millions de fois, renaît sans cesse à l'Histoire, sous les cendres chaudes de plus de trente Républiques africaines...

... Ce soir, tandis qu'ils se cherchaient l'un l'autre jusqu'à ce que la terrasse fût salie des hauteurs noirâtres de l'aurore, une poussière chut d'en haut sur l'échiquier ; mais à cette heure où le regard au Nakem vole autour des souvenirs, la brousse comme la côte était fertile et brûlante de pitié. Dans l'air, l'eau et le feu, aussi, la terre des hommes fit n'y avoir qu'un jeu...

The probability that the publisher was aware of the analogy between the two works-as Dembri averred-would seem only reasonable since Seuil issued both books; furthermore, the possibility that the intention to imitate originated with the publisher is supported by the similarity in the cover blurbs. Schwarz-Bart's work is described as follows: "Glissant de cette légende à la chronique, puis au romanesque pur, l'auteur nous décrit la vie et la mort souvent dérisoires des Justes, leur promenade sanglante au long des siècles chrétiens." Ouologuem's reprise is billed thusly: "La promenade des Nègres va de la fresque à la chronique (1202-1900), puis au romanesque contemporain et au drame souvent dérisoire des Fils de la Nuit". ${ }^{1}$ The supreme irony in the blurb on Ouologuem's book lies in the publisher's declaration that "Dès maintenant, Ouologuem montre tout ce que l'imaginaire 
africain peut apporter au roman français." This is, of course, an equivocal statement and can, as it were, work both ways. Ouologuem has not, to my knowledge, admitted that he used Le Dernier des Justes as a blueprint for his novel, but once that fact is obvious, there are many oblique references in the same spirit as that just quoted which one could interpret as veiled confessions or spoofs, as in the interview with Mel Watkins in which Ouologuem states: My novel is not traditional and, although it is based in fact and history, it is not autobiographical. I wrote the book with references to international examples. Afro-American writers have influenced its style and there are Greek and Latin references that are intended to heighten its meaning on a human level. It addresses the problems of all civilizations at specific periods of development; it is not just an African novel... ${ }^{2}$

Now, does the derivation negate the value of the work? Or may the writer, as with sonnets, assume prescribed structures when writing novels and, in good Renaissance style, borrow freely of what he likes? This opens a whole new area of critical conjecture. I have, however, a bit of advice for Mr. Ouologuem. The biographical note on the French edition of Le Devoir de violence says that he is preparing a doctoral thesis in sociology; I would certainly counsel him to avoid in that endeavor the methodology adopted in the composition of his novel. Furthermore, many of the passages of Ouologuem's follow-up Lettre à la France Nègre which an uninitiated reader would admire as sheer vitriol and righteous indignation can now, in light of Ouologuem's extensive debt, only be considered persiflage or pathetic irony. ${ }^{3}$ Le Devoir de violence is not the first real African novel! It is as deeply set in European literary tradition as, say, Ferdinand Oyono's Une vie de boy or Camara Laye's L'Enfant noir. I would suggest that Ahmadou Kourouma's Les Soleils des Indépendances, also published in 1968 (Presses de l'université de Montréal; reprinted by Editions du Seuil, 1970), is a much more profoundly African novel.

${ }^{1}$ The fact that the phrase "Drame -souvent dérisoire -des Fils de la Nuit" later appears in Ouologuem's Lettre à la France Nègre (Paris: Nalis, copyright 1968, p. 190) means nothing because Lettre was printed in 1969.

${ }^{2}$ Mel Watkins, “Talk with Ouologuem”, New York Times Book Review, March 7, 1971, p. 7

${ }^{3}$ The essay entitled "Lettre aux pisse-copie, nègres d'écrivains célèbres" (pp. 163-79), with its formula for literary brain-picking, now emerges not as the satire it appears to be but rather as an all-too-real modus operandi.

\section{ANNEXE 3}

Droit de réponse de Yambo Ouologuem (« Le devoir de violence », Le Figaro Littéraire du 10 juin 1972) à l'article de Guy Le Clec'h « Ouologuem n'emprunte qu'aux riches (Le Figaro Littéraire, 13 mai 1972). IMEC, SEL 2923.8

M. Yambo Ouologuem nous somme de publier les lignes suivantes, en réponse à l'article de Guy Le Clec'h, paru dans Le Littéraire du 13 mai et intitulé : «Yambo Ouologuem n'emprunte qu'aux riches. "

L'ARTICLE paru à mon sujet dans Le Figaro du 13 mai pose deux questions différentes. La première est relative au sujet de mon Diplôme d'études supérieures d'anglais. Ce dernier ne porte pas sur Graham Greene, mais sur Coleridge. La seconde question concerne un prétendu plagiat de Mr Graham Greene. Voici ma réponse :

En raison même de la nature explosive du sujet de mon roman, Le Devoir de violence (scènes de tortures, de cannibalisme, de démence, de faits légendaires et historiques, avec des clins d'œil au récit à clés, aux contestations raciales), être objectif signifiait 
faire entendre au besoin plusieurs voix contradictoires à l'image même des choses contradictoires, des préjugés, superstitions et susceptibilités touchant inévitablement les problèmes des Noirs.

Ainsi, le passage de Mr Graham Greene incriminé de plagiat, mais en fait cité en guillemets (tout comme quelques lignes de Schwarz Bart) dans mon manuscrit déposé chez mon avocat, précédait une scène folle où un Blanc, déguisé sous les traits de l'administrateur Chevalier, faisait s'accoupler une Noire et un chien. Je suis Noir. Il est évident que si les faits évoqués par moi avaient été le fruit de mon imagination, mes frères de race ne m'auraient guère pardonné d'avoir sali les Noirs.

Or, l'accouplement de la Noire et du chien est un fait véridique, comme tous les faits rapportés par mon roman. (Mr Jean Chalon le sait, puisque c'est lui qui m'a interviewé et communiqué la substance de mes propos à Mr Robert Kanters.) Le Blanc en question, qui avait eu connaissance de l'existence au Musée de l'Homme à Paris d'un spécimen inoui (L'Homme-Chien, en fait un Russe à tête de chien poilu et au corps d'homme) a cherché à créer le Noir-Chien : par ledit accouplement... Dans ces conditions, mettre le texte de Mr Greene entre guillemets, c'était non pas faire œuvre de plagiaire, mais ne pas me faire désavouer par les miens, en plaçant sous l'angle littéraire un fait d'ordre juridique. Les références à Graham Greene, à Kipling et à d'autres ont été publiquement données par moi au New York Times, au New-Yorker et ailleurs, lors de conférences tant auprès de professeurs que de diverses Black Studies Programs. «Si Graham Greene avait assisté à la scène, voilà comment il aurait pu la décrire. » Pourquoi Graham Greene ? Parce que l'auteur du Fond du problème et des Comédiens est le rare Blanc qui aie l'objectivité lucide des écrivains concernés par l'Afrique de l'incompréhensible, par Haïti inconcevable. La question fondamentale que je pose à travers ces techniques et qui n'a échappé à aucun lecteur ou critique averti, ni a fortiori aux membres du jury Renaudot, lesquels ne sont guère illettrés, est celle-ci : « Dans un monde de violence où le "devoir d'amour" est passé dans le domaine du mensonge, qui aidera le Noir à sortir de la condition qui est la sienne ? Ce n'est certes pas l'éditeur du Devoir de violence avec lequel je suis en conflit et auquel j'ai refusé mon deuxième roman.

Il est peu reluisant que nous soyons actuellement en discussion pour des histoires de comptes. Ce n'est donc pas Yambo Ouologuem qui emprunte aux riches, ce sont les riches qui empruntent à Yambo Ouologuem : en lui faisant assumer, contrairement aux règles de l'édition, les détails matériels de remerciements d'usage aux membres du jury Renaudot. Et il est significatif que cet éditeur plaide coupable en mon nom sans même m'interroger, et que, sans la moindre réclamation de Mr Graham Greene, il retire mon livre de la vente dans le monde entier.

Yambo Ouologuem

\section{NOTES}

1. Jusqu'à la révélation éventuelle d'archives inédites laissées par Yambo Ouologuem.

2. L'auteur remercie, à cet égard, Le Seuil, en particulier Olivier Bétourné, Directeur des Éditions jusqu'en avril 2018, Hugues Jallon, qui lui a succédé et Frédéric Mora, Directeur éditorial du département littérature française, pour leur confiance accordée lors de la consultation du fonds du Seuil à l'IMEC et leur autorisation à la publication, ci-après, des documents de ce fonds. À ces 
remerciements, l'auteur associe l'IMEC, André Derval, Directeur des collections, et Albert Dichy, Directeur littéraire, pour leur soutien.

3. Cette étude complète ainsi la thèse de Sarah Burnautzki, Les Frontières racialisées de la littérature française: Contrôle au faciès et stratégies de passage, menée à l'École des Hautes Études en Sciences Sociales et à la Ruprecht-Karls Universität Heidelberg et publiée sous ce titre chez Honoré Champion, Paris, en 2017. Première chercheuse à consulter intégralement les dossiers du Seuil à l'IMEC, Sarah Burnautzki les a ensuite exploités - avec une restriction quant à leur reproduction (op. cit. p.36) - en décrivant, dans les rapports entre Yambo Ouologuem et Marie NDiaye d'une part, le monde littéraire français d'autre part, «l'existence d'une ligne de couleur servant à contrôler un ordre littéraire inégalitaire ", " un espace littéraire subjugué par des rapports de pouvoir racialisés" (présentation de l'éditeur). Sans nier quelque légitimité à cette thèse, la présente étude s'écarte de son approche par la primauté donnée à l'exposition - rendue désormais possible - des documents eux-mêmes, présentés de manière la plus large et la factuelle possible et sollicités pour constituer d'eux-mêmes le récit de la genèse éditoriale et de la réception du Devoir de violence. Laissant donc à la lectrice et au lecteur, chercheur(se) ou non, le soin de les interpréter.

4. IMEC, SEL 3772.2.

5. Ibid.

6. En 1960, semble-t-il, l'été même où le Mali devient indépendant.

7. Ce que confirme la recherche menée par Sarah Burnautzki, op. cit. p. 35, dans les Archives de Paris, dossiers d'élève du lycée Henri IV, 1371 W 160-163 (1960).

8. Entretien du 6 février 2018 avec François Dalbard, compagnon d'hypokhâgne. Le nom de Dalbard est attribué à un personnage (prénommé Jean-Luc) du Devoir de violence (Seuil, 2018, Troisième partie, à partir de la page 166).

9. Sarah Burnautzki, op. cit. p.35, n'a pas trouvé trace, dans les Archives de Paris, d'une inscription de Yambo Ouologuem en deuxième année de classe préparatoire au lycée Henri IV.

10. IMEC, SEL 3772.2.

11. La transcription des documents présents dans le présent article suit fidèlement les originaux, graphies, lacunes et erreurs comprises.

12. Note de lecture signée "TREMBLAY ", communiquée à l'auteur le 8 décembre 1964. IMEC, SEL 3772.2.

13. Ibid.

14. IMEC, SEL 3772.2.

15. Qui y publia Cahier d'un retour au pays natal en 1956.

16. IMEC, SEL 3772.2.

17. La version définitive date $d u X{ }^{e} I^{e}$ siècle les prémisses du récit, mais il est vrai que celui-ci débute réellement au $\mathrm{XVI}^{\mathrm{e}}$ siècle.

18. Les titres définitifs seront: I. La légende des Saïf, II. L'extase et l'agonie, III. La nuit des géants, IV. L'aurore.

19. IMEC, SEL 3772.2.

20. François-Régis Bastide (1926-1996), éditeur, animateur radio (notamment au « Masque et la Plume » où il recevra Yambo Ouologuem après l'attribution du prix Renaudot au Devoir de violence qu'il aura lui-même édité). Auteur de nombreux livres, dont Les Adieux (Paris, Gallimard, 1956), roman qui obtient le prix Femina.

21. Jean Cayrol (1911-2005), poète, romancier (prix Renaudot 1947), scénariste (Nuit et brouillard d'Alain Resnais, 1956) et réalisateur.

22. Le nom, déjà mentionné de cette manière dans une autre note de lecture, deviendra Nakem dans la version définitive.

23. On ne sait si Cayrol se trompe ici (car le roman commence bien plus tôt) ou met l'accent sur cette période qui occupe l'essentiel du roman. 
24. Rien dans les dossiers n'indique explicitement si François-Régis Bastide s'est rangé tardivement à l'avis de Jean Cayrol ou si ce dernier est venu, au contraire, le soutenir. Dans ce cas, la lettre de refus signée de F.-R. Bastide refléterait un avis collectif, celui, par exemple, du comité de lecture.

25. IMEC, SEL 3772.2.

26. Ibid.

27. Ibid.

28. Ce qui ne signifie pas l'impression, mais implique la préparation de la copie, la composition, les corrections, la mise en page, les épreuves d'auteur, jusqu'à l'impression et le brochage.

29. IMEC, SEL 4645.

30. Ibid.

31. IMEC, SEL 3772.2.

32. Lettre déjà citée plus haut.

33. Lettre, 19 avril 1968. IMEC, SEL 3777.2.

34. IMEC, SEL 3777.2.

35. Ibid.

36. Sujet qui sera objet de discussions, parfois de controverses au Mali.

37. La notice, une sélection basée probablement sur les informations fournies par l'auteur, ne mentionne pas qu'il a aussi enseigné au lycée de Charenton (information confirmée par $\mathrm{M}^{\text {me }}$ Adama Diallo, épouse de Yambo Ouologuem à l'époque de l'écriture et de la publication du Devoir de violence) : «Six années de vie en France, de longs mois d'enseignement au lycée de Charenton et au petit séminaire de Conflans, la préparation d'un diplôme d'études supérieures d'anglais passé avec succès - puis celle de l'agrégation de lettres » (« Un nègre à part entière » Le Monde, 12 octobre 1968, article rédigé, à partir des commentaires de Y. Ouologuem, par Philippe Decraene, spécialiste des questions africaines).

38. Une analyse de la réception dans la presse africaine, en particulier au Mali et au Sénégal, voisins et liés par une histoire commune au temps de leurs indépendances, est encore à faire. On peut cependant noter dès ici, la réaction de Léopold-Sédar Senghor dans le numéro 33, mars 1969, de Congo-Afrique, revue fondée par la Compagnie de Jésus (pères jésuites) au CongoLéopoldville (1961) : «Je ne nie pas son très grand talent, mais il n'y a pas que le talent, il n'y a pas que le génie littéraire, il y a aussi une attitude morale, en face de la vie, en face des grands problèmes. Je pense que c'est affligeant. Je ne veux pas employer un mot sévère, quand on voit des nègres puisqu'il faut les appeler par leur nom, qui ont un succès littéraire et qui disent aux blancs ce qui est agréable aux blancs, et qui n'osent pas affirmer leur foi dans leur ethnie, dans leurs idées. On ne peut pas faire une œuvre positive quand on nie tous ses ancêtres. »

39. Le Figaro Littéraire, 23 septembre-29 septembre 1968.

40. Sarah Burnautzki, op. cit., p.102.

41. IMEC, SEL 4645.

42. Le Monde, 19 novembre 1969.

43. Le Figaro Littéraire, 25 novembre-1 ${ }^{\text {er }}$ décembre 1968.

44. Le restaurant où se réunissent les jurys des prix Renaudot et Goncourt.

45. IMEC, SEL 3772.2.

46. Jean-Louis de Rambures, « Retour offensif du roman », Le Monde, 12 juillet 1967.

47. Le monde tel qu'il est, de Salvat Etchart, Paris, Mercure de France, 1967.

48. IMEC, SEL 3772.2.

49. Article déjà cité du 12 octobre 1968.

50. Le Monde, 14 décembre 1968.

51. Le Monde, 15 novembre 1968.

52. $\mathrm{N}^{\circ} 1186$.

53. IMEC, SEL 3772.2.

Continents manuscrits, HS | 2018 
54. Ouologuem parle vraisemblablement de la lettre du 18 mai 1968.

55. Lettre du 5 février 1969, IMEC, SEL 3772.2

56. Siège du Seuil à l'époque.

57. IMEC SEL 2923.9.

58. Les Mille et une bibles du sexe, sous le pseudonyme de Utto Rodolph, Paris, Éditions du Dauphin, 1969. Réédité sous le nom de Yambo Ouologuem, La Roque d'Antéron, Vents d'ailleurs, 2015, préface de Jean-Pierre Orban et Sami Tchak.

59. Le Secret des orchidées, sous le pseudonyme de Nelly Brigitta, Paris, Éditions du Dauphin, 1968. Réédité à Montréal, Poche Select, coll. « Romance au coin du feu », 1979.

60. Les Moissons de l'amour, sous le pseudonyme de Nelly Brigitta, Paris, Éditions du Dauphin, 1970. 61. On se reportera à l'analyse que Sarah Burnautzki fait de ces deux « romans d'amour » et des échos entre eux et Le Devoir de violence (Les Frontières racialisées de la littérature française, op. cit. p. 172 et p. 347-364).

62. Ce que conteste sa directrice, Anne Tromelin, dans un entretien avec Céline Gahungu (Université Paris 4, ITEM) en juin 2017.

63. L'auteur remercie Céline Gahungu des informations communiquées sur ce roman inédit, qu'elle a étudié dans les dossiers du Seuil à l'IMEC, et sur lequel elle publiera plus tard ses analyses. On lira aussi ce qu'en dit Sarah Burnautzki, op. cit., p. 175.

64. IMEC, SEL 3907.2.

65. IMEC, SEL 3907.5.

66. Ce que contredisent les lettres et notes antérieures.

67. Lettre manuscrite de Y. Ouologuem à F.-R. Bastide, 26 août 1969. IMEC, SEL 3907.5

68. Lettre de P. Flamand à Y. Ouologuem, 3 juin 1970. IMEC, SEL 3772.2

69. IMEC, SEL 3772.2.

70. Ibid.

71. Bound to Violence, traduction de Ralph Manheim, «A Helen and Kurt Wolff book », New York, Harcourt Brace Jovanovich, 1971.

72. IMEC, SEL 2923.3.

73. Ibid.

74. Lettre de Helen Wolff à Paul Flamand, 12 août 1971. IMEC, SEL 2923.3.

75. Lettre de Jacqueline Lesschaeve à Georges Borchardt, 28 juillet 1971. IMEC, SEL 2923.3.

76. Ibid.

77. À titre de repère, les dédommagements que réclameront les éditeurs américains au Seuil après les accusations de plagiat seront légèrement inférieurs à cinq mille dollars.

78. Lettre de P. Flamand à G. Borchardt, 6 août 1971. La somme de 30.000 dollars est confirmée dans une lettre de ce dernier, 16 août 1971. IMEC, SEL 2923.3.

79. Un des trois partenaires de la maison éditrice de Bound to Violence, Harcourt Brace Jovanovich.

80. Lettre à P. Flamand, 5 août 1971. IMEC, SEL 2923.3.

81. Mot de G. Borchardt à J. Lesschaeve, 3 août 1971. IMEC, SEL 2923.3.

82. Lettre de B. Gordey, éditeur de Doubleday, à P. Flamand, 14 septembre 1971. IMEC, SEL 2923.3.

83. Lettre de H. Wolff à P. Flamand, 12 août 1971. IMEC, SEL 2923.3.

84. Bound to Violence, traduction de Ralph Manheim, Londres, Secker and Warburg, 1971.

85. Dixit Tom Rosenthal, de Secker \& Warburg, note. IMEC, SEL 2923.3.

86. Lettre de B. Gordey à $P$. Flamand, 14 septembre 1971, art. cit.

87. Également plusieurs fois ministre sous les présidences de François Mitterrand.

88. It's a Battlefield, Londres, William Heinemann, 1934. C'est un champ de bataille, Paris, Laffont, 1953.

89. La Ferme africaine, Paris, Gallimard, 1942. Le livre sera adapté au cinéma par Sidney Pollack sous le titre Out of Africa (1985).

90. Pour indiquer que les ressemblances ne sont pas le fait du traducteur Ralph Manheim. 
91. P. Flamand à Y. Ouologuem, lettre recommandée avec accusé de réception du 29 mars 1972. IMEC, SEL 2923.8.

92. Puisque c'est ce dont l'auteur était accusé, on emploiera généralement ici le terme de "plagiat ", en réservant à d'autres études l'analyse littéraire en profondeur de ce que sont les « emprunts » de passages à d'autres œuvres, parfois subtilement réécrits et transposés de façon complexe, par Yambo Ouologuem dans Le Devoir de violence au sein de ce qu'il décrit lui-même comme un « système ».

93. Paris, L'Harmattan, coll. «L'Afrique au cœur des lettres », avant-propos de J.-P. Orban, 2011. Titre original : Africa Writes Back, the "African Witers Series" and the Launch of African Literature, Oxford, James Currey Publisher, 2008.

94. Ibid., p. 136.

95. Ibid., p. 137. Et lettre de Graham Greene à Paul Flamand, $1^{\text {er }}$ juin 1972, dans laquelle il n'accable pas Le Seuil, ayant toujours cru, écrit-il, à leur bonne foi. L'ironie est davantage dirigée contre Yambo Ouologuem. IMEC, SEL 2923.8

96. Lettre de Tom Rosenthal. IMEC, SEL 2923.8

97. Lettre de P. Flamand à Y. Ouologuem déjà citée du 29 mars 1972 et lettres de P. Flamand aux éditeurs étrangers dans IMEC, SEL 2923.8.

98. Lettre à Tom Rosenthal. IMEC, SEL 2923.8.

99. Lettre à Georges Borchardt, 4 mai 1972. IMEC, SEL 2923.6.

100. Lettre de Paul Flamand à Yambo Ouologuem, 13 mars 1973. IMEC SEL 2923.8.

101. "Ouloguem's Blueprint for Le devoir de Violence", dans Research in African Literatures, Automne 1971, Vol. II, $n^{\circ} 2$, p. 117-120. Article complet et original en annexe 2.

102. Le Figaro littéraire, $\mathrm{n}^{\circ} 1356,13$ mai 1972.

103. Texte complet de la réponse de Yambo Ouologuem en Annexe 3.

104. Lettre de Paul Flamand à Helen Wolff, 4 mai 1972. IMEC, SEL 2923.6 et 2923.8.

105. Lettre de Paul Flamand à Georges Borchardt, 4 mai 1972. IMEC, SEL 2923.6.

106. Lettre de Paul Flamand au Times Literary Supplement, 9 mai 1972. IMEC, SEL 2923.6. Cette lettre sera publiée en anglais dans le TLS du 19 mai 1972.

107. «Qui a rédigé le "prière d'insérer" imprimé au dos du devoir de violence? », « Est-ce que le livre de Ouologuem est paru dans plus ou moins le même état où il se trouvait lorsque l'auteur a offert le manuscrit aux Editions du Seuil ?", "Puisque vous étiez au courant au plus tard le 16 août 1968 [...], j'aimerais savoir si votre maison aurait signalé les “échos” au Jury du Prix [Renaudot]. » Lettre d'Eric Sellin à Paul Flamand, 20 juin 1972. IMEC, SEL 2923.8.

108. Lettre de Paul Flamand à Eric Sellin, 3 juillet 1972. IMEC, SEL 2923.8.

109. Lettre d'Eric Sellin à Paul Flamand, 6 juillet 1972. IMEC, SEL 2923.8.

110. Lettre de $\mathrm{M}^{\text {me }}$ A. (nom réduit ici aux initiales), 29 janvier 1969, IMEC, SEL 3772.2

111. Lettre de J.-F. D. (nom réduit ici aux initiales) au Seuil, 29 novembre 1968. IMEC, SEL 2923.9.

112. Réponse de F-R. Bastide au précédent, 4 décembre 1968. IMEC, SEL 2923.9.

113. Lettre de P.B. (nom réduit ici aux initiales) au Seuil, 26 mai 1969. IMEC, SEL 2923.9.

114. Réponse de F.-R. Bastide au précédent, 6 juin 1969. IMEC, SEL 2923.9.

115. Lettre du 5 février 1970. IMEC, SEL 2923.9.

116. Qui deviendra l'editor de Ouologuem pour Les Pèlerins de Capharnaüm.

117. Voir supra

118. Un plat de porc aux bananes vertes, cosigné avec Simone Schwarz-Bart, Le Seuil, 1967.

119. Peu après la parution du Dernier des Justes en 1959, André Schwarz-Bart va vivre un an au Sénégal avec son épouse Simone, née Brumant. Avec elle, Guadeloupéenne, il entreprend ensuite l'écriture d'un vaste cycle sur le drame de l'esclavage, en symétrie avec la tragédie juive, entre l'Afrique, Paris et les Antilles. Cycle dont il a conçu la charpente avant même l'édition du Dernier des Justes. Le Plat de porc aux bananes vertes est le premier volume en 1967, il publie le deuxième en 1972, La Mulâtresse Solitude (les autres volumes seront posthumes). 
120. IMEC, SEL 2923.9.

121. IMEC, SEL 2923.9.

122. «Le plagiat est nécessaire. Le progrès l'implique. Il serre de près la phrase d'un auteur, se sert de ses expressions, efface une idée fausse, la remplace par l'idée juste », écrit Lautréamont dans ses Poésies, et il en applique le principe dans Les Chants de Maldoror, vaste collage comme l'a signalé Aragon dans Les collages (Catalogue d'exposition, 1930, réédition, Paris, Hermann, 1965).

123. Simone Schwarz-Bart confirme la blessure de son mari au moment de la parution du Devoir de violence (entretien de Jean-Pierre Orban, mai 2018, avec Simone Schwarz-Bart).

124. IMEC, SEL 2923.9.

125. À noter que cette préoccupation sera celle d'André Schwarz-Bart lui-même : écrire une œuvre « anonyme » comme l'étaient celles du Moyen Âge (témoignage de Simone Schwarz-Bart, février 2018, à J.-P. Orban).

126. IMEC, SEL 2923.9.

127. Sauf surprise qui surgirait, par exemple, des archives laissées, à sa mort, par Yambo Ouologuem.

128. Lettre citée du 22 août 1968.

129. Ibid.

130. Lettre de Yambo Ouologuem à Paul Flamand, 15 mars 1970. IMEC, SEL 2923.9.

131. Par l'intermédiaire de l'écrivain Roger Grenier (1919-2017), membre du comité de lecture des Éditions Gallimard.

132. Yambo Ouologuem reprend là une formule - presque borgésienne - qu'il a utilisée dans Lettre à la France nègre : « Une interminable perspective de références et de possibilités de lecture : Les Mille et Une Nuits sur un socle de tortures agoniques, avec les désespoirs souverains des salauds. » (Nalis, 1968, p. 178, Serpent à plumes, 2003, p. 202).

133. Alain Bosquet (1919-1998), Les Tigres de papier, Paris, Grasset, 1968.

134. Ouologuem cite la page 175 de l'ouvrage, mais le document qu'il joint avec la mention de Mac Donald - qui ne se retrouve pas ailleurs - est la page 167). Ce passage se retrouve aux pages 185-186 de la réédition de Lettre à la France nègre au Serpent à plumes (2003). La page 175 (Serpents à plumes, p. 199) comporte une autre liste différente d'auteurs de romans policiers.

135. Lettre à la France nègre, Nalis, p. 166, Serpent à plumes, p. 185.

136. Lettre à la France nègre, Nalis, p. 166, Serpent à plumes, p. 184.

137. Il s'agit de l'expertise demandée par le Tribunal à la suite de la plainte de Ouologuem introduite le 18 février. Voir supra.

138. Lettre recommandée avec accusé de réception aux Éditions du Seuil, 17 mai 1972. IMEC, SEL 2923.8.

139. IMEC, SEL 2923.4.

140. Lettre recommandée avec accusé de réception de Yambo Ouologuem aux Éditions du Seuil, 10 mars 1972 ; IMEC SEL 2923.3.

141. IMEC, SEL 2923.4.

142. Lettre de P. Flamand à Edward A. Hodge, des Éditions Harcourt Brace Jovanovich, 18 avril 1973. IMEC, SEL 2923.4.

143. Dans un film documentaire de 2003 produit par la télévision malienne (ORTM), où Yambo Ouologuem apparaît fugacement (il y dit : «Je n'ai pas de livres, je suis en train de vous dire que j'ai refusé ce truc-là pour injures, injures raciales »), la mère de l'écrivain déclare : « Yambo est revenu de la France très enflé. Il était méconnaissable et se déplaçait péniblement. Yambo était silencieux. Il n'adressait la parole à personne. » Yambo Ouologuem, Le Hogon du Yamé, film de Moussa Ouane.

144. Note du 13 novembre 1973. IMEC, SEL 2923.4.

145. IMEC, SEL 2923.5.

146. Ibid. 
147. Les formules religieuses apparaissent dans la correspondance de Ouologuem après son départ de France. On sait qu'à son retour au Mali, Yambo Ouologuem s'adonne de plus en plus à la religion musulmane, en devient un pratiquant strict et un exégète. Sur cet aspect, dans ses dimensions personnelles, historiques, ethniques et idéologiques (entre les œuvres de jeunesse et la pratique religieuse ultérieure), on se reportera entre autres à Christopher Wise (ed.), Yambo Ouologuem: Poscolonial Writer, Islamist Miltant, Lynne Riener Publishers, Boulder, USA, Londres, Royaume-Uni, 1999.

148. Ibid.

149. Message de P. Flamand à Y. Ouologuem, 26 avril 1976 et note de P. Flamand à G. Kiejman, 3 mai 1976. IMEC, SEL 2923.5.

150. IMEC, SEL 2923.5.

151. Ibid.

152. Note (signée Daniel Clovel) interne au Seuil du 26 octobre 1982. IMEC, SEL 3772.2.

153. IMEC, SEL 3772.2.

154. Note de Clovel citée.

155. IMEC, SEL 4645. Aux demandes extérieures de réédition formulées au cours des années 1980 et 1990 , les Éditions du Seuil répondront qu'elles ne peuvent y donner suite à cause des accusations de plagiat et parce qu'elles ont perdu la trace de Yambo Ouologuem et tout contact avec lui malgré certains efforts (ainsi la lettre d'Isabelle Bardet au père de Yambo Ouologuem indiquant que les Éditions du Seuil essaient de contacter son fils pour obtenir des réponses de sa part aux courriers reçus à propos de son œuvre, 21 octobre 1991, IMEC, SEL 3772.2). En 2003, Le Devoir de violence est réédité par Le Serpent à plumes en accord et suite à un contrat avec Ava Ouologuem, fille de l'auteur. Après épuisement du tirage, Le Devoir de violence n'est pas réimprimé au Serpent à plumes.

156. Avec l'accord et la signature de la fille de l'auteur.

\section{RÉSUMÉS}

En septembre 1968, paraît aux Éditions du Seuil le roman d'un jeune Malien inconnu de vingthuit ans : Yambo Ouologuem. Le 18 novembre suivant, Le Devoir de violence obtient le premier prix Renaudot attribué à un écrivain africain. Son succès est rapide et, traduit dans dix langues, l'ouvrage dépasse les frontières, des États-Unis au Japon. Mais le 5 mai 1972, le Times Literary Supplement (TLS) londonien accuse l'auteur de plagiat à l'encontre de l'écrivain britannique Graham Greene. Un scandale éclate. Il poursuivra Yambo Ouologuem jusqu'à sa mort en 2017. Cinquante ans après la première édition du Devoir de violence et alors que le roman reparaît au Seuil dans la collection "Cadre Rouge » qui l'avait accueilli à l'origine, quarante-six ans, mois pour mois, après le début de l'« Affaire Ouologuem » dans le TLS, qu'en est-il du bien ou malfondé des rumeurs qui ont surgi, en sens divers, sur la genèse et le traitement éditorial de ce livre culte devenu livre maudit? S'appuyant sur le seul dossier solide à ce jour, celui des archives du Seuil déposées à l'IMEC (Institut Mémoires de l'Édition contemporaine) et rendues publiques pour la première fois, cette étude vise à relater, sur la seule base des documents disponibles, en réduisant au minimum les extrapolations risquées et les interprétations hâtives, l'histoire du Devoir de violence et, à travers elle, de son auteur, depuis ses premières approches des Éditions du 
Seuil en 1963 jusqu'à sa retraite définitive au Mali vers 1976. Et son enfermement dans le silence public.

In September 1968, Le Devoir de violence (Bound to violence), the work of an as yet unknown Malian author, aged twenty-eight, Yambo Ouologuem, was published by the Editions du Seuil. On November 18 of that same year, the novel won the prize Renaudot. This was the first time ever that a major French literary prize was awarded to an African writer. Following the novel's considerable success in France, it was soon to be translated into ten languages and crossed many a border from the United States to Japan. But on May 5 , 1972, the Times Literary Supplement (TLS) accused the author of plagiarizing the work of the British writer Graham Greene. A scandal breaks out and will hound Yambo Ouologuem until his death in 2017. Fifty years after the first publication of the Devoir de violence and just as the novel is republished by Le Seuil, which of the various rumours regarding the genesis and the editorial treatment of this cult-cum-cursed book are well-founded or ill-founded? In this essay, Jean-Pierre Orban traces the history of the Devoir de violence and its author, from 1963 (date of the first presentation of a manuscript to Le Seuil) to the end the 1970s (when he retired in Mali and of he confined himself to silence). This work-which endeavours risky extrapolations and hasty interpretations-relies on the only solid files to date, those of the archives of the Institut Mémoires de l'Édition contemporaine (IMEC), publicly disclosed in the present production for the first time.

\section{INDEX}

Mots-clés : Yambo Ouologuem, Le Devoir de violence, Lettre à la France nègre, littérature francophone, littérature africaine, Mali, roman, histoire de l'Afrique, esclavage, colonisation, érotisme, homosexualité, plagiat, relations auteur-éditeur, Seuil, Gallimard, Fayard, Harcourt Brace Jovanovich, Heinemann, Times Literary Supplement, Le Figaro Littéraire, Eric Sellin, Graham Greene, André Schwarz-Bart, Gustave de Maupassant, John D. Mac Donald, Paul Flamand, François-Régis Bastide, Paul-André Lesort, Série Noire, Jean Cayrol

\section{AUTEUR}

\section{JEAN-PIERRE ORBAN}

Jean-Pierre Orban est chercheur associé à l'Institut des textes et manuscrits modernes (CNRSENS, Paris), spécialisé en littérature francophone. Écrivain, il est auteur de romans, de nouvelles et de pièces de théâtre. 